\title{
DESIGN, FABRICATION AND TEST OF AN OPERATIONALLY RESPONSIVE AIRCRAFT WITH NIIRS \\ EVALUATED IMAGER
}

\author{
A Thesis \\ presented to \\ the Faculty of California Polytechnic State University, \\ San Luis Obispo
}

\author{
In Partial Fulfillment \\ of the Requirements for the Degree \\ Master of Science in Aerospace Engineering
}

by

Colin Burt

August 2013 
(C) 2013

Colin Burt

ALL RIGHTS RESERVED 


\section{COMMITTEE MEMBERSHIP}

TITLE:

Design, Fabrication and Test of an Operationally

Responsive Aircraft with NIIRS

Evaluated Imager

AUTHOR:

Colin Burt

DATE SUBMITTED: August 2013

COMMITEE CHAIR: Dr. Eric A. Mehiel

Associate Professor

Aerospace Engineering

COMMITEE MEMBER: Dr. Kira Abercromby Associate Professor

Aerospace Engineering

COMMITEE MEMBER: Dr. Kurt W. Colvin Associate Professor

Aerospace Engineering

COMMITEE MEMBER: Mr. Joe Pitman

Engineer

NASA 


\section{ABSTRACT \\ Design, Fabrication and Test of an Operationally \\ Responsive Aircraft with NIIRS \\ Evaluated Imager \\ Colin Burt}

Unmanned Aerial Systems (UAS) are a growing asset. Currently UAS are on the cutting edge with resources being spent developing the capabilities mostly for military use. This project is intended to create a system for non-defense customers. Specifically, the Operationally Responsive Aircraft (ORA) will appeal to academic institutions, individual consumers, future customers new to the UAS industry, as well as anybody trying to get airtime for custom sensors.

The system developed in this project utilizes dual aluminum external payload bays attached to a ParkZone Radian aircraft. Each external payload bay can contain approximately $500 \mathrm{~cm}^{3}$, with a height and width limit of $4.1 \mathrm{~cm}$ and $11.0 \mathrm{~cm}$ respectively. The custom sensors must weigh less than or equal to $3.2 \mathrm{lbs}$ combined. The external payload bays were designed to hold an imaging payload which produces a composite map of the land surveyed. The system incorporates an Arduino Uno, SD Shield, as well as a CMOS camera and board. The processor saves individual images to an SD card. Once the aircraft has landed, the operator combines the images with Microsoft Research Image Composite Editor to create the composite map. This imaging payload has a NIIRS value of $4.0+/-0.4$, which is equivalent to identifying a basketball court within a residential environment. 


\section{ACKNOWLEDGMENTS}

My career at California Polytechnic State University, San Luis Obispo has been the best time of my life. My classmates, coworkers, mentors, teachers, friends and family have made it possible for me to become the man I am today. I will forever be indebted to you.

I would have never made it through the Aero program without my friends. Senior design all-nighters and meeting in the library everyday for Aero 300 will never be forgotten. Those long nights would have broken us if we were alone, but together we thrived, and I thank you for that. I never want to work that hard again, but it is nice to know that I have it in the tank if the time calls.

To Joe, Eric, Tammy and all of Exploration Sciences, the real life engineering experience encountered through this job has taught me so much more than I can even begin to explain. Hopefully your great engineering expertise has rubbed off on me. Joe, without you this project would have never been possible, sincerely. You have openned so many doors for my life. Thank you. You always say a handful of good engineering minds can solve any problem. I beleive that now. To Eric, thank you for always being there when I needed to talk through my problems. All the CAD help and great advice over the past 2 years has truely been priceless. To Paul, Chas, Mark and Adam, our work on SDEM has been awesome. I will never forget the hardwork and great times.

To Mike Vallone, you have always been there for me, from registering for the first quarter of classes to helping with this project in my last quarter. You are one of the nicest most genuine people I know. Thank you for everything.

To my pilot Chas, great job. No way could I have flown the plane without you. It was a successful flight everytime the plane came down safely no matter what imagery was captured. We have seen our share of stress. I am so thankful you were there with me the entire way. To Reed, without you I would still be trying to save an image to an SD card. Thank you for pushing me though everything software. I could not have accomplished what I did without your help.

To my light at the end of the tunnel, Sara Young. I always had you in the back of my mind while working. The quicker I got done, the more time I could spend with my love. Your support through the everyday stress of being a Cal Poly Aero major has been vital to my success. I cannot thank you enough.

And last but not least, to my family, Mom, Dad, Keenan and Dave. You have provided support when I needed it the most. My confidence has never waned because of the love you have shown me. I attribute my love of planes to my Dad, who worked on the C-17 and has trained me to look in the sky everytime I hear an engine far off in the distance. Mom, hearing your voice to this day is the only thing that will always make me feel better, no matter what. I know you will always have my back. I cannot even start to explain how much that means to me. I love you. 


\section{Table of Contents}

List of Tables $\quad$ viii

List of Figures $\quad$ ix

Nomenclature $\quad$ xi

1 Introduction 1

1.1 Topic Area . . . . . . . . . . . . . . . . . . . . . . . . . . 1

1.2 Capabilities of Current Technologies . . . . . . . . . . . . . . . 4

1.2.1 Boeing Insitu's ScanEagle . . . . . . . . . . . . . . . . . . 4

1.2.2 Northop Grumman's Bat . . . . . . . . . . . . . . . 5

1.2.3 UAS Technologies Silent Falcon . . . . . . . . . . . . 7

1.2.4 MLB's Bat UAV Family . . . . . . . . . . . . . . . . . . . . 9

1.2.5 AeroVironment's RQ-11 Raven . . . . . . . . . . . . . . . . . 12

1.2 .6 MCSO's Falcon UAS . . . . . . . . . . . . . . . . . 14

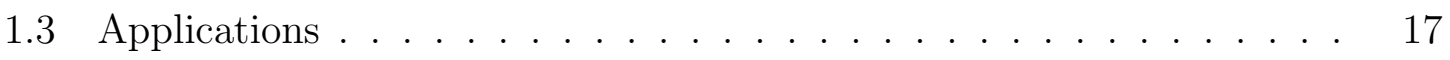

1.4 Project Goals . . . . . . . . . . . . . . . . . . . . . . 22

1.4.1 Requirements ................... . . 24

2 Imaging Payload 27

2.1 System Description . . . . . . . . . . . . . . . . 27

2.1.1 Imager . . . . . . . . . . . . . . . . . . 27

2.1.2 Processor . . . . . . . . . . . . . . . . . . 31

2.1.3 SD Shield . . . . . . . . . . . . . . . . . . . . . . . . . . . . . . 32

2.2 Data Interface . . . . . . . . . . . . . . . . . . . . . . . . 34

2.3 Power Interface . . . . . . . . . . . . . . . . . . . . . 35

3 External Payload Bay 37

3.1 Leading Edge Compartment . . . . . . . . . . . . . . . . . 37

3.2 Trailing Edge Compartment . . . . . . . . . . . . . . . . . 39

3.3 Combined External Payload Bay . . . . . . . . . . . . . . . . 39

3.4 Mechanical Interface . . . . . . . . . . . . . . . . . . . . . . . . . . . . . . . . . 41

3.5 Payload Bay As Built . . . . . . . . . . . . . . . . . . 43

4 Flight Hardware 46 
$4.1 \quad$ Airframe . . . . . . . . . . . . . . . . . . . . . . 46

4.2 Controller and Receiver . . . . . . . . . . . . . . . . . 47

4.3 Altimeter . . . . . . . . . . . . . . . . . . 47

4.3.1 Spektrum Telemetry Module . . . . . . . . . . . . . . . 47

$4.3 .2 \quad \mathrm{Z} \log 6 \ldots \ldots \ldots \ldots \ldots \ldots$

5 Software 51

5.1 Microsoft Research Image Composite Editor . . . . . . . . . . . . . 51

5.2 Arduino Code . . . . . . . . . . . . . . . . . . . . . . . . . 51

6 Imaging Performance Specifications 54

6.1 NIIRS General Image Quality Equation . . . . . . . . . . . . . . 54

6.1.1 Ground Sample Distance (GSD) . . . . . . . . . . . . . 56

6.1.2 Relative Edge Response (RER) . . . . . . . . . . . . . 60

6.1 .3 Edge Overshoot Factor $(\mathrm{H}) \quad \ldots \ldots \ldots 6$

6.1.4 Signal-to-Noise Ratio (SNR) . . . . . . . . . . . . . . . . 68

6.1 .5 Noise Gain $(\mathrm{G}) \ldots \ldots \ldots$

6.2 NIIRS Evaluation and Error . . . . . . . . . . . . . . . . . 69

6.2 .1 Error Propogation . . . . . . . . . . . . . . . . . 70

6.2.2 NIIRS Validation Test Plan . . . . . . . . . . . . . . . 71

6.3 Resolution vs Coverage Area . . . . . . . . . . . . . . . . . 74

6.4 CMOS Camera and Board Specifications . . . . . . . . . . 74

7 Test Results 78

7.1 NIIRS Validation . . . . . . . . . . . . . . . . . . . . 78

7.2 Composite Map . . . . . . . . . . . . . . . . . . . 80

7.3 Crash . . . . . . . . . . . . . . . . . . . 83

7.4 Requirement Validation . . . . . . . . . . . . . . . . 84

8 Final Remarks 90

8.1 Conclusions . . . . . . . . . . . . . . . . . . . . . . . 90

8.2 Future Work . . . . . . . . . . . . . . . . . . . . . . . . . . . . 92

8.2 .1 Autopilot . . . . . . . . . . . . . . . . . . . 92

8.2 .2 GPS Image Tagging $\ldots \ldots \ldots$

8.2 .3 Imaging Upgrades . . . . . . . . . . . . . . . . . . . . . . . . 93

$\begin{array}{ll}\text { Bibliography } & 95\end{array}$

$\begin{array}{ll}\text { Appendices } & 100\end{array}$

$\begin{array}{lll}\text { A MATLAB and Arduino Code } & 100\end{array}$

B Images for NIIRS Evaluation 101 


\section{List of Tables}

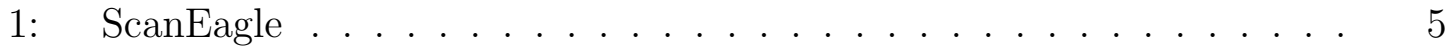

2: Northrop Grumman Bat . . . . . . . . . . . . . . . . . . 7

3: $\quad$ Silent Falcon with Large Wing Configuration . . . . . . . . . . . . 9

4: MLB Super-Bat . . . . . . . . . . . . . . . . . . . . . . . 11

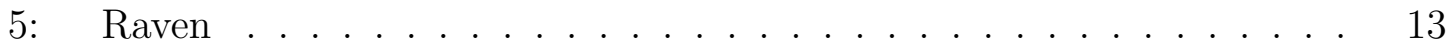

6: Falcon UAS . . . . . . . . . . . . . . . . . . . . . 14

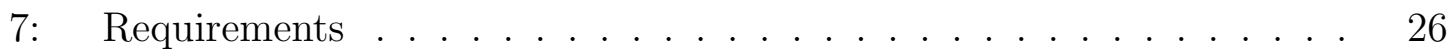

8: $\quad$ GIQE Version 3.0 Constants . . . . . . . . . . . . . . . . . . . . . . 29

9: $\quad$ Statistics of GIQE Terms for Imagery Used to Develop GIQE 4.028 . 30

10: NIIRS Variable Estimation . . . . . . . . . . . . . . . . . . . 31

11: NIIRS Estimation . . . . . . . . . . . . . . . . . . . . 31

12: Image Processing Time For Various Pixel Sizes . . . . . . . . . . . . 53

13: GIQE Version 3.0 Constants . . . . . . . . . . . . . . . . . 55

14: Statistics of GIQE Terms for Imagery Used to Develop GIQE 4.0 . . 56

15: GSD Assumed and Derived . . . . . . . . . . . . . 60

16: RER Assumed and Derived . . . . . . . . . . . . . . 66

17: H Assumed and Derived . . . . . . . . . . . . . . . . . 68

18: GIQE Values For ORA Imager with Medium Resolution . . . . . . 70

19: ORA Weight Breakdown . . . . . . . . . . . . . . 86

20: ORA Cost Breakdown . . . . . . . . . . . . . . . 87

21: $\quad$ Requirement Validation . . . . . . . . . . . . . . . . . . . . 89

22: Image 1 NIIRS Data . . . . . . . . . . . . . . . . . . . . . 101

23: Image 2 NIIRS Data . . . . . . . . . . . . . . . . . . . . 103

24: Image 3 NIIRS Data . . . . . . . . . . . . . . . . . . . . 105

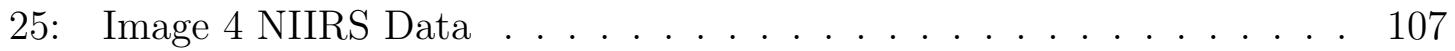

26: Image 5 NIIRS Data . . . . . . . . . . . . . . . . . . . . 109 


\section{List of Figures}

1: Wasp, ${ }^{6}$ Puma, ${ }^{7}$ Shadow ${ }^{8}$ and Global Hawk UAS $^{9}$ (Tier N/A, I, II, and III respectively) . . . . . . . . . . . . . . . . . . . . . . . . . . 3

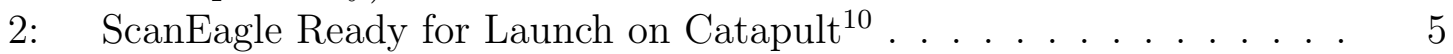

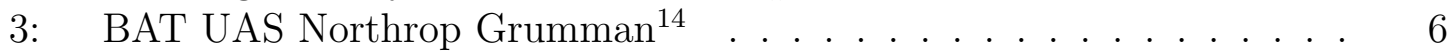

4: Solar/Electric Silent Falcon ${ }^{16} \ldots \ldots$. . . . . . . . . . 8

5: $\quad$ FalconVision, Gimbaled Dual Imaging Payload ${ }^{16} \ldots \ldots$. . . . . . . 8

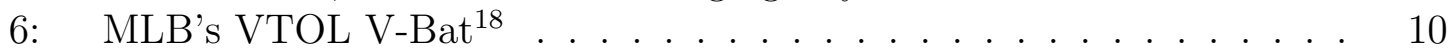

7: MLB's Super-Bat ${ }^{18} \ldots \ldots \ldots \ldots$. . . . . . . . . . 10

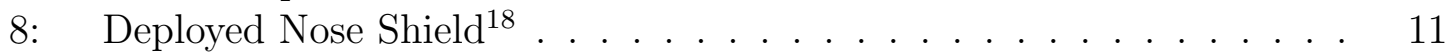

9: $\quad$ Super-Bat Ready for Takeoff with Car-Top Catapult ${ }^{18}$. . . . . . . . 12

10: AeroVironment's RQ-11 Raven ${ }^{19}$. . . . . . . . . . . . . . . . 13

11: Falcon UAS and $\mathrm{GCS}^{21} \ldots \ldots \ldots \ldots . \ldots \ldots$

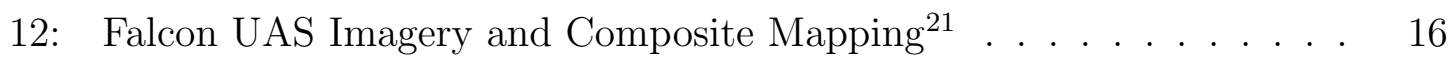

13: Prediction of Water Flow ${ }^{21} \ldots \ldots$. . . . . . . . . . . . . . 17

14: RQ-16 T-Hawk ${ }^{24} \ldots \ldots \ldots$. . . . . . . . . . . . 19

15: Microdrone 1000 with Imager Payload ${ }^{25}$. . . . . . . . . . . . . . . 20

16: COTS TTL Serial Camera with Board ${ }^{27}$. . . . . . . . . . . . . 27

17: Interfaces Between Power Source, Arduino, and CMOS Imager . . . . 28

18: ORA's Onboard Processor, the Arduino Uno ${ }^{30}$. . . . . . . . . . . . 32

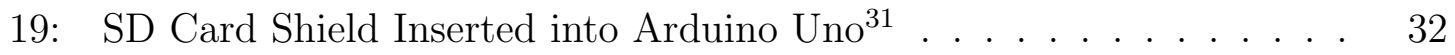

20: Entire Imaging Payload System . . . . . . . . . . . . . . . . . . . 33

21: Imaging Payload Contained within Leading Compartment . . . . . . 34

22: External Payload Bay Fore Section 3-view $(\mathrm{cm})$. . . . . . . . . . . . 38

23: 3D Printed Case Fabricated with ABS Plastic (cm) . . . . . . . . . 39

24: External Payload Bay Aft Section 3-view $(\mathrm{cm})$. . . . . . . . . . . . . 40

25: External Payload Bay Combined Section 3-view $(\mathrm{cm})$. . . . . . . . . 41

26: Isometric View of External Payload Bay with Spar and Tab . . . . . 42

27: Frontal View of Payload Bay with Wing and Spar . . . . . . . . . . . 43

28: Bottom View of Payload Bay with Wing and Spar . . . . . . . . . . . 44

29: External Payload Bay Front Compartment Isometric . . . . . . . . . 45

30: External Payload Bay Rear Compartment Isometric . . . . . . . . . . 45

31: COTS ParkZone Radian Sailplane ${ }^{32}$. . . . . . . . . . . . . . . 46

32: Spektrum Telemetry Module ${ }^{33} \ldots$. . . . . . . . . . . . . . 48 
33: Spektrum Altitmeter Module ${ }^{33} \ldots \ldots \ldots \ldots$. . . . . . . 48

34: ZLog Version Z6R Records and Stores Altitude ${ }^{34} \ldots \ldots . . . . .550$

35: ZLog Flight Altitude Data Example . . . . . . . . . . . . . . 50

36: Correction Factor for Arduino Time Stamp . . . . . . . . . . . . . 53

37: Focal Length of Convex Lens Relating to the Distance and Size of the

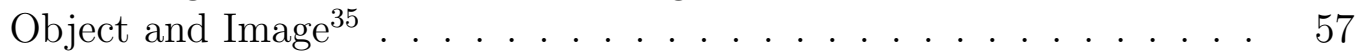

38: Google Earth Overlayed with ORA Imagery . . . . . . . . . . . . 59

39: Relative Edge Response Between Bright and Dark Targets ${ }^{38} \ldots \ldots$. . . 61

40: Normalized Relative Edge Response ${ }^{39} \ldots \ldots$. . . . . . . . . . . 62

41: Tilted Edges at Stennis Space Center Test Range ${ }^{38} \ldots$. . . . . . . . 63

42: Image Analyzed For RER and H Evaluation . . . . . . . . . . . . 64

43: Image Brightness for the Row of Pixels Containing Edge . . . . . . . 65

44: Normalized Image Brightness for the Row of Pixels Containing Edge . 66

45: Edge Response Overshoot for Column of Pixels Containing Edge . . . 67

46: Pixel Density Per Image within Common Flight Altitudes . . . . . . . 75

47: Coverage Area Per Image Depending on Altitude . . . . . . . . . . 75

48: Orchard Level 3 Validation at $413 \mathrm{ft}$. . . . . . . . . . . . . . . 79

49: Basketball Court Level 4 Validation at $416 \mathrm{ft} \ldots \ldots$. . . . . . . . 79

50: Tent Level 5 Validation at $432 \mathrm{ft} \ldots \ldots \ldots$. . . . . . . . . 80

51: ORA Images Overlayed onto Google Earth . . . . . . . . . . . . . 81

52: Test Flight Altitude . . . . . . . . . . . . . . . . . . . . . . 82

53: Crash Landing Flight Altitude . . . . . . . . . . . . . . 84

54: ORA Post Crash Landing . . . . . . . . . . . . . . . . . 85

55: External Payload Bay Post Crash Landing . . . . . . . . . . . 85

56: Image $1 \ldots \ldots \ldots \ldots$

57: Vertical Edge Response for Image $1 \ldots \ldots \ldots$

58: Horizontal Edge Response for Image 1 . . . . . . . . . . . . . . 102

59: Image $2 \ldots \ldots \ldots \ldots \ldots \ldots$

60: Vertical Edge Response for Image $2 \ldots \ldots$

61: Horizontal Edge Response for Image 2 . . . . . . . . . . . . . . 104

62: Image $3 \ldots \ldots \ldots \ldots \ldots$

63: Vertical Edge Response for Image $3 \ldots \ldots$. . . . . . . . . . . 106

64: Horizontal Edge Response for Image $3 \ldots \ldots$

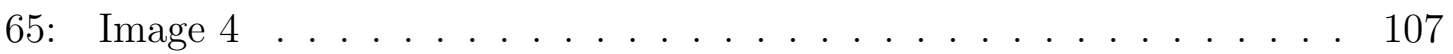

66: Vertical Edge Response for Image $4 \ldots \ldots \ldots$

67: Horizontal Edge Response for Image $4 \ldots \ldots$

68: Image $5 \ldots \ldots \ldots \ldots \ldots$

69: Vertical Edge Response for Image 5 . . . . . . . . . . . . . . . . 110

70: Horizontal Edge Response for Image 5 . . . . . . . . . . . . . . 110 
Nomenclature

$\begin{array}{ll}\text { AGL } & \text { Above Ground Level } \\ \text { AUVSI } & \text { Association for Unmanned Vehicle Systems International } \\ \text { DEM } & \text { Digital Elevation Model } \\ \text { DSM } & \text { Digital Spektrum Modulation } \\ d_{i} & \text { Distance of Image from Lens } \\ d_{o} & \text { Distance of Object from Lens } \\ \text { ER } & \text { Edge Response } \\ \text { EO } & \text { Electro-Optical } \\ f & \text { Focal Length } \\ \text { G } & \text { Post-Processing Noise Gain } \\ \text { GCS } & \text { Ground Control System } \\ \text { GIQE } & \text { General Image Quality Equation } \\ \text { GIS } & \text { Graphical Interface Systems } \\ \text { GND } & \text { Ground } \\ \text { GSD } & \text { Ground Sample Distance } \\ \text { H } & \text { Post-Processing Edge Overshoot Factor } \\ h_{i} & \text { Height of Image from Lens } \\ h_{o} & \text { Height of Object from Lens } \\ \text { IR } & \text { Infrared } \\ \text { ISR } & \text { Intelligence, Survailance and Reconnaissance } \\ M & \text { Magnification } \\ \text { LIDAR } & \text { Light Detection and Radar } \\ \text { MCSO } & \text { Mesa County Sheriff's Office } \\ \text { MSL } & \text { Mean Sea Level } \\ \text { MRICE } & \text { Microsoft Research Image Composite Editor } \\ \text { MTOW } & \text { Max Takeoff Weight } \\ \text { NASA } & \text { National Aeronautics and Space Administration } \\ \text { NIIRS } & \text { National Imagery Interpretability Rating Scale } \\ \text { NOAA } & \text { National Oceanic and Atmospheric Administration } \\ \text { ORA } & \text { Operationally Responsive Aircraft } \\ p & \text { Imager Pixel Pitch (Length of Pixel) } \\ \text { PWR } & \text { Power } \\ R & \text { Distance between Imager and Target } \\ \text { RC } & \text { Remote Controlled } \\ \text { RER } & \text { Relative Edge Response } \\ & \end{array}$




$\begin{array}{ll}\text { RTC } & \text { Real Time Clock } \\ \text { RX } & \text { Camera Output } \\ \text { SNR } & \text { Signal to Noise Ratio } \\ \text { SUAS } & \text { Small Unmanned Aerial System } \\ \text { SWIR } & \text { Short Wave Infrared } \\ \text { TX } & \text { Camera Input } \\ \text { UAS } & \text { Unmanned Aerial System } \\ \text { UAV } & \text { Unmanned Aerial Vehicle } \\ \text { USAF } & \text { U.S. Air Force } \\ \text { USGS } & \text { U.S. Geological Survey } \\ \text { VTOL } & \text { Vertical Takeoff and Landing }\end{array}$




\section{Introduction}

\subsection{Topic Area}

Unmanned Aerial Systems, or UAS, have been in service for the last 70 years. UAS are now an important part of many countries air defences. Modern UAS have come a long way since first being used by the U.S. Air Force in the 1940s. Early model drones were built for reconaissance, but were not efficient due to major flaws in operating systems at the current techonology level. Over the years, UAS have been developed into the highly sophisticated machines in use today. Modern UAS are used for many important applications including weather prediction, news brodcasting, nuclear radiation measurements, and of course defense. A vast majority of these missions fall under the classificiation of intelligence, survaillance and reconnaissance (ISR). ${ }^{1}$

ISR encompasses various data which can be aquired with a wide variety of systems. The role of the UAS is expanding rapidly in this area and, in doing so, revolutionizing the ability to gather information about the global environment. Satellites have historically been heavily relied upon for global observation. UAS are a great complement to satellites because they can collect data anywhere at anytime while offering the ability to change out sensor equipment.

There are many important factors when choosing an ISR platform including: image quality, coverage area, response time, operating costs, portability, detection foot- 
print, and reliability. A Small Unmanned Aerial System (SUAS) outperforms larger scale UAS in the area of response time, operating costs, portability, and detection footprint. Limitations of SUAS typically include lower image resolution, coverage area and endurance.

The US Air Force, US Army and US Marine Corps each categorize unmanned aerial vehicle (UAV) platforms into different sets of tiers. Size, speed, operating altitude, functionality and capabilities are just some aspects that differentiate UAVs. The three sets of tiers are quite similar but vary in substantial ways. The Air Force defines each tier relating to altitude and endurance, while the Army utilizes range to distinguish between systems. The Marines' set of UAV tiers are dependent on size as well as launchability and will be used in this project to classify each platform. ${ }^{2}$ The four tiers of the US Marines are as follows:

- Tier N/A: Micro UAVs.

- Tier I: Small UAVs (hand-launched).

- Tier II: Medium Tactical UAVs (catapult-launched).

- Tier III: Large Tactical UAVs .

AeroVironment produces many of these smaller scale UAVs. The Wasp is an example of a Micro UAV. It weighs less than $1 \mathrm{lb}$ with a wing span less than 2.5 ft. It is easily transported and deployed by a single operator. The Puma, which is also produced by AeroVironment, would be considered a Tier I UAV due to its handlaunchable take-off. The $8.5 \mathrm{ft}$ wingspan creates an endurance of 2 hours while still 
being man portable. ${ }^{3}$ AAI's Shadow 200 is an example of a Tier II Tactical UAV. It is launched with a pneumatic catapult and has a $14 \mathrm{ft}$ wingspan. The Shadow has a range of 68 miles and a 6 hour endurance. A truck is needed to transport the vehicle via land, while two C-130s are necessary to take the entire system overses. ${ }^{4}$ Northrop Grumman's Global Hawk is in the largest class of UAV, Tier III. With a $116 \mathrm{ft}$ wingspan and a take-off gross weight of 25,000 lbs, the Global Hawk can fly over 11,000 miles with an endurance of more than 31 hours. The performance of this aircraft is at the top of its class, however you pay for what you get. Each Global Hawk costs $\$ 31,000$ per hour to operate. The annual flying costs for the USAF is just below $\$ 17$ million a year for each aircraft. ${ }^{5}$ Figure 1 illustrates examples of each UAV tier in increasing order from left to right and top to bottom.
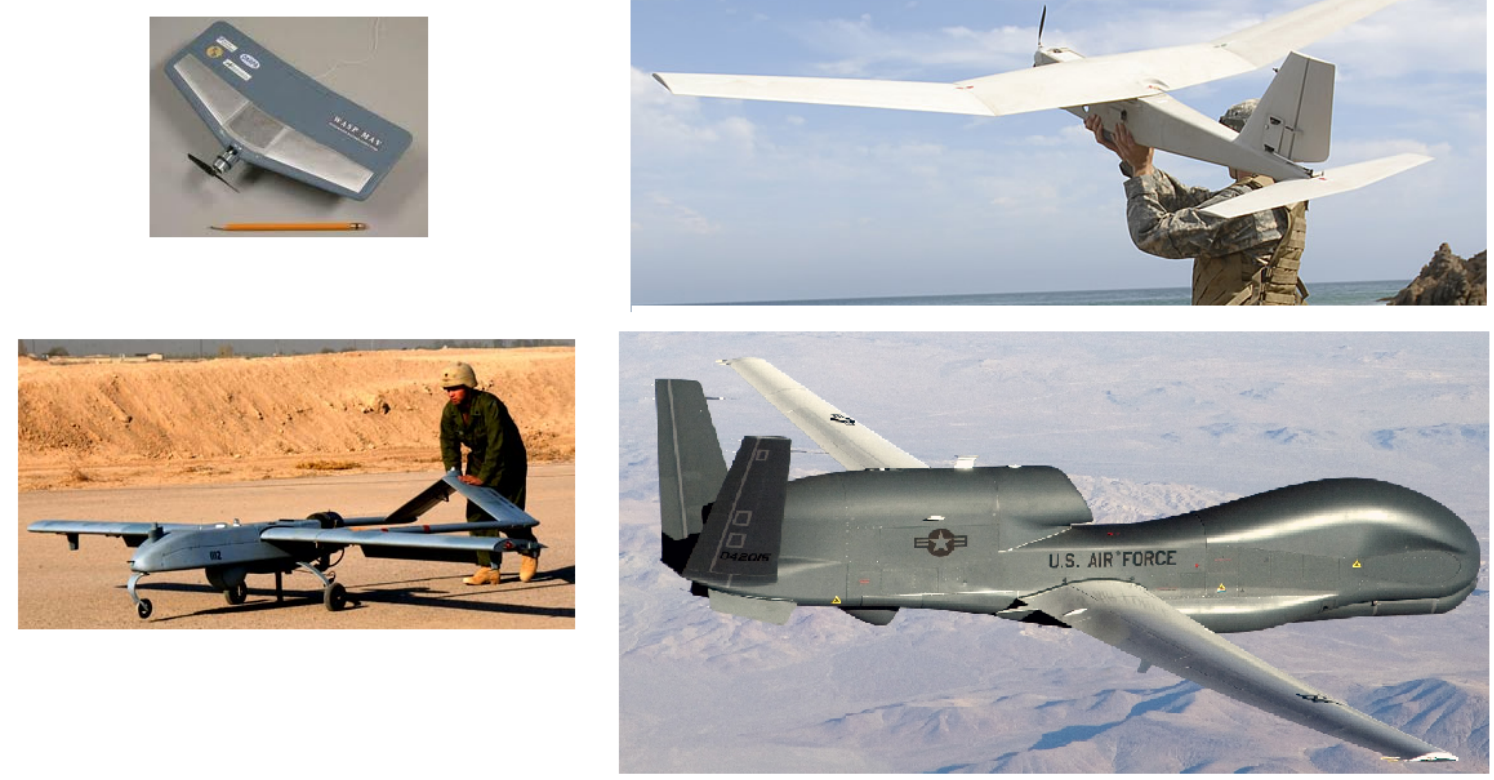

Figure 1: Wasp, ${ }^{6}$ Puma,,${ }^{7}$ Shadow, ${ }^{8}$ and Global Hawk $\mathrm{UAS}^{9}$ (Tier N/A, I, II, and III respectively) 


\subsection{Capabilities of Current Technologies}

While there are many UAVs currently on the market, the following systems were reviewed extensively due to their high performance, portability and versatility in combination with their relatively low cost. A majority of the systems below are in Tier I and Tier II platforms, i.e. launched either by hand or with catapult.

\subsubsection{Boeing Insitu's ScanEagle}

The ScanEagle was developed by Insitu and originially intended to track fishing boats that catch tuna. Its mission was to ensure that fish bought in supermarkets were caught without causing any harm to dolphins. The United States Marine Corps purchased this system in 2004 from the Boeing-Insitu partnership with the intended use of naval operations and battlefield surveillance. ${ }^{10}$ The ScanEagle is launched with a pneumatic catapult, shown in Figure 2. The aircraft is retrieved with a Skyhook system. This is a hook attached to the edge of the wingtip designed to catch a rope hanging from a 30 to 50 foot pole. Eliminating the need for a runway creates an efficient vehicle for naval operatations. The ScanEagle contains a modular payload allowing the ability to switch out payloads depending on needs. Currently the system includes a color electro-optical (EO) camera as well as a infrared (IR) camera giving it the ability to perform both day and night operations. Key capabilites and metrics

are shown in Table $1{ }^{11}$ The UAV by itself costs around $\$ 100,000$ dollars ${ }^{12}$ while the entire system, including catapult, Skyhook, and ground control system (GCS), can 
range upwards of $\$ 3.2$ million as of $2006 .{ }^{13}$

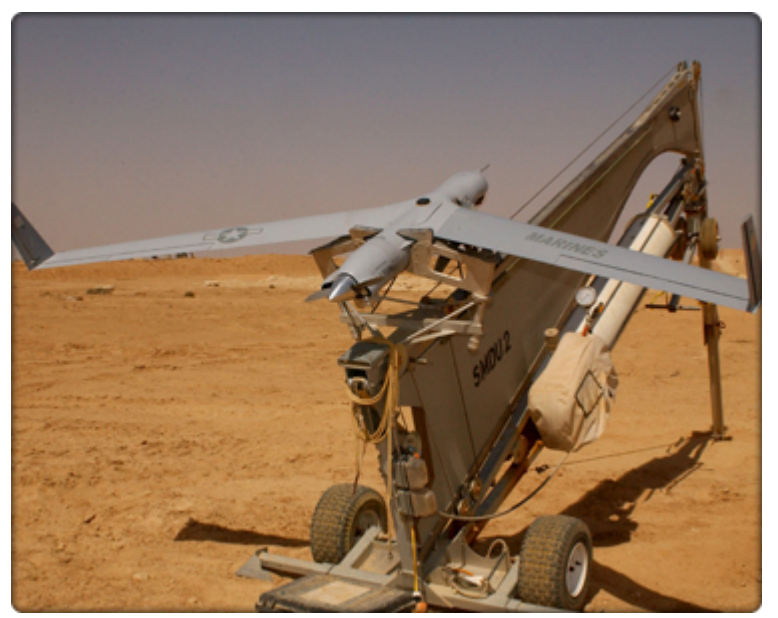

Figure 2: ScanEagle Ready for Launch on Catapult ${ }^{10}$

Table 1: ScanEagle

\begin{tabular}{cc}
\hline \hline Capability & Metric \\
\hline Endurance & $24+$ hours \\
Ceiling & $19,500 \mathrm{ft}$ \\
Max Speed & 80 knots \\
Loiter Speed & 55 knots \\
Wingspan & $10 \mathrm{ft}$ \\
Max Takeoff Weight & $44 \mathrm{lbs}$ \\
Takeoff & Pneumatic Catapult \\
Landing & Skyhook \\
UAV Cost & $\$ 100,000$ \\
System Cost & $\$ 3.2$ Million \\
\hline
\end{tabular}

\subsubsection{Northop Grumman's Bat}

The KillerBee UAV was jointly designed in 2005 by Swift Engineering and Northrop Grumman to meet requirements for the U.S. Air Force, Marine Corps, and Department of Homeland Security. Swift Engineering began manufacturing the KillerBee UAV, GCS, launcher and recovery system alone after the partnership collapsed in 
early 2007. Northrop Grumman acquired the KillerBee from Swift Engineering in 2009 and renamed it Bat.

The blended wing body of the Bat, shown in Figure 3, reduces aerodynamic drag which enhances fuel economy and endurance compared to conventional airframes. The blended body also increases the allowable payload size. It is launched from a pneumatic rail launcher which was designed for the AAI Shadow UAS. A net is utilized to retrieve the Bat creating a completely autonomous launch and recovery system, viable for land, sea and air operations. ${ }^{14}$

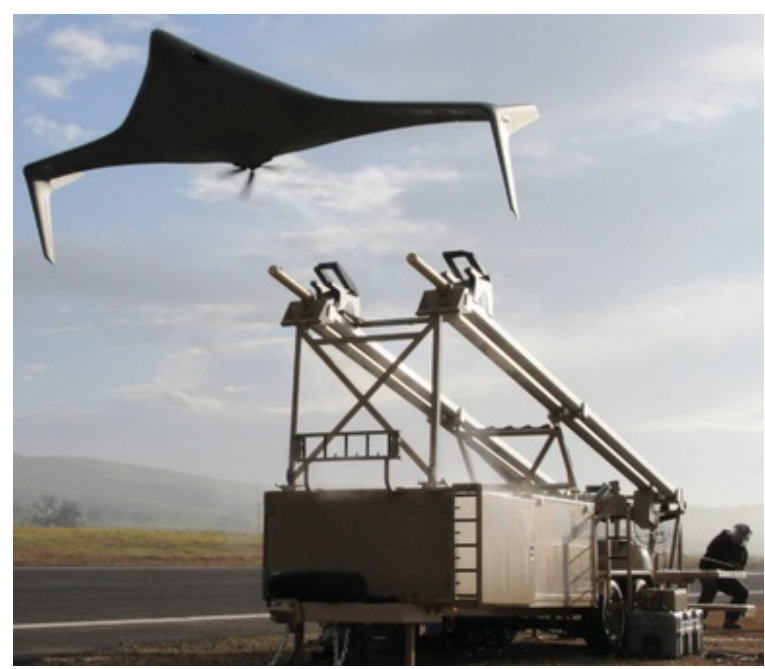

Figure 3: BAT UAS Northrop Grumman ${ }^{14}$

The Bat is equipped with EO sensors, IR sensors, laser range finders, laser designators (utilized for target aquisition), as well as a camera for still imagery and real-time video. It is equipped with a synthetic aperture radar, moving target indicator, signal/communication intelligence, chemical/biological agent detection systems and flare dispersers. The Bat is not yet commercially available, so the cost is unstated, 
but the rest of its key capabilities are shown in Table $2 .{ }^{15}$

Table 2: Northrop Grumman Bat

\begin{tabular}{cc}
\hline \hline Capability & Metric \\
\hline Endurance & 15 hours \\
Ceiling & $15,000 \mathrm{ft}$ \\
Max Speed & 89 knots \\
Loiter Speed & 63 knots \\
Wingspan & $12 \mathrm{ft}$ \\
Max Takeoff Weight & $210 \mathrm{lbs}$ \\
Takeoff & Pneumatic Rail Launcher \\
Landing & Net Retrieval System \\
UAV Cost & NA \\
\hline
\end{tabular}

\subsubsection{UAS Technologies Silent Falcon}

UAS Technologies, a company out of Albuquerque New Mexico, currently has a patent pending for the Silent Falcon, depicted in Figure 4. It is a solar/electric, all composite, modular SUAS designed for both millitary and public safety applications. The aircraft utilizes thin film photo voltaic solar energy collection to charge lithium polymer batteries. These batteries power a silent and efficient propulsion system that is undetectable when $200 \mathrm{ft}$ above ground level. The Silent Falcon has increased versatility due to three interchangeable wing configurations, $8 \mathrm{ft}, 12 \mathrm{ft}$, and $18 \mathrm{ft}$. The difference in lift between the small and large wingspan increases its endurance from 6 hours to 14 hours. ${ }^{16}$ Table 3 shows characteristics of the Silent Falcon's $18 \mathrm{ft}$ configuration.

The payload, patented FalconVision and shown in Figure 5, features an EO and IR gimbaled camera which processes video onboard, while refencing altitude and heading. 


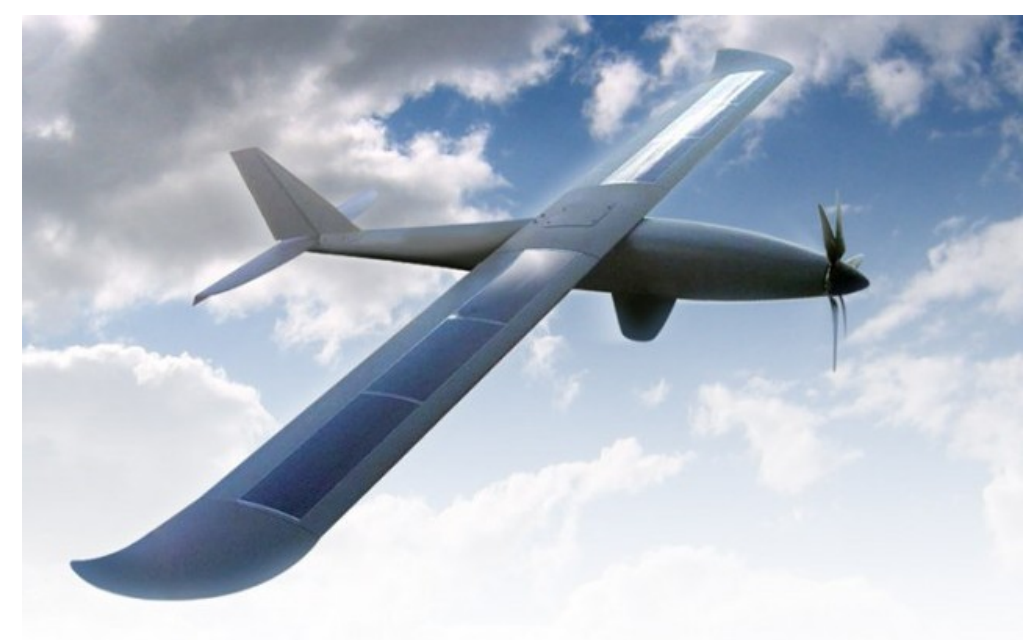

Figure 4: Solar/Electric Silent Falcon ${ }^{16}$

The FalconVision utilizes image stabilization and can track targets. Optional features include multi-target tracking, auto-zoom, SWIR (Short wave infrared) imager, laser pointer, laser range finder, as well as high altitude operation (above 12,000 ft sea level), ${ }^{17}$ which are not included in the $\$ 150,000$ asking price.

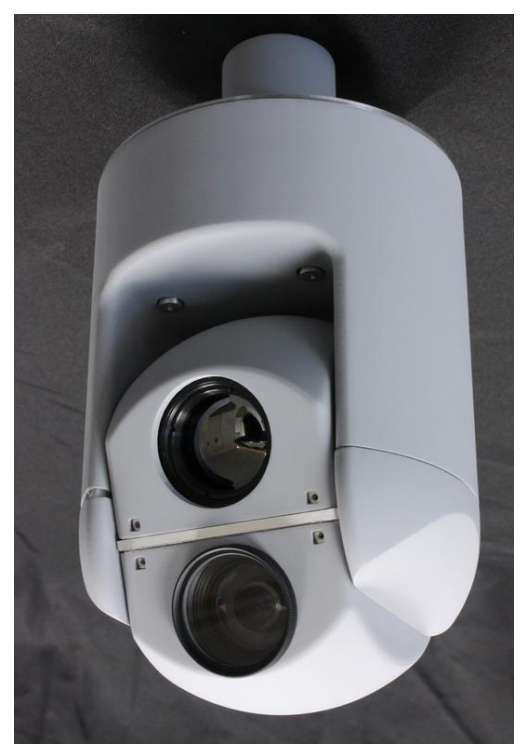

Figure 5: FalconVision, Gimbaled Dual Imaging Payload ${ }^{16}$ 
Table 3: Silent Falcon with Large Wing Configuration

\begin{tabular}{cc}
\hline \hline Capability & Metric \\
\hline Endurance & 14 hour \\
Ceiling & $12,000 \mathrm{ft}$ \\
Max Speed & 60 knots \\
Stall Speed & 12 knots \\
Wingspan & $18 \mathrm{ft}$ \\
Max Takeoff Weight & $31 \mathrm{lb}$ \\
Takeoff & Bungie or Wheeled \\
Retrieval & Net, Skid, or Wheeled \\
Baseline Cost & $\$ 150,000$ \\
\hline
\end{tabular}

\subsubsection{MLB's Bat UAV Family}

MLB is a company, based out of Mountain View California, that provides customers with cost-effective access to aerial information specializing in UAS. They have 3 commercially available unmanned fixed-wing aircrafts: a vertical-takeoff-and-land (VTOL) system, a payload carrying aircraft and a drone designed to gather data relating to ISR. The V-Bat, shown in Figure 6, merges sailplane-like wings with a ducted fan. The fan serves as both propulsion unit and control surface. A nose-skid is placed to diminish tip-over damage. The $\mathrm{V}$-Bat only requires $20 \mathrm{ft} \mathrm{x} 20 \mathrm{ft}$ of space in order to perform VTOL. The product is still under developement, but the estimated price is $\$ 320,000 .^{18}$

The Super-Bat is a similar, less robust, product with a more reasonable price. It is equipped with a EO, IR, and SWIR gimbaled camera that can stream video live. A digital camera can be mounted under the wing for high-resolution photography. Figure 7 depicts the system midflight. When landing, a carbon-fiber nose shield 


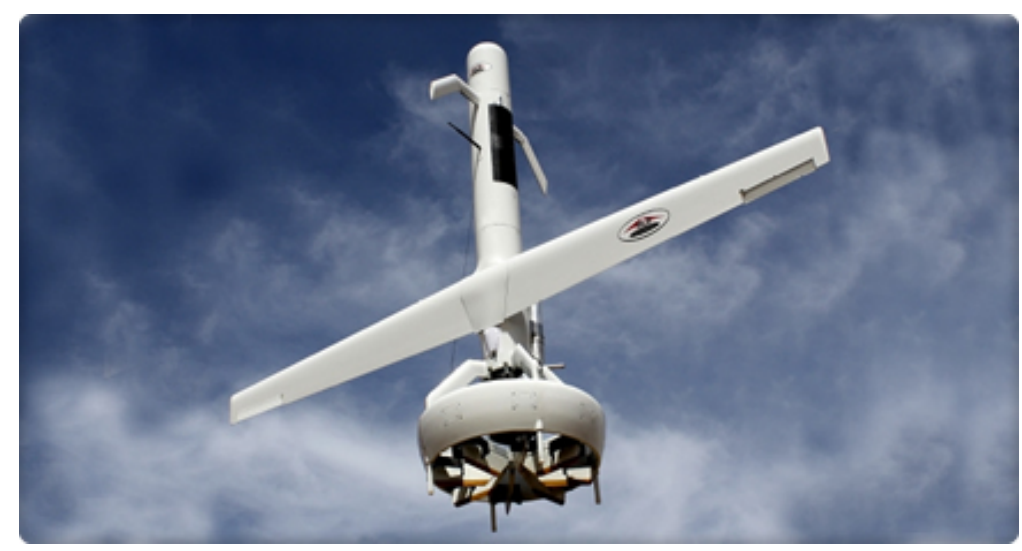

Figure 6: MLB's VTOL V-Bat ${ }^{18}$

protects the sensors from damage. In Figure 7 the nose shield is orientated such that it is protecting the payload, while in Figure 8 the shield is deployed for sensor operation.

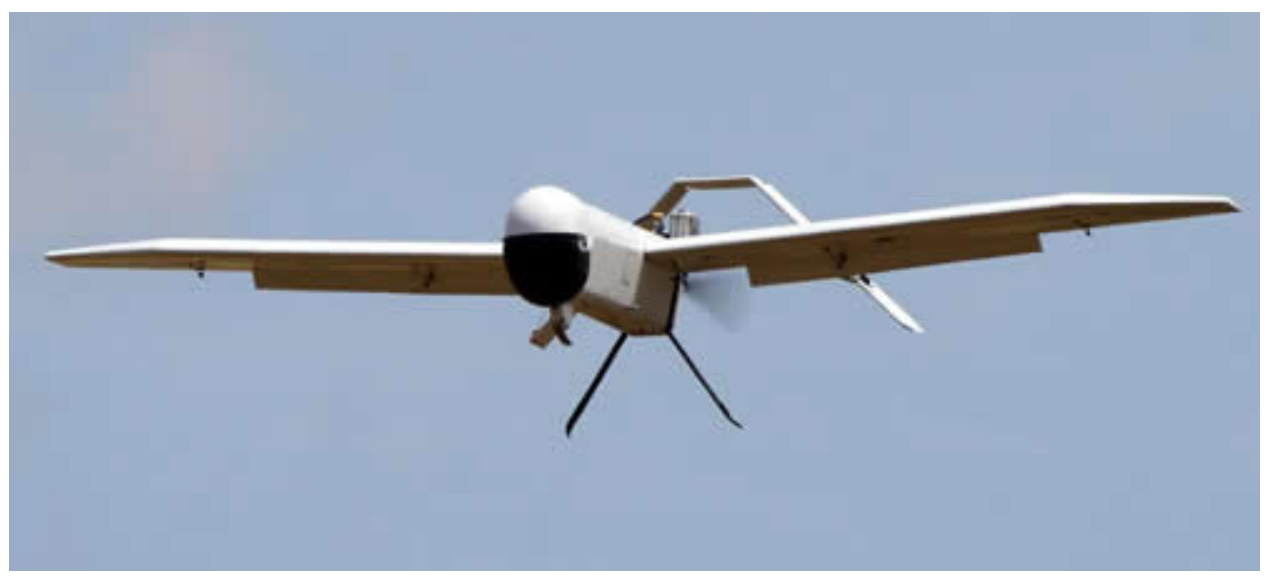

Figure 7: MLB's Super-Bat ${ }^{18}$

A 26cc 2-stroke engine with a pusher propellor makes up the propulsion unit for this aircraft. A Piccolo Command Center provides the ability to perform autonomous flight operations utilizing waypoints supplied by the user pre takeoff. The system launches via a car-top (non-moving), bungee-powered catapult, illustrated in Figure 


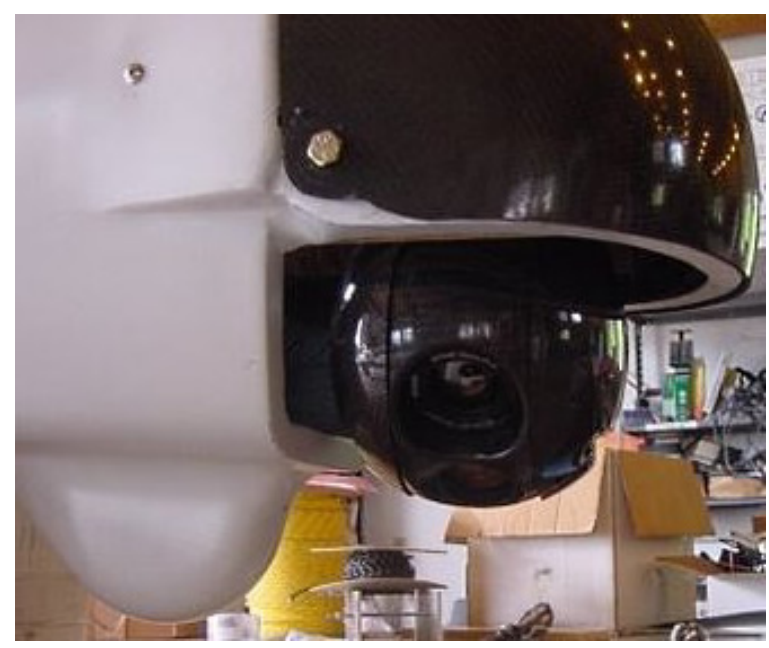

Figure 8: Deployed Nose Shield ${ }^{18}$

9, and lands autonomously on skids within a $320 \mathrm{ft}$ x $130 \mathrm{ft}$ area. The Super-Bat's range is 400 miles, fuel limited, and 6 miles telemetry limited. There are also additional options of long range (55 miles) Iridium satellite links, an emergency parachute system, as well as increased power and propulsion capabilites which are not included in the $\$ 120,000$ baseline price. The key metrics of this aircraft are illustrated in Table 4.

Table 4: MLB Super-Bat

\begin{tabular}{cc}
\hline \hline Capability & Metric \\
\hline Endurance & 10 hour \\
Ceiling & $10,000 \mathrm{ft}$ \\
Max Speed & 65 knots \\
Stall Speed & 35 knots \\
Wingspan & $8.5 \mathrm{ft}$ \\
Max Takeoff Weight & $34 \mathrm{lb}$ \\
Takeoff & Car-Top Catapult \\
Retrieval & Skids within $320 \mathrm{ft} \times 130 \mathrm{ft}$ \\
Baseline Cost & $\$ 120,000$ \\
\hline
\end{tabular}




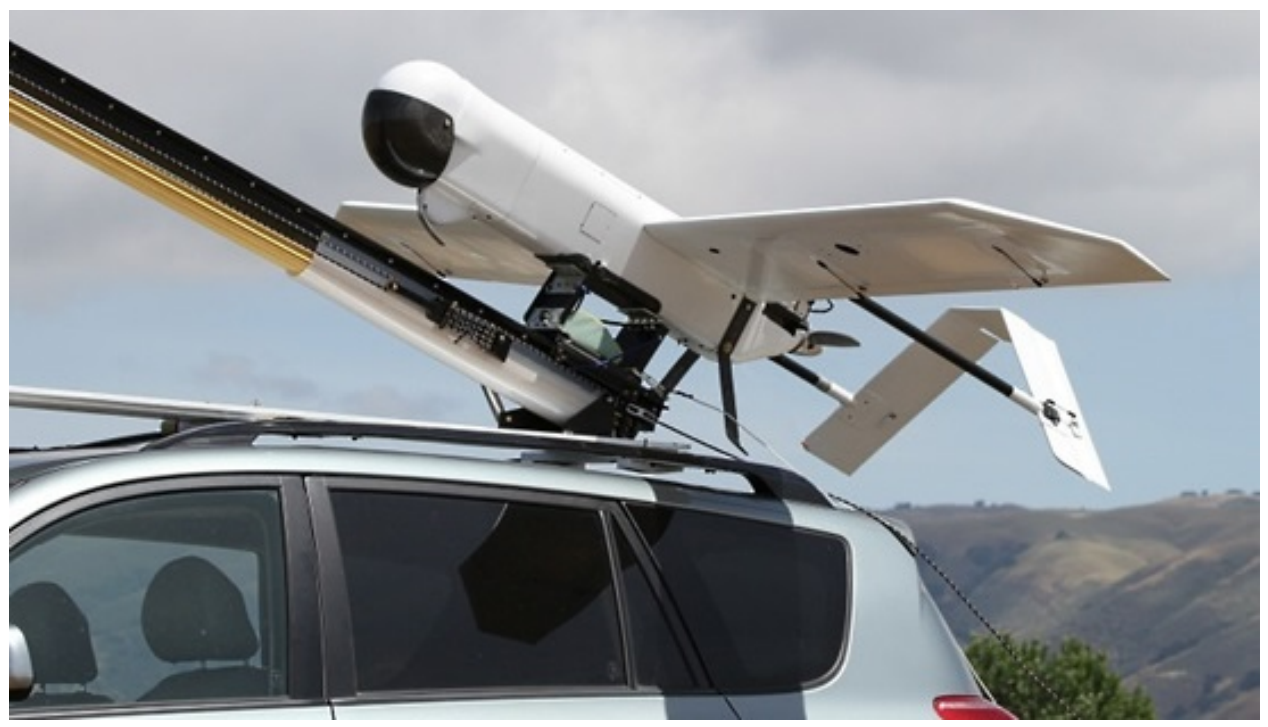

Figure 9: Super-Bat Ready for Takeoff with Car-Top Catapult ${ }^{18}$

\subsubsection{AeroVironment's RQ-11 Raven}

The Raven was designed and manufactured by AeroVironment and won the US Army's SUAS contract in 2005. It was also adopted by US Special Operations Command, the US Marines, and US Air Force as well as other countries military forces. It is light-weight (4.2 lbs), hand-launchable and has an autonomous navigation system along with a deep-stall autoland feature. A forward or side-looking EO nose camera with pan/tilt ability and stabilization make up the day operations payload. This EO camera can be replaced with an IR nose camera for night operations. It can stream either the EO or IR imagery back to the GCS. The Raven, illustrated in Figure 10, has a max operating altitude of $500 \mathrm{ft}$ above ground level (AGL) with a 14,000 ft mean sea level (MSL) max launch altitude. ${ }^{19}$

The US Army quickly fell in love with the Raven and its portable eye-in-the-sky. 


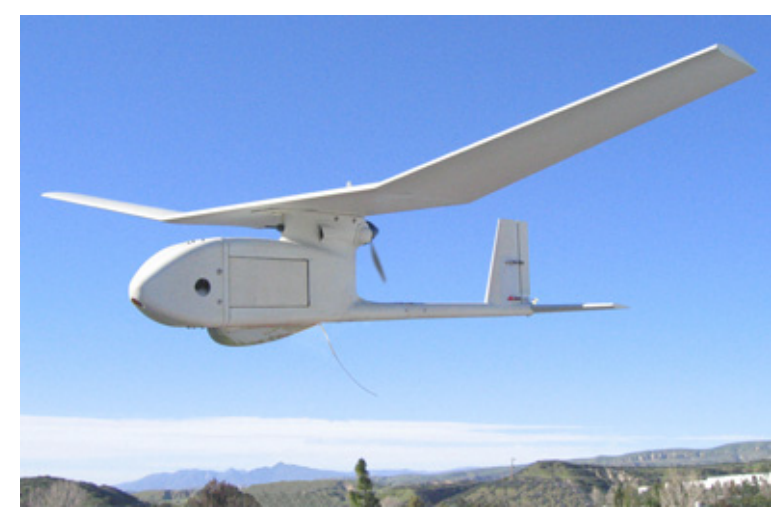

Figure 10: AeroVironment's RQ-11 Raven ${ }^{19}$

This system is deployed over Afghanistan to scout territory and peer over hills instead of having troops walk the point. They are also being used to monitor roads and detect roadside bombs. The Raven is classified as a Tier I UAS due to the hand-launched take-off and the ability to fit in a soldier's rucksack. ${ }^{20}$ The Raven's capabilities are presented in Table 5.

Table 5: Raven

\begin{tabular}{cc}
\hline \hline Capability & Metric \\
\hline Endurance & 80 minutes \\
Ceiling & $500 \mathrm{ft}$ \\
Max Speed & 44 knots \\
Stall Speed & 17 knots \\
Wingspan & $4.5 \mathrm{ft}$ \\
Max Takeoff Weight & $4.2 \mathrm{lb}$ \\
Takeoff & Hand Launched \\
Retrieval & Deep Stall \\
UAV Cost & $\$ 35,000$ \\
System Cost & $\$ 250,000$ \\
\hline
\end{tabular}




\subsubsection{MCSO's Falcon UAS}

The Falcon UAS, illustrated in Figure 11, was developed by the Mesa County Sheriffs Office (MCSO) in Colorado and has recieved an FAA Certificate of Authorization for flight operations covering all 3,300 square miles of the Sheriffs Office's jurisdiction while flying under 400 feet. They are planning on utilizing the UAS for ISR when the Sheriffs are called to help injured mountain bikers. The Falcon contains a gimbaled 10x Zoom Sony Block camera as well as a thermal IR camera. It is hand or bungee launched for takeoff and lands on its belly or deploys a parachute to safely reach the ground. The UAS provides real-time video within a 3 mile range, and in that range, the imager can be pointed at various angles specified by the operator at the GCS. The user can either take control of the aircraft with a stabilized joystick control or set GPS waypoints for navigation. The Falcon can be disassembled and transported by backpack or a ruggedized rifle case. Table 6 shows the specifications of the unmanned craft. ${ }^{21}$

Table 6: Falcon UAS

\begin{tabular}{cc}
\hline \hline Capability & Metric \\
\hline Endurance & 1 hour \\
Ceiling & $1,500 \mathrm{ft}$ \\
Max Speed & 49 knots \\
Loiter Speed & $22 \mathrm{knots}$ \\
Wingspan & $8 \mathrm{ft}$ \\
Max Takeoff Weight & $9.5 \mathrm{lb}$ \\
Takeoff & Hand or Bungee Launch \\
Retrieval & Belly Landing or Parachute \\
Pixel Resolution & $6 \mathrm{~cm} /$ pixel \\
Baseline System Cost & $\$ 18,500$ \\
\hline
\end{tabular}




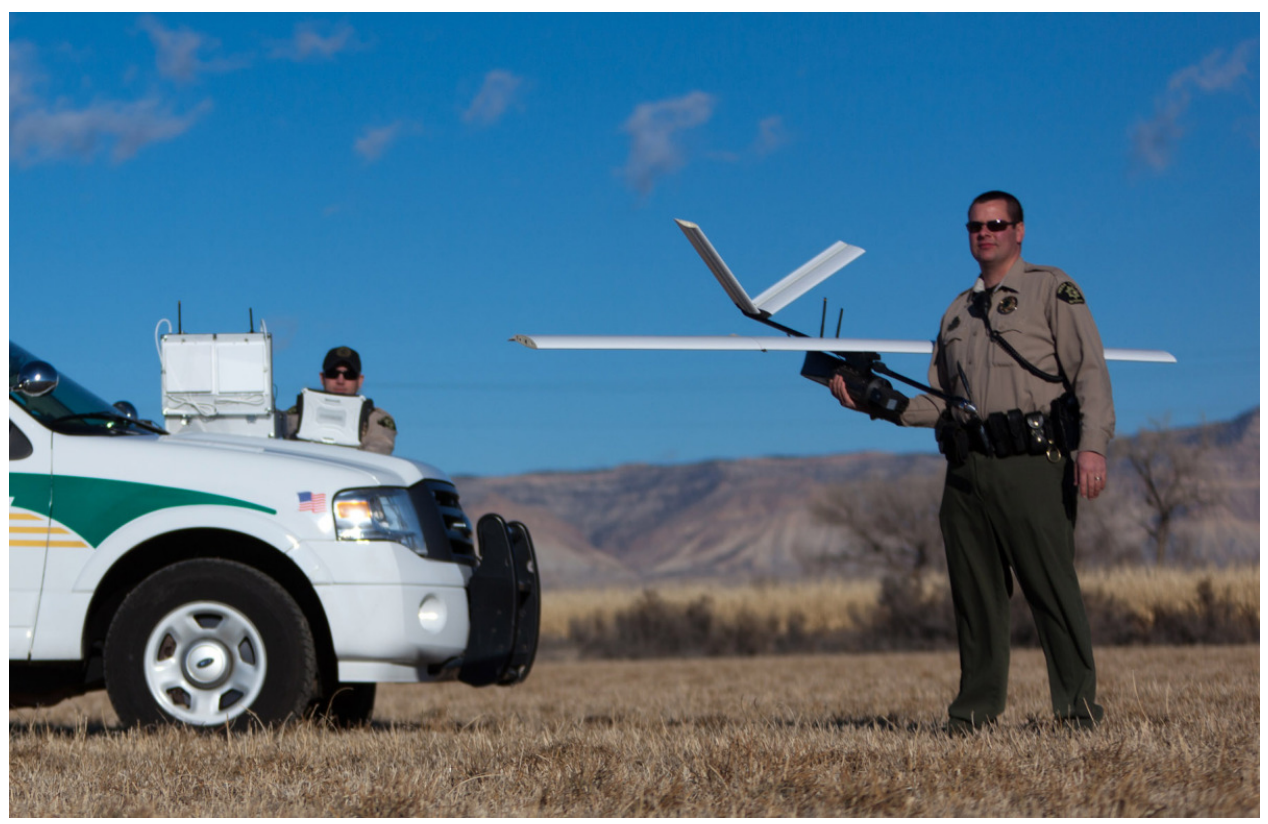

Figure 11: Falcon UAS and GCS ${ }^{21}$

By teaming up with DroneMapper, the Falcon UAS can compile a composite map and pull information from DroneMapper's database depending on GPS location to create Digital Elevation Models (DEMs) and Digital Surface Models. They utilize Ground Control Points, provided by Compass Data, to see how accurate their map is as well as correct any distortion of the imagery. Figure 12 shows individual images captured and combined to create a composite map. With DroneMapper the orthomosaic map can be altered to illustrate the change in elevation. As you can imagine, the DEM would be a great resource when planning for possible floods as well as irrigating crops. An example of such imagery is shown in Figure 13.

There are two possible options for the Falcon UAV flight hardware. Either a Kestrel 2.4 autopilot or an Ardupilot autopilot can come equipped with the airframe. 


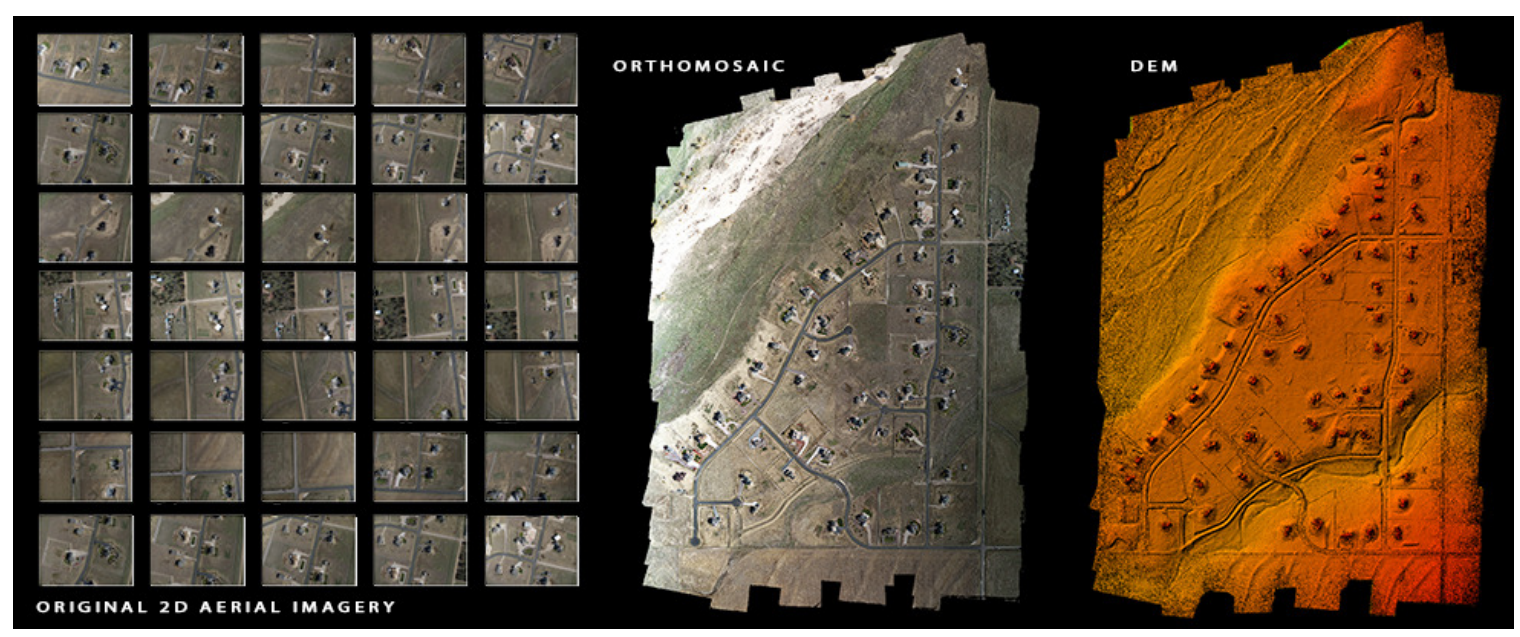

Figure 12: Falcon UAS Imagery and Composite Mapping ${ }^{21}$

The Ardupilot version is less expensive and will be considered the baseline for comparison. They are asking a price of $\$ 15,000$ for the complete airframe (Ardupilot equipped) with back up batteries and motors, including a video transmitter, 2-axis gimbal, EO camera, 2 parachutes, and a pelican carrying case. The IR camera is not included in the baseline price and must be purchased separately $(\$ 4,000$ to $\$ 9,000$ depending on performance). The GCS is comprised of a laptop with software, wireless mouse, wireless joystick, 10" attached monitor and integrated commbox. The integrated commbox includes all necessary hardware to receive the live video feed, communicate with the computer, and communicate with the autopilot. The ground control station is priced at $\$ 3,500$. Without any operator training, the entire system adds up to a baseline price of $\$ 18,500 .^{22}$ 


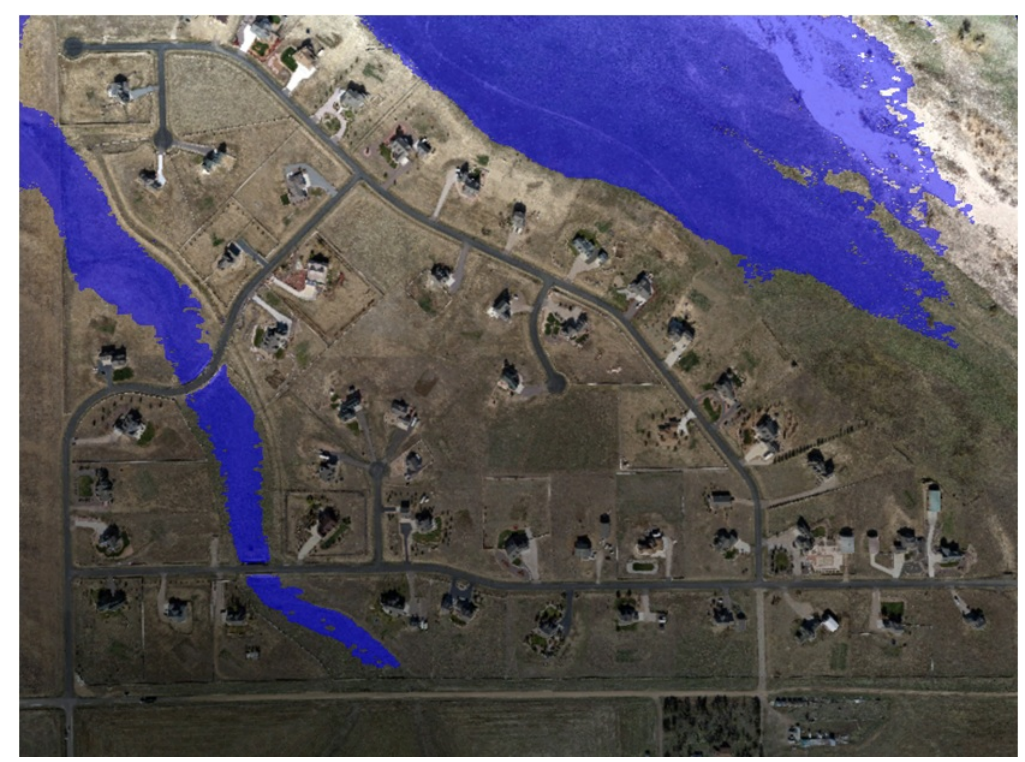

Figure 13: Prediction of Water Flow ${ }^{21}$

\subsection{Applications}

The unmanned aircraft industry is producing exteremly useful products. These UAS have a large variation in not only capabilities but also pricing. In the 70 year existense of the UAV, the military has been the only customer for the unmanned drones. But times are changing. We are entering into an era where the customer base is starting to grow out of defense and into commercial operations. Currently there are only a few non-military entities that are utilizing these machines for ISR. These are mostly large scale or government organizations that have enough money to do so, for example NOAA (The National Oceanic and Atmospheric Administration) and NASA (National Aeronautics and Space Administration).

In April 2010, the Global Hawk completed the first flights for science research. A joint venture between NOAA and NASA has obtained previously unattainable 
data relevant to climate change, hurricanes, Pacific storms, endangered species, and more. Northrop Grumman outfitted a Global Hawk with a modular honeycomb pallet system that NOAA uses to store payloads. One sensor being used is a cloud physics LIDAR (Light Detection and Ranging) instrument for measuring properties of greenhouse and ozone depleting gases. Other instruments used on NOAAs Global Hawk include a radar for profiling wind and rain, as well as a microwave radiometer for measuring temperature and moisture, which saw action mostly over the Pacific Ocean. ${ }^{23}$

On the other side of the Pacific after four nuclear reactors at the Fukushima Daiichi complex in Japan were catastrophically damaged during the March 2011 earthquake, a hybrid drone was undergoing one of its first civilian trials as well. They needed information about the upper reaches of each reactor building, but because the exposed fuel rods were giving off hazardous gamma radiation, sending in piloted aircraft was out of the question. The task required something that could hover and take images amid gusty coastal winds, as well as fly into the wreckage. It was a job for Honeywells RQ-16 T-Hawks, drones roughly the size of a $1 \mathrm{ft}$ cube. The T-Hawk, depicted in Figure 14, is known as Dusty Bin by military units that have been using it for patrols in Afghanistan and Iraq.

The sturdy T-Hawk-a single rotor tucked inside a shroud, plus two stubby protrusions for navigational gear and sensors-can knock into things without breaking to pieces. Over three months and 40 missions, the T-Hawks' sensors, including radiation 


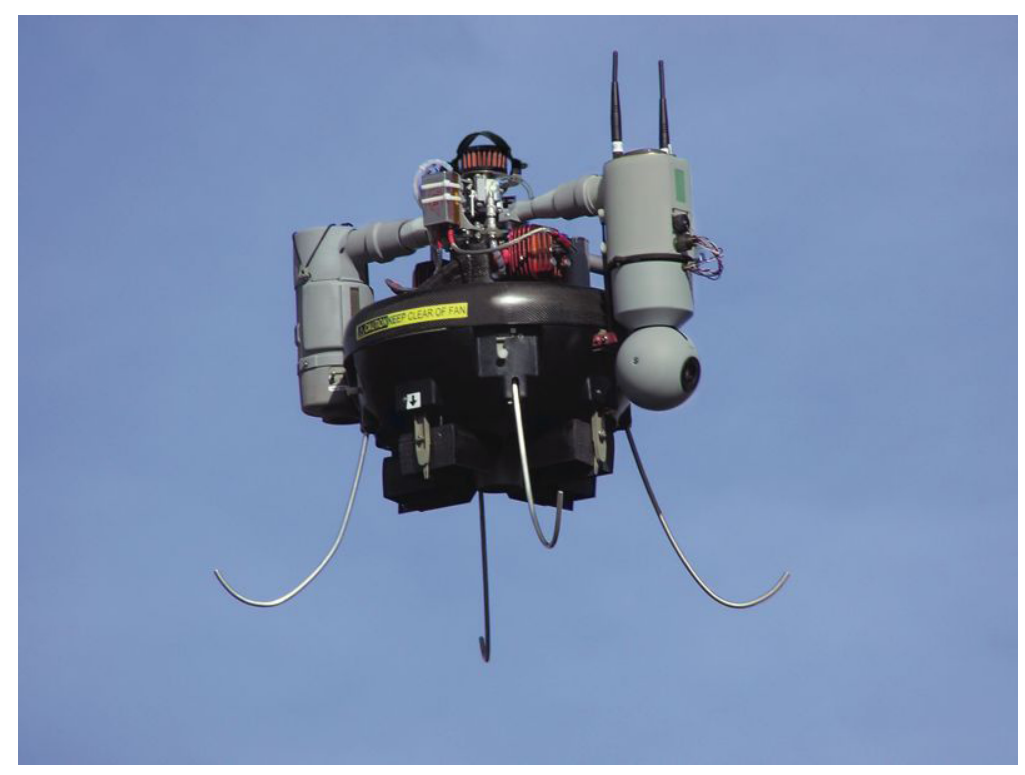

Figure 14: RQ-16 T-Hawk ${ }^{24}$

dosimeters attached with zip-ties, scrutinized the damage at Fukushima. Reactor engineers watched the live video and made on-the-spot suggestions to the drones' pilots about where to go next. Using the T-Hawks, the engineers and operators were able to perform assessments out of range of the high-radiation zones.

In Britain, real estate firms have used multi-rotor vehicles to provide potential buyers with aerial videos of properties (not yet legal in the United States). Authorities in Germany used microdrones, illustrated in Figure 15, to carry sampling equipment in order to test hazardous smoke during a chemical plant fire. In Colorado, the Mesa County Sheriff's Office utilizes a smaller DraganFlyer X6 rotorcraft for capturing data above crime scenes, accidents, and fires. They also developed the Falcon fixed-wing drone, see Subsection 1.2.6, to aid in searches for lost hikers.

The U.S. Geological Survey (USGS) flies RQ-11 Ravens, see Subsection 1.2.5, for 


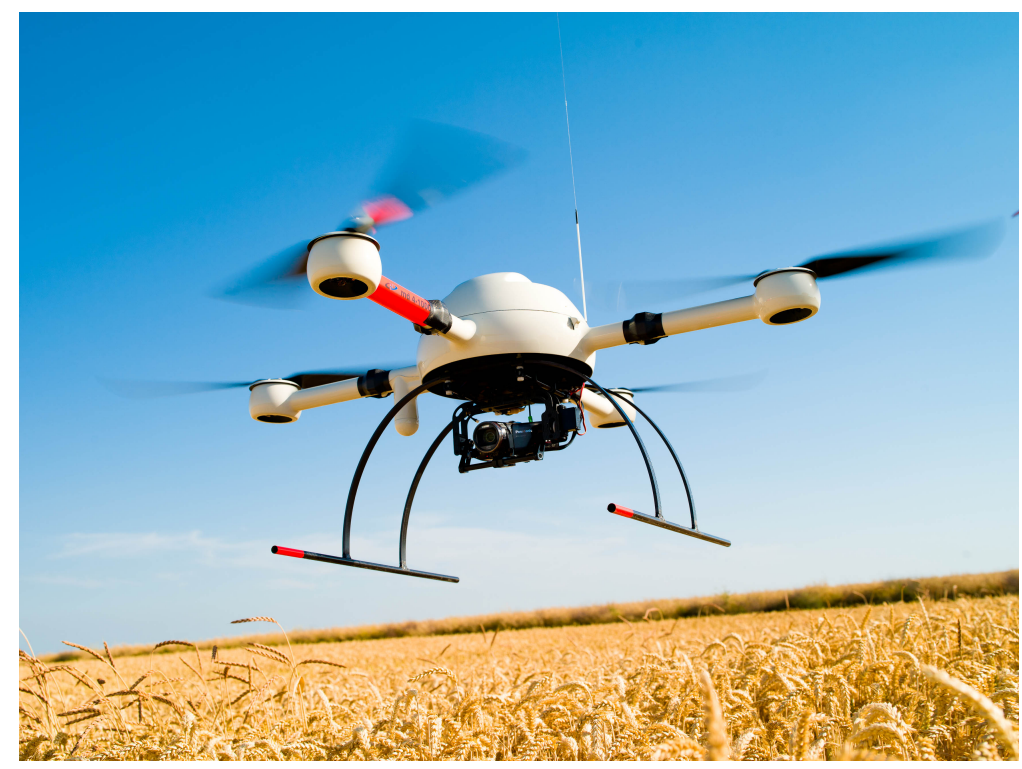

Figure 15: Microdrone 1000 with Imager Payload ${ }^{25}$

land management services. In one project, a Raven examines drainage infrastructure at a West Virginia surface mine. The Office of Surface Mining uses the aquired images to pick out troubled spots, such as a landslide that has blocked the flow of contaminated water to a treatment pond. After the issue is identified, an inspector follows up on foot.

Another potential area that fits well with the fixed-wing UAS capabilities is wildfire survaillance. Mike Hutt, USGSs unmanned aircraft project manager, says the USGS UAVs show their greatest worth not in spotting a fire at its outset, when the smoke is easy to see, but in the final, grueling task of stamping out every last ember. In rough country, buried hotspots can be hard to pinpoint, especially when fallen trees or rocks have thrown an insulating cover over them. "One fire in Colorado that they thought was out, wasn't," says Hutt. "On a huge fire, mop-up is very labor-intensive. 
If they had a small unmanned aircraft, handcrews could operate it." 26

The USGS has taken on dozens of these kinds of unmanned trials: checking fence lines in Hawaii that keep feral hogs from protected vegetation, counting migratory sandhill cranes and monitoring the temperatures of mountain streams threatened by climate change. "We expect that by 2020, unmanned aircraft will be the primary platform [for data collection] for the Department of the Interior," says Hutt. ${ }^{26}$

Even though there are many instances where unmanned drones are being utilized by non-defense entities, which mostly consist of larger corporations like NOAA and USGS, there are still valuable UAS operations that can be performed with existing technology. Unmanned vehicles can provide rich photographic detail to existing maps; inspecting roofs, towers and bridges for necessary repairs; gathering news; or serving as temporary signal relays.

The power industry is one area of business that is anxiously awaiting the arrival of UAVs. They hope that drones can speed up preparations for transmission-line repair after big storms, explains Drew McGuire, an engineer in Southern Company, one of America's largest generators of electricity based out of Atlanta, Georgia. "Repair work depends on accurate assessment," he says, "and poor assessment means wasted money and longer outages." The industry wants a camera-wielding aircraft that can arrive on the scene faster than helicopters (which might be grounded by storms), inspect more power-line miles per dollar, and get imagery back faster. ${ }^{26}$ Lightweight unmanned fixed wing aircrafts, relatively inexpensive to risk in poor weather, might 
meet such needs.

Although there is enormous potential for drone use in emergency situations, infrastructure inspection and ecological monitoring, many buyers still are not sure exactly what they need. "The industry is pretty immature," says Embry-Riddles Currier of the current offerings at AUVSI (Association for Unmanned Vehicle Systems International). He compares it to the early years of auto manufacturing, when motorists had hundreds of brands, and no company dominated. "Its hard to tell which is a production-ready aircraft by just looking at it," says Roy Minson, a vice president at AeroVironment Inc. ${ }^{26}$

\subsection{Project Goals}

This project intends to produce an ISR UAV that creates a composite map of the land surveyed while being able to accomodate various sensors. Versatility and ease of operation will be maximized as these top level requirements flow down to the subsystems, which can be seen in the requirements, Section 1.4.1.

The Operationally Responsive Aircraft (ORA) with an imaging payload will be designed for the specific mission of a cattle farmer surveying a plot of land in order to locate a grazing herd. Because details of the cattle are not needed, just the location, a NIIRS level 4 is necessary. This is equivalent to identifying a farm building or a basketball court. The National Image Interpretability Rating Scale (NIIRS) is discussed in more detail in Section 6.1.

This project also attempts to solve the issue of potential buyers of UAS technology 
not knowing exactly what they want. Like Minson said, it is difficult to tell which system is air worthy, especially when you do not have prior experience in the field of aeronautics or remote sensing. If one is new to the industry, an inexpensive trainer would be perfect for learning the ins-and-outs of operating a UAV. There are rules and regulations in place that are unknown to many future operators. Currently, without a FAA permit, drones are limited to flying no higher than $400 \mathrm{ft}$ above ground during day with operator line of sight. Registration or not, the UAS cannot come within 5 miles of an airport.

Honolulu officials learned the 5 mile airport rule the hard way. After the city bought a $\$ 75,000$ drone to assist with port security, the FAA notified them that operating the UAV would put it too close to the international airport on Oahu. The aircraft now sits in storage. ${ }^{26}$ A trainer UAV could have made Honolulu's blunder quite less expensive.

A bare-essentials UAS would also open doors for individual commercial customers, not just the corporations spending tax-payers' dollars. By creating an operationally responsive aircraft (ORA), customers will have the chance to capture any kind of data suitable to their needs, as long as their sensors fit within the payload bay. Many low-end customers do not need a robust sensor system that produces real-time video linked with Graphical Interface Systems (GIS). A simple imager with composite mapping technology would be the perfect training system while still provding enough intelligence to be a productive, appealing ISR platform. Examples of professions that 
may like to utilize such a system include: professors, scientists, power-line inspectors, nuclear radiation engineers, fire-fighters, etc.

A conventional design routine will be skipped when developing ORA. A commercialoff-the-shelf (COTS) airframe will perform well enough for the bare-essential operation as well as save countless hours of design and fabrication. In order to keep the costs low and endurance high, a simple, light, low performance imager will be utilized. As time goes on, technology will advance, heightening the performance of electronics, making them more robust while their size and weight will diminsh. If one is willing to spend more money, a higher resolution sensor package can always be obtained. Any system decision will be weighed against the key metrics of simplicity, cost, user appeal, and designer/manufactor difficulty.

\subsubsection{Requirements}

There are two top level requirements on the system: produce a composite map of the land surveyed and be operationally responsive. All other requirements flow down from these and are in place to maximize ease of operation and versatility. The imaging system needs to have the optical quality of NIIRS level 4 in order to successfully perform the mission of identifying a herd of cattle. Table 7 illustrates the two top level requirements. The subsystem requirements flow down from these system requirements.

The airframe shall have the ability to accomodate various sensor packages while minimizing cumbersome integration. To quantify the easy of payload integration, a 
requirement will be set where the system shall have the ability to switch out sensor packages within 5 minutes. It shall be operable by a single person. This means that the system shall be have the ability to be launched by one operator. To be easily transportable by an individual, the air worthy system must weigh less than 10 lbs with no heavier than a $25 \mathrm{lb}$ GCS. The endurance is a key metric in ISR. The system shall at least have the ability to stay in the air for 20 minutes. More emphasis will be given to the payload operations, however a 20 minute endurance should provide enough coverage while not imposing limiting performance constraints. The mission profile will be determined to meet FAA regulations in order to mitigate the need for written approval. Opertaions will be limited to day with operator line of sight. ORA will stay more than 5 miles from any airport and under $400 \mathrm{ft}$. A $\$ 1,000$ price requirement will be set on the system in order to maximize consumer appeal.

Quick production of the data from the visible imager will increase customer appeal. In order to ensure efficiency, the composite map, produced by stiching together all aerial photographs, will be accessible within 10 minutes of landing. Setting a requirement relating to the time of landing is to ensure that no overbearing communication constraints are set on the system, like mandatory downlinks. The payload shall be sufficiently protected, in the case of an emergency. The system shall be designed to not only allow for future upgrades but encourage them. Examples of such upgrades include GPS tagging pictures, a higher resolution imager and on-board data processing. All of these requirements can be seen in Table 7 . 
Table 7: Requirements

\begin{tabular}{cc}
\hline \hline Criteria & Requirement \\
\hline \hline System & Produce One Composite Image \\
& Ability to Accomodate Various Sensors \\
\hline ORA & Operatable by 1 person \\
& Weigh Less than $10 \mathrm{lbs}$ \\
& Endurance of 20 Minutes \\
& Max Altitude of at Least $400 \mathrm{ft}$ \\
Cost Less than $\$ 1,000$ \\
\hline GCS & Weigh Less than 25 lbs \\
\hline Payload Bay & Changed Out within 5 Minutes \\
& Protected During Landing \\
\hline Imaging System & NIIRS Level 4 \\
& Map Accessible within 10 Minutes of Landing \\
& Allow For Future Upgrades \\
\hline \hline
\end{tabular}

These requirements will be revisited after the system is developed. They will be validated if the final product meets the requirements stated here. 


\section{Imaging Payload}

\subsection{System Description}

The operationally responsive aircraft (ORA) has the ability to contain two independent imaging payloads. These payloads are made up of three components: the processor, imager, and SD card shield. This eletro-optical (EO) imaging payload is designed to produce a single composite image of the entire land surveyed.

\subsubsection{Imager}

The camera is a basic TTL Serial Camera installed on a board that converts the signal into a JPEG. This COTS camera and module saved much time and stress. Instead of having to convert an analog signal to a digital signal, the camera board produced an easy to use JPEG image. The camera utilized in the imaging payload is shown in Figure 16.

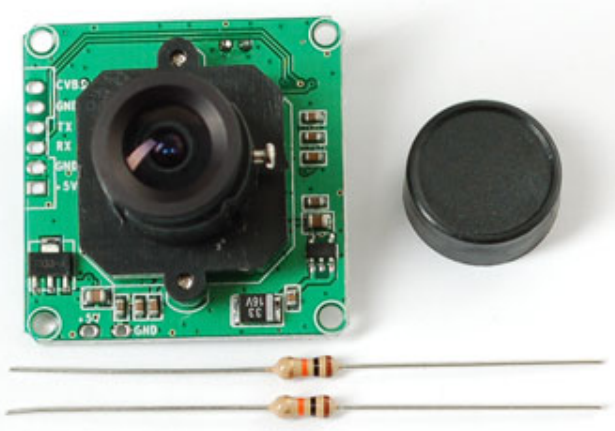

Figure 16: COTS TTL Serial Camera with Board ${ }^{27}$ 
There are four wires that are needed to operate the CMOS camera through the Arduino. PWR, GND, TX, and RX all located on the left of the board in Figure 16. The power source (PWR) feeding into the camera needs to be at least 5 Volts while it is attached to ground (GND). TX stands for transmitting and is the output from the arduino board and camera. RX represents receiving and is where the camera and arduino take an input. Therefore the TX pin of the arduino connects to the RX pin of the camera and vise versa.

This is used in order to tell the camera when to take a picture. RX is the connection that ouptuts the JPEG image from the camera. The data pins on the arduino are 3.3 Volt logic. The two 10K resistors in Figure 16 are used to drop the 5 Volts RX camera output to 2.5 Volts in order to prevent over-powering the data pins. Details of the connection can be seen in Figure 17.

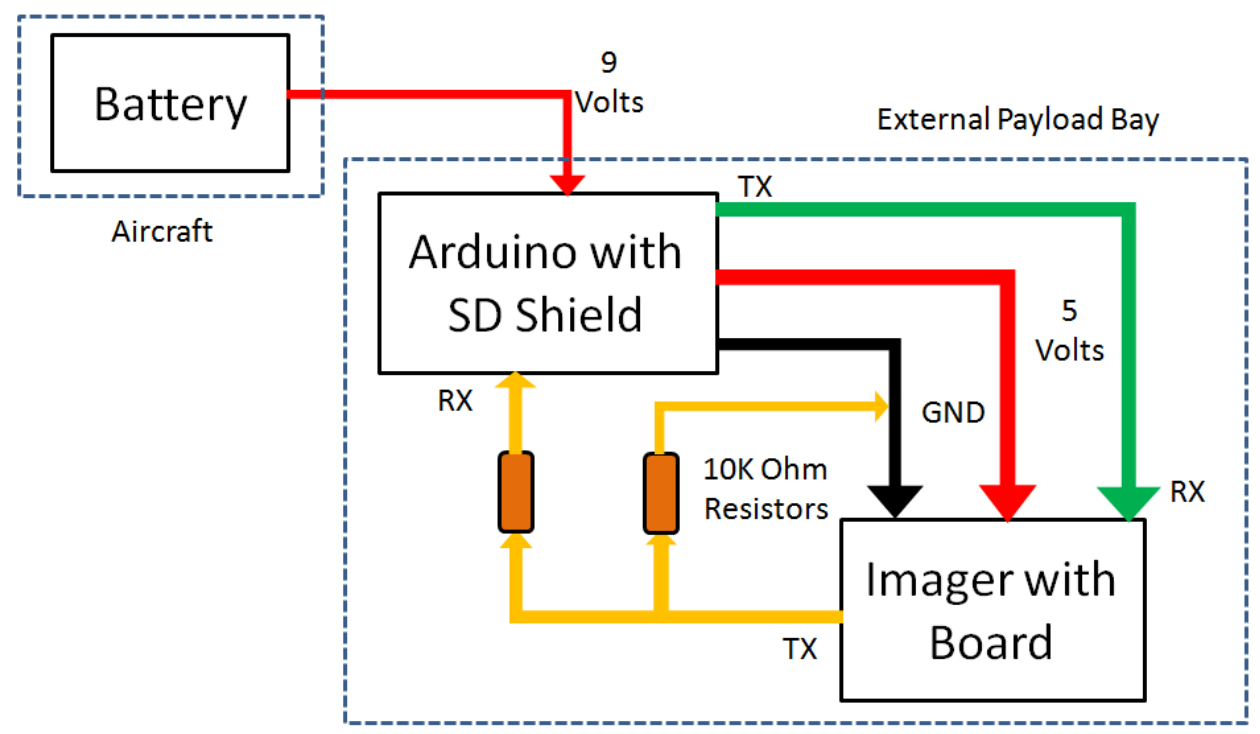

Figure 17: Interfaces Between Power Source, Arduino, and CMOS Imager 


\section{NIIRS Overview}

The National Image Interpretability Rating Scale is in place for standardizing optical performance. It helps when designing new imaging systems and performing trade studies to meet desired levels of image quality. The scale goes from 0 to 9 , where at level 9 you can see individual barbs on a barbed wire fence. A NIIRS level 4 imager is needed in order to identify the location of a herd of cattle within a composite map. By NIIRS criteria, a level 4 imager has the ability to identify a basketball court within a residential area. The NIIRS criteria does not explicitly state a level where a herd of cattle may be distinguished. It is assumed that if an imager can identify a basketball court, it may also identify a herd of cattle. For more detailed information on the levels see Section 6.2.2. The NIIRS General Image Quality Equation (GIQE),

$$
\mathrm{NIIRS}=c_{o}+c_{1} \log _{10}(\mathrm{GSD})+c_{2} \log _{10}(\mathrm{RER})+c_{3} \frac{G}{\mathrm{SNR}}+c_{4} H
$$

takes into account ground sampling distance, relative edge response, niose gain, signalto-noise ratio and edge overshoot as well as the constants shown in Table 8.

Table 8: GIQE Version 3.0 Constants

\begin{tabular}{ccccc}
\hline \hline$c_{0}$ & $c_{1}$ & $c_{2}$ & $c_{3}$ & $c_{4}$ \\
\hline 11.81 & -3.32 & 3.32 & -1 & -1.48 \\
\hline
\end{tabular}

\section{NIIRS Estimation}

Prior to purchasing the camera, Equation 2.1 was evaluated given the imager's specifications and some assumptions. Because the manufacturer did not provide 
specifics on RER and $H$ the average values in Table 9 were used to fill in the missing characteristics. There is not much info with respect to NIIRS values for UAVs. Table 9 is a range of values for certain satellite systems used to develope a 4th version of the GIQE. Using these values may not be exact but should provide enough accuracy for a rough estimate.

Table 9: Statistics of GIQE Terms for Imagery Used to Develop GIQE $4.0^{28}$

\begin{tabular}{cccc}
\hline \hline Term & Minimum & Mean & Maximum \\
\hline GSD & $3 "$ & $20 "$ & $80 "$ \\
RER & 0.2 & 0.92 & 1.3 \\
G & 1 & 10.66 & 19 \\
SNR & 2 & 52.3 & 130 \\
G/SNR & 0.01 & - & 1.8 \\
H & 0.9 & 1.31 & 1.9 \\
\hline
\end{tabular}

From the camera specifications, ${ }^{27}$ the $\mathrm{G}$ and SNR are $16 \mathrm{~dB}$ and $45 \mathrm{~dB}$ respectively. GSD is length per pixels. A $60^{\circ}$ viewing angle was provided by the manufacturer and assumed to correlate to the length of the image. The GSD will change depending on the resolution setting $(640 \mathrm{x} 480,320 \times 240,160 \times 120)$. At $400 \mathrm{ft}$, the $60^{\circ}$ viewing angle takes in a length of $462 \mathrm{ft}$. Dividing that length by the number of pixels lengthwise produces a GSD of 8.5, 17 and 34 for high, medium and low resolutions respectively. GSD, G and SNR provided by the specifications along with assumed values of 0.92 for RER and 1.31 for H, Table 10, produce NIIRS values of 6.3, 5.3 and 4.3, Table 11, depending on the resolution setting. By this calculation, the imager should be able to meet the requirement of a NIIRS level 4, even at its lowest resolution. By no means will this estimation be perfect, but the fact that the imager can change 
resolution settings provides a contingency plan. If the lowest resolution does not meet the requirement, the resolution setting can be changed in order to decrease GSD and therefore produce a improved optically performing system.

Table 10: NIIRS Variable Estimation

\begin{tabular}{cc}
\hline \hline Variable & Value \\
\hline GSD (high res) & 8.5 \\
GSD (med res) & 17 \\
GSD (low res) & 34 \\
RER & 0.92 \\
G & 16 \\
SNR & 45 \\
H & 1.31 \\
\hline
\end{tabular}

Table 11: NIIRS Estimation

\begin{tabular}{ccc}
\hline \hline Resolution & Pixels & NIIRS \\
\hline High & $640 \times 480$ & 6.3 \\
Medium & $320 \times 240$ & 5.3 \\
Low & $160 \times 120$ & 4.3 \\
\hline
\end{tabular}

\subsubsection{Processor}

Arduino is an open-source physical computing platform based on a simple microcontroller board. The Arduino Uno, which is shown in Figure 18, is used in this project. Processing pictures pushes the limit of Arduino's capabilities. Even though Arduino is not optimized for image processing, it worked well for this project. Due to my inexperience with coding in $\mathrm{C}++$, the open-source nature of Arduino was vital to this project's success. The tutorial that came with the TTL camera and other related projects greatly influenced my work. ${ }^{29}$ 


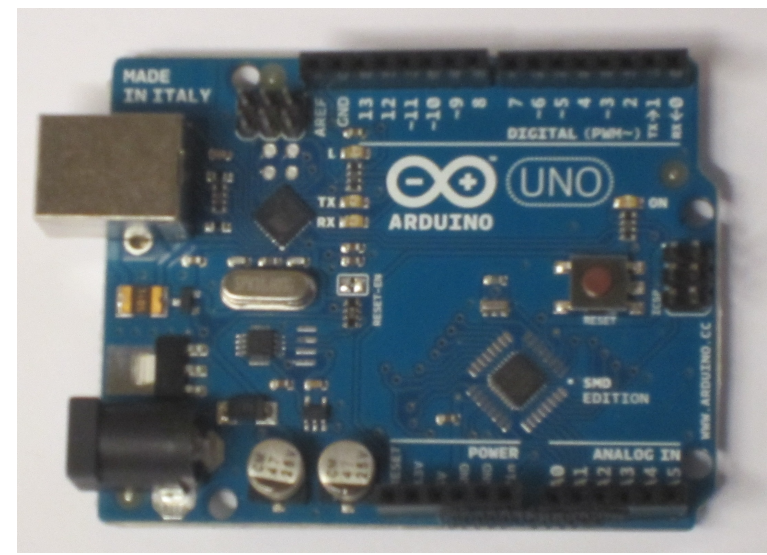

Figure 18: ORA's Onboard Processor, the Arduino Uno ${ }^{30}$

\subsubsection{SD Shield}

The SD card shield, or data logging shield, is made by Adafruit. The shield used in this project is shown in Figure 19. With other SD shields issues arose where the internal clock slowed down after initializing. Take note of the watch battery integrated with the board. This makes sure that the Arduino's internal clock is powered and keeping good time, no matter the external power source.

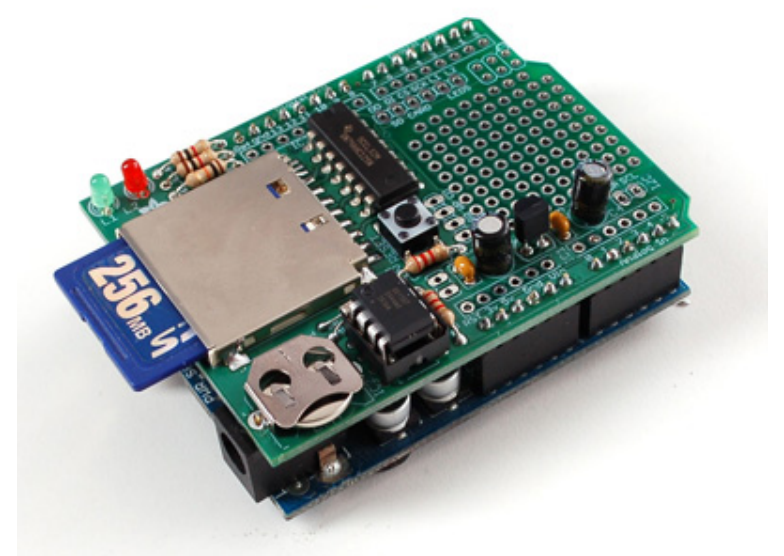

Figure 19: SD Card Shield Inserted into Arduino Uno ${ }^{31}$

Figure 20 illustrates the payload hardware in its entirety. The only thing that is 
missing is the cord of the external power supply feeding into the Arduino Uno. The yellow wire that is not connected is used to produce an audio-video signal. It is not needed to save a JPEG to an SD card. When the payload is flight ready, a strip of tape is applied around the camera-SD shield interface to prevent vibrations from weakening the connection between the camera and processor. The $10 \mathrm{~K}$ resistors are soldered onto the SD Shield. This eliminates the need for a breadboard in order to lower the voltage of the camera's RX pin.

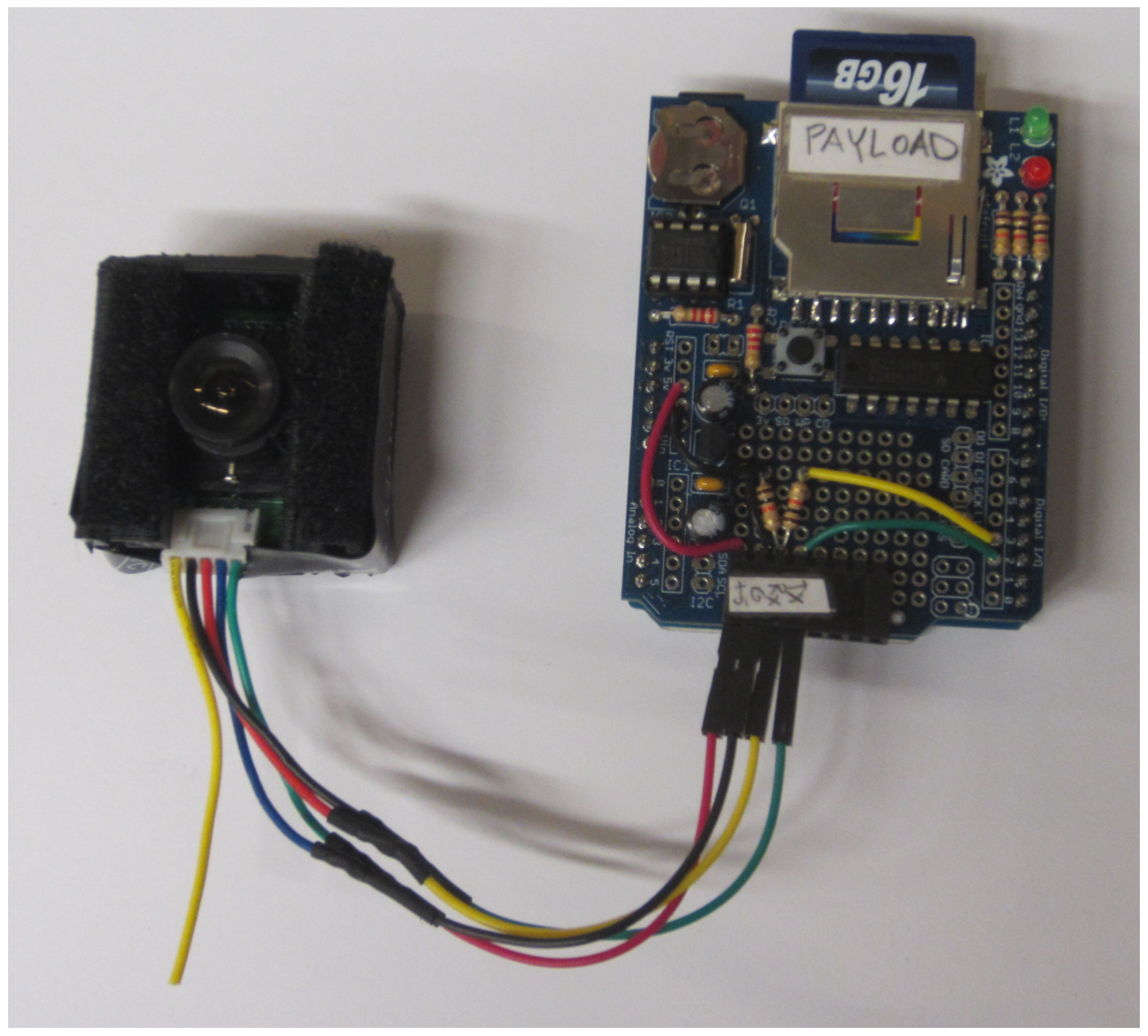

Figure 20: Entire Imaging Payload System 


\subsection{Data Interface}

There is no data interface between the aircraft and payloads. The images are saved to an SD card within the external payload bay. Operators can remove the SD card when the aircraft is landed after easily detaching the trailing edge. Figure 21 shows all three elements of the imaging payload installed within the external bay with the trailing edge compartment removed.

Saving data to an onboard SD card is the simplest way to store data. No downlink between the aircraft and and GCS is necessary. Excluding the payload's transmitter from the aircraft decreases weight and power draw while increasing simplicity. A downlink operation would significantly raise the overall price of ORA.

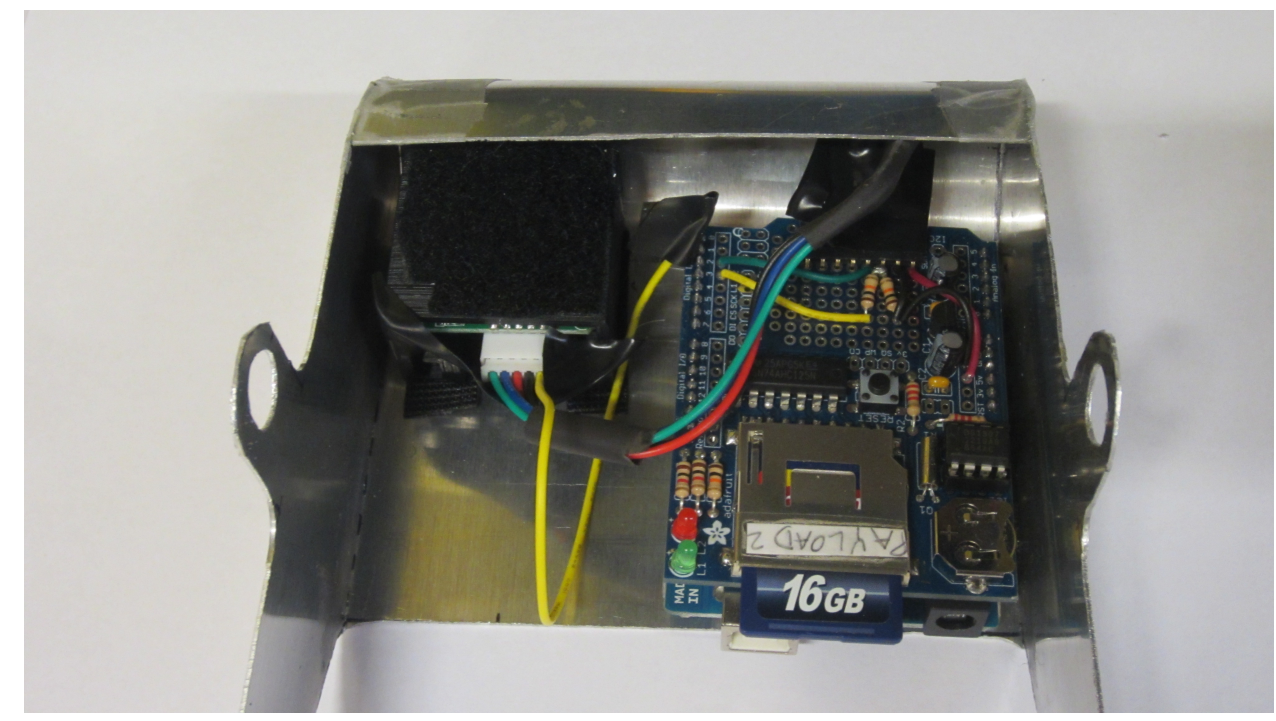

Figure 21: Imaging Payload Contained within Leading Compartment

The on-board processor, an Arduino Uno, has open serial ports for auto-pilot data reading. The current generation ORA payload does not interact with an auto-pilot 
because the test aircraft is flown via remote control. Future integration could include altitude, attitude and/or GPS location writing to each image title or header. This will allow the possibility of scaling or altering the images depending on altitude. The GPS location can be used to place the images in a specific order to create a more detailed and accurate composite image. The orientation of the plane will also show if there needs to be any image correction for relief displacement.

\subsection{Power Interface}

The payload power source can range from 8 to 12 volts with the aircraft supplying a male $2.1 \mathrm{~mm} \times 5.5 \mathrm{~mm}$ DC Plug. In the test platform, the payload power supply consists of a rechargeable 9 volt located in the cockpit of the aircraft. Two were needed to power two separate payloads. When the same power source supplied both bays, the battery did not last long enough. It died before the flight battery powering the propellor did. The current, with two payloads in parallel, is too much for the rechargeable 9 volt batteries.

The 9 volt powers the Arduino Uno, which in turn powers the TTL Serial camera with it's 5 volt external power supply. The imager needs at least 5 volts to operate. Arduino specifications state the external power pin will not supply 5 volts unless the boards power source is above 7 volts. However, issues have occurred when the Arduino Uno's power supply drops below 8 volts. Anything above 12 volts might overheat the voltage regulator and damage the board.

The rechargeable 9 volt is the most cost-effective way to power the payload. These 
batteries were used in every ORA test flight. They might not be the most powerful source with respect to its weight and size, but it is an efficient, re-usable COTS solution integrated easily within the Radians cockpit. 


\section{External Payload Bay}

The external payload bay consists of two compartments, fore and aft. The intent behind the separation of the leading and trailing edge compartments was to provide access to the payload hardware without the need to take off the entire payload bay. Maximizing the ease of access to the SD card enabled quicker production of the composite map. Thin gage (1/16" thick) aluminum was utilized to produce both sections of the external bay. Aluminum was a great choice for the payload bay due to the facts that it is light-weight, easy to work with, abundant and cost-effective.

\subsection{Leading Edge Compartment}

A 3-view and isometric drawing of the leading edge compartment is illustrated in Figure 22. All the right angles were bent with a bending press after the aluminum was cut with a jig saw. The fore section of the payload bay runs the entire chord of the wing. This elongated design minimizes rotation of the bay with respect to the aircraft without elaborate attachment methods. The leading edge was bent by hand due to the complex nature of the curved surface. By no means is the leading edge perfect, but it is close to a half circle with a $4.1 \mathrm{~cm}$ diameter.

The $1.6 \mathrm{~cm}$ diameter hole in the fore section allows the imager to see out the bottom. A case, 3-view illustrated in Figure 23, was designed in order to keep the camera facing the downward direction. It was fabricated out of ABS plastic by a 3D 


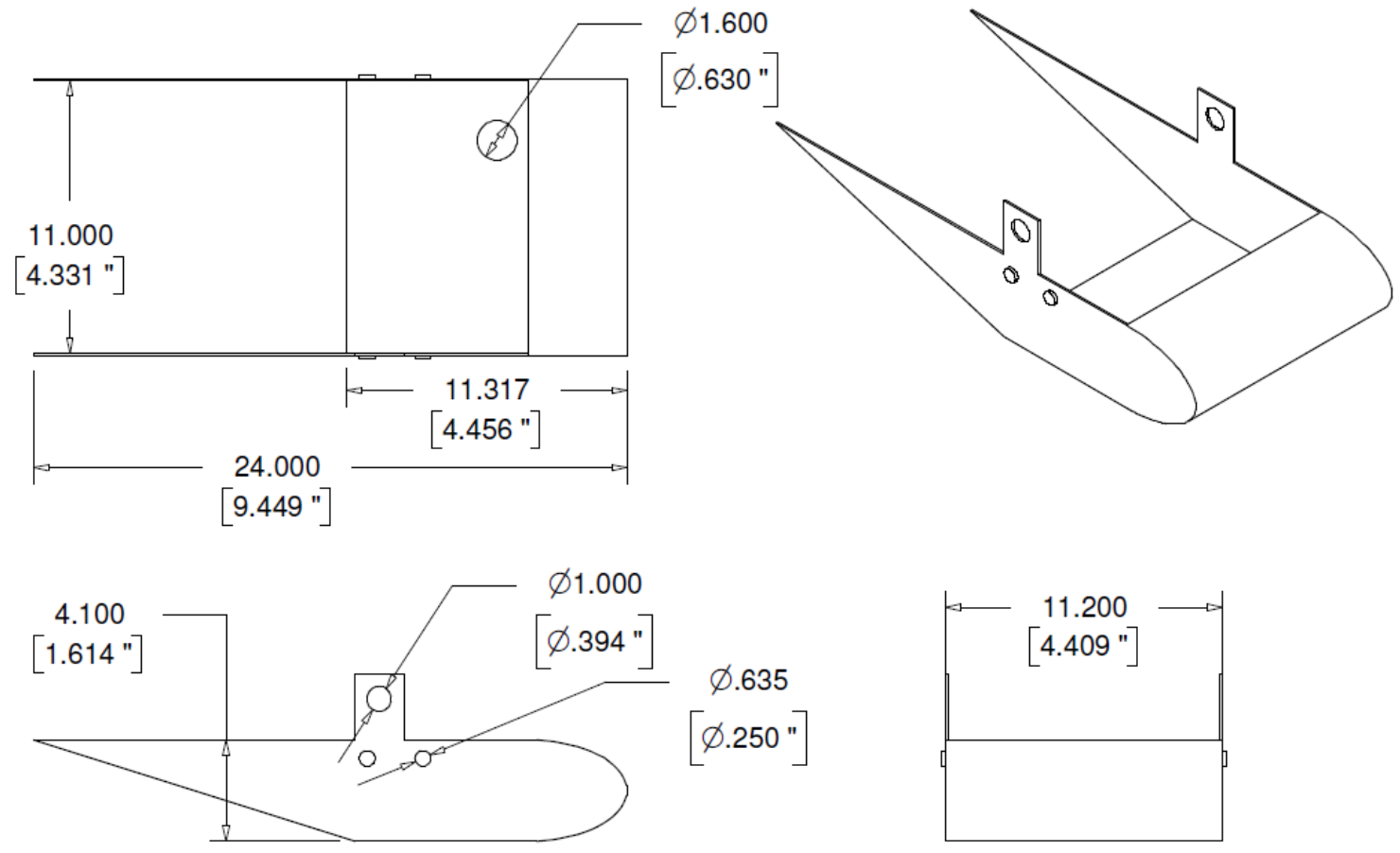

Figure 22: External Payload Bay Fore Section 3-view (cm)

printer. The case was fastened to the aluminum bay with velcro. It is deep enough to prevent protrusion of the imager through the hole, which will protect the camera during landings.

The $0.635 \mathrm{~cm}$ magnets align with the aft section's magnets when combined. They were utilized to provide enough force to keep the compartments together mid-flight, while still allowing removal of the trailing edge while the aircraft is grounded. Each magnet is secured such that they have opposite polarities on the same plane with respect to their neighbor. This orientation causes the rear compartment to snap into place while helping prevent rotation of the trailing edge relative to the leading edge. 

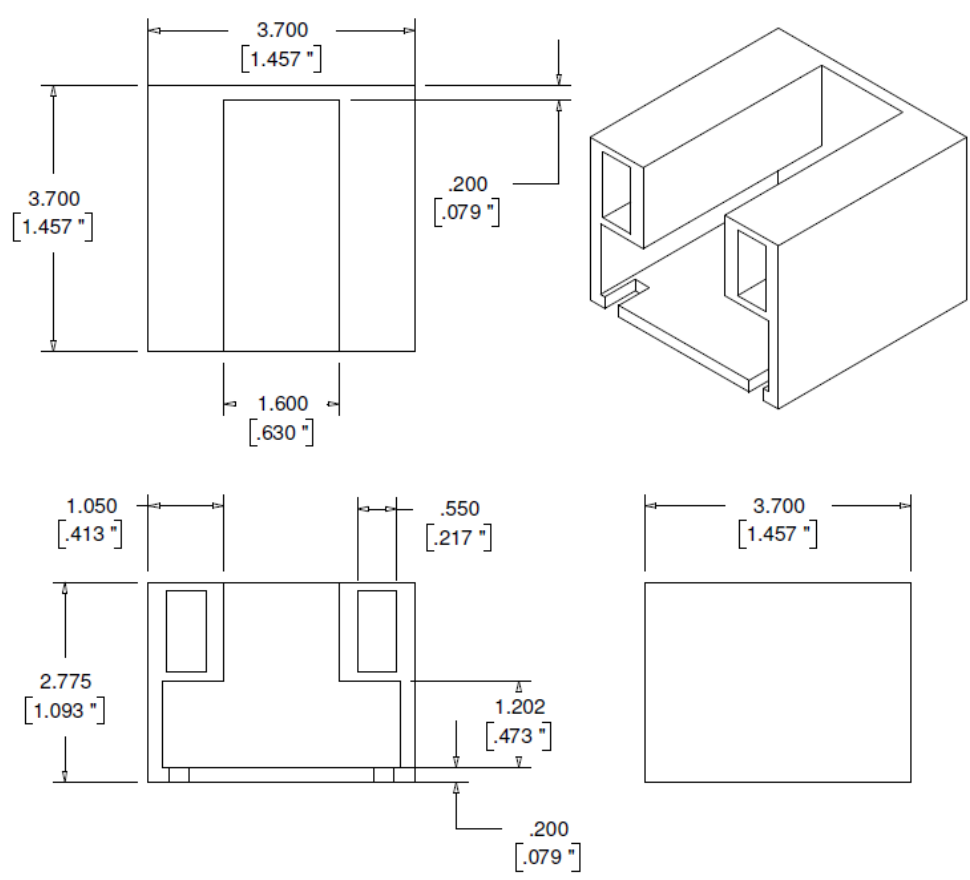

Figure 23: 3D Printed Case Fabricated with ABS Plastic $(\mathrm{cm})$

\subsection{Trailing Edge Compartment}

A 3-view and isometric drawing of the rear compartment is shown in Figure 24. The aft section fits inside the fore section. Both pairs of magnets are inside the compartment. They are glued in place with opposite polarities in the same plane to match the leading edge compartment in Figure 22. The $3.5 \mathrm{~cm}$ section of the aft compartment overlaps and rests on the bottom of the leading edge compartment.

\subsection{Combined External Payload Bay}

A 3-view and isometric drawing of the fore and aft sections combined is illustrated in Figure 25. The magnets are placed such that they are acting on each other through the aluminum walls. This weakens the effectiveness of the magnets but also creates 

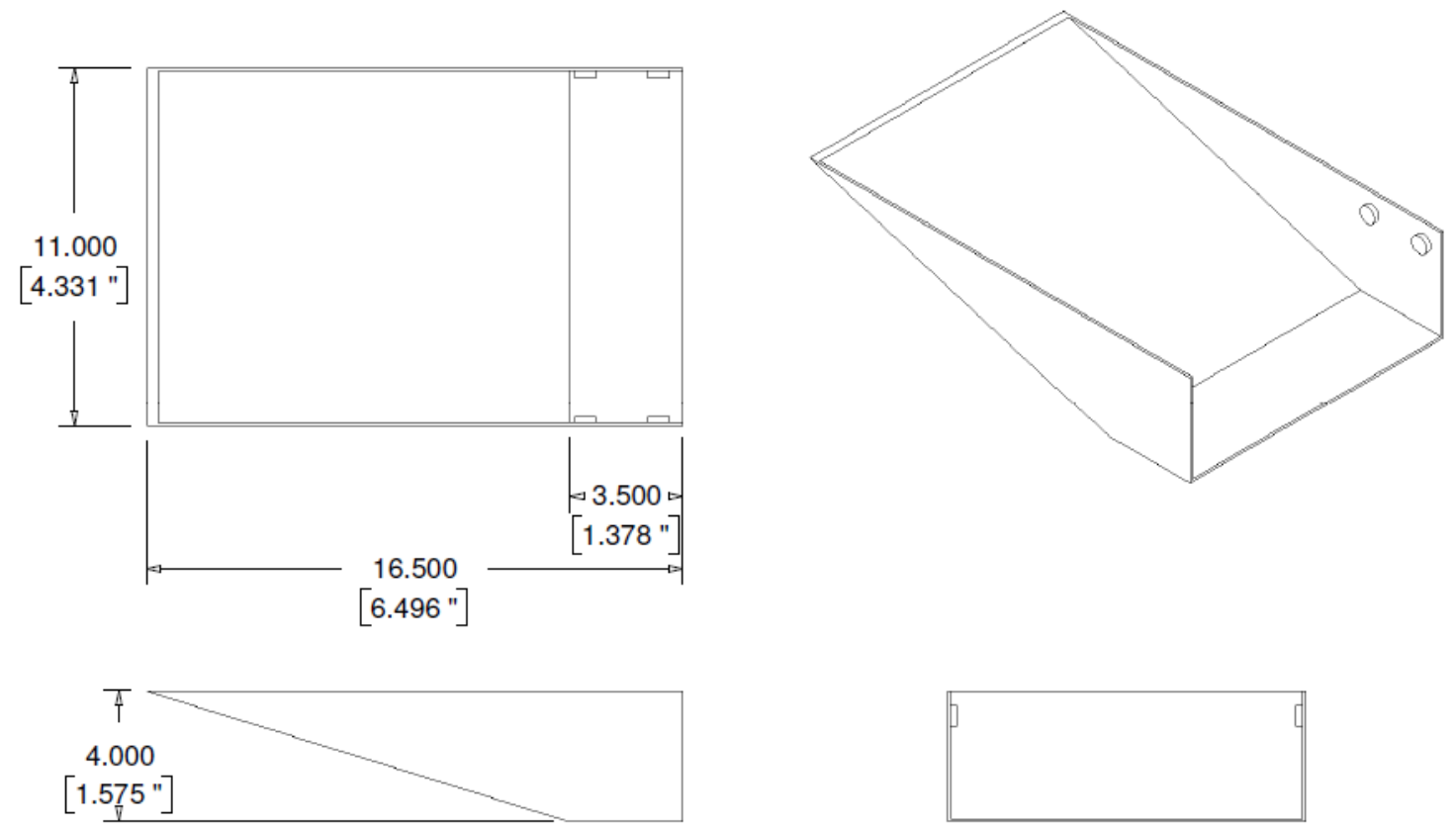

Figure 24: External Payload Bay Aft Section 3-view (cm)

a more accessable front compartment. The first iteration of the external payload bay had magnets between the walls of the compartments. This placement created issues when re-attaching the trailing edge. Magnets would regularly interfere with each other and sometimes come loose from the payload bay walls. Even though the new magnet orientation places the magnets in the free stream (behind a propellor), the added ease of integration out weighs the slight drag increase.

Without the imaging system, the external payload bay can accomidate approximately $500 \mathrm{~cm}^{3}$ for another sensor package. There is a limiting height and width of $4.1 \mathrm{~cm}$ and $11.0 \mathrm{~cm}$ respectively. The payload contained within the bay also needs to accommodate the curved leading edge and the aft section overlap. ORA has a maximum takeoff weight (MTOW) of 5.3 lbs determined by sequential test flights with 


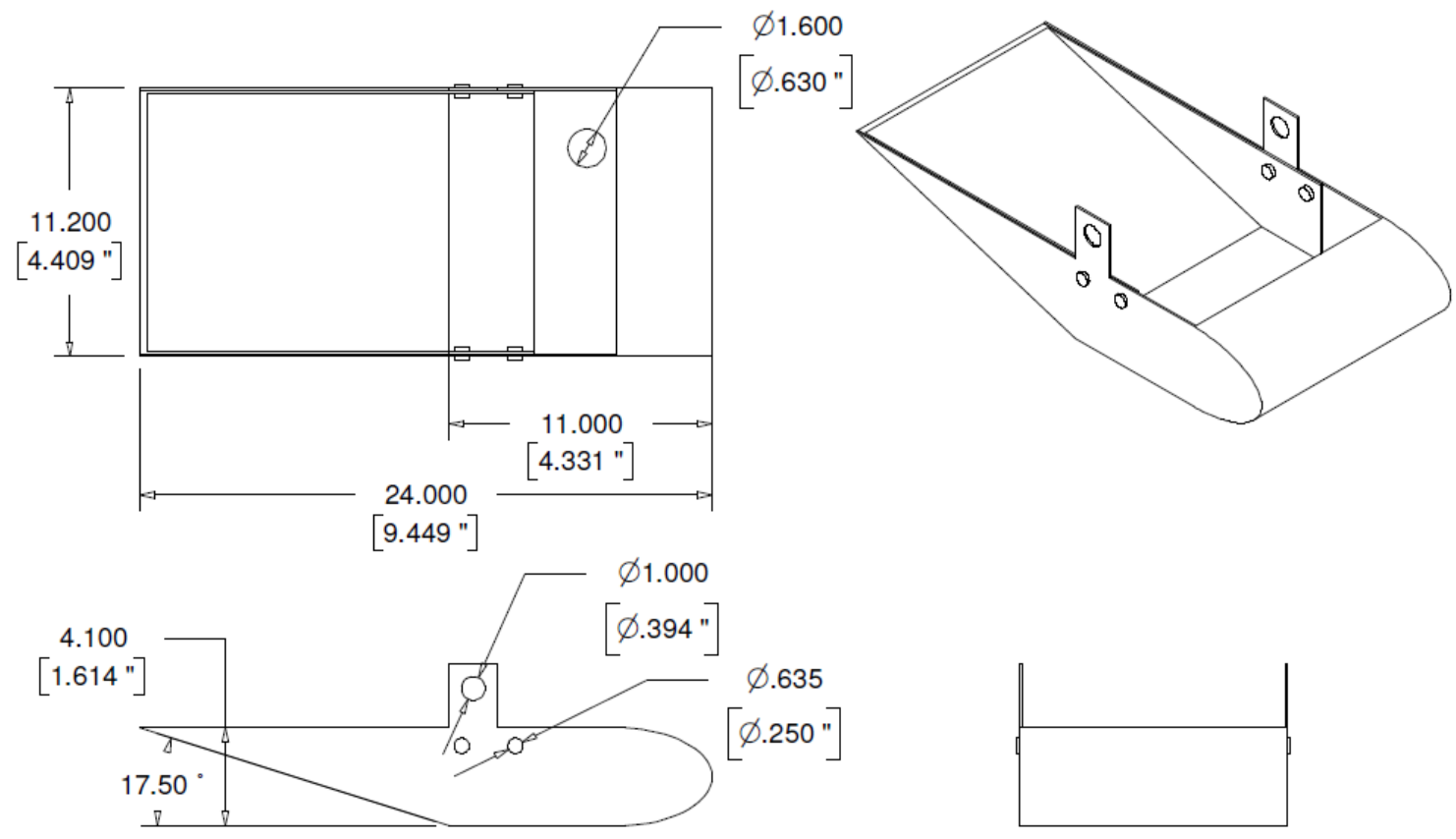

Figure 25: External Payload Bay Combined Section 3-view $(\mathrm{cm})$

increasingly heavy payloads. The empty airframe weighs just under $1 \mathrm{lb}$ while the avionics including servos, the reciever and wires weigh 0.7 lbs. The empty external payload bay weighs $0.23 \mathrm{lbs}$. Therefore each payload bay can accomodate a total of 3.2 lbs before the MTOW is reached.

\subsection{Mechanical Interface}

The Radian airframe has a carbon composite spar running through each wing in between the third and quarter cord. The external bays were designed to attach to the spar, illustrated in Figure 26, because it is the only hard point on the airframe. The fore section was fabricated to run the entire length of the chord in order to minimizing any shaking.

In order to detach the external payload bay from the aircraft, the wing and spar 
need to be completely removed from the airframe. Once the wing is removed, the spar may be pulled out, which will allow the bay to fall from the underside of the wing. The only wire that needs to be disconnected before removal is the external power supply.

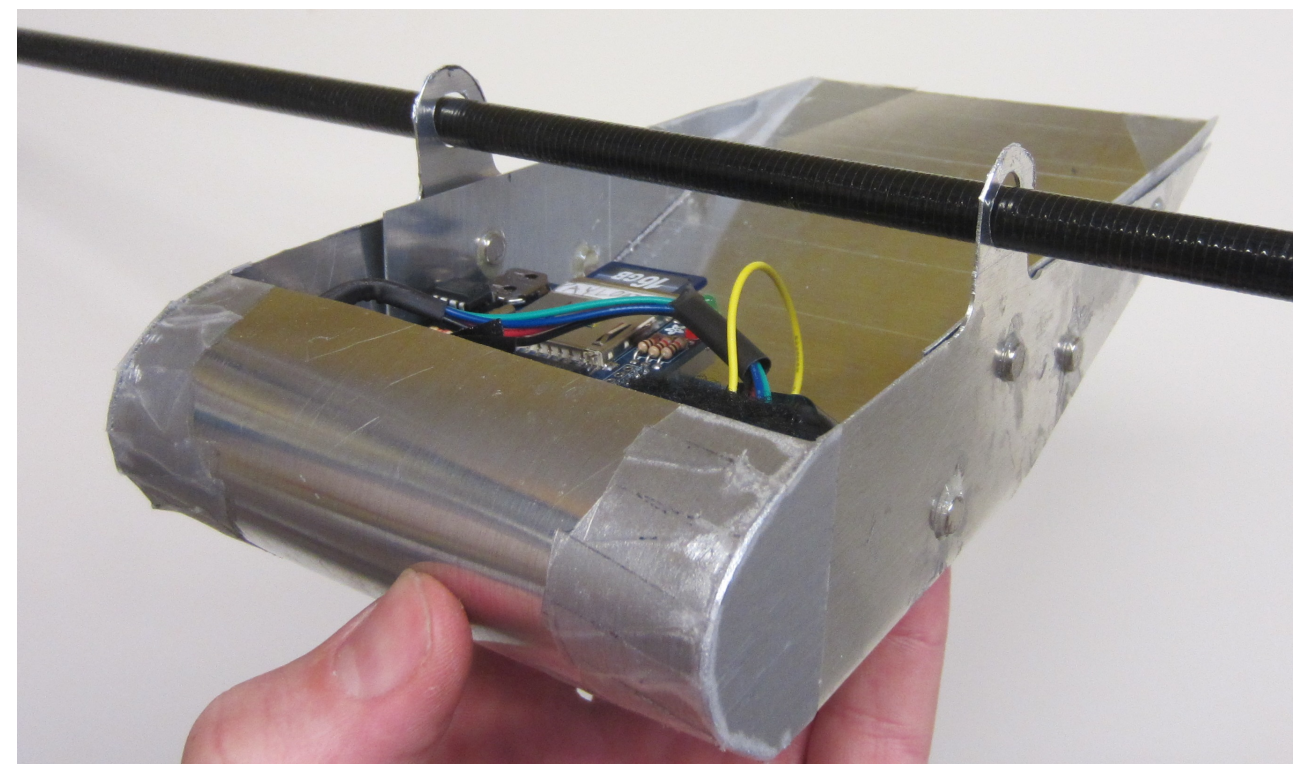

Figure 26: Isometric View of External Payload Bay with Spar and Tab

For the most efficient swapping, it is recommended that separate stand-alone external bays be fabricated and dedicated for specific payloads. The decision to switch out payloads can be made on the fly and completed within a few minutes. After landing, it takes 2 minutes and 45 seconds, worst case, to remove the wing, pull out the spar, detach the payload, install the new payload, then reattach the wing and spar. The entire system, spar, wing and payload bay, is captured in Figure 27 and Figure 28. 


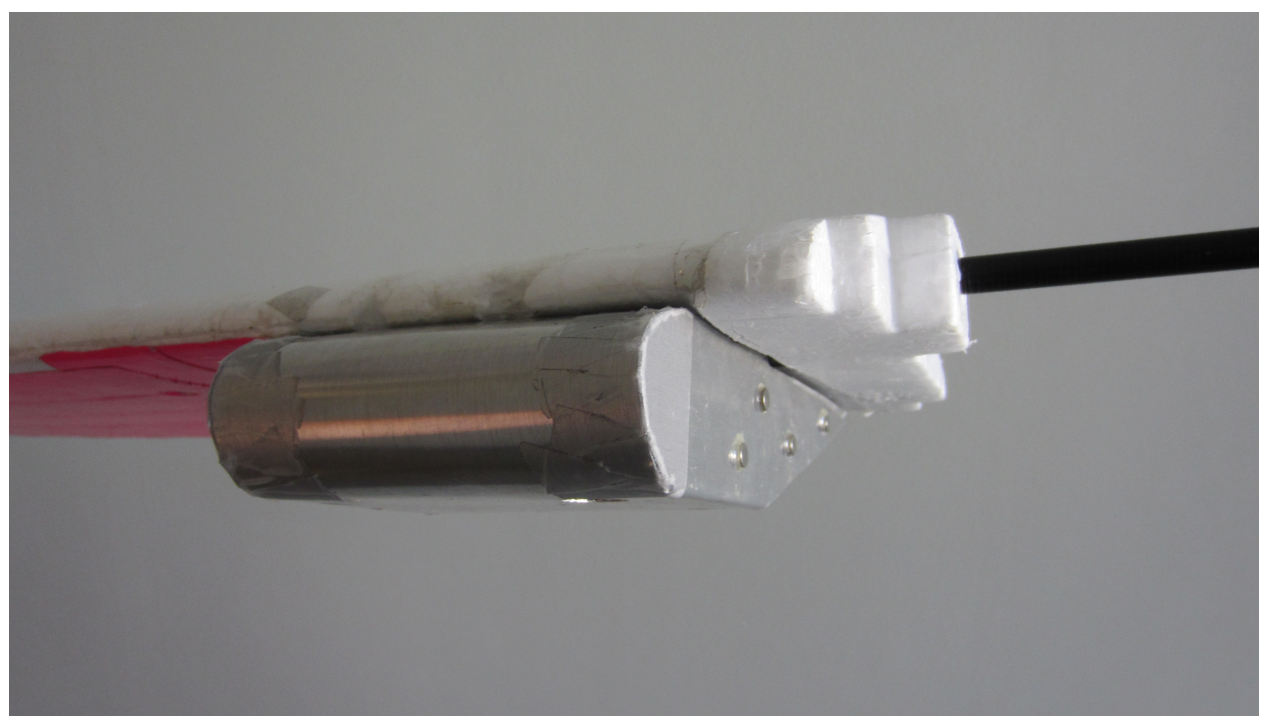

Figure 27: Frontal View of Payload Bay with Wing and Spar

\subsection{Payload Bay As Built}

The fore section of the external payload bay is shown in Figure 29. The holes in the vertical plane on the port and starboard side of the payload bay get recessed within the wing and are used to attach to the spar. Fillets minimize stress concentrations at each corner, this can be seen at the base of the tabs that grab the spar in Figure 29. The hole on the bottom face of the leading edge compartment allows the camera to see out of the payload bay. Velcro strips fasten the camera case and Arduino Uno to the aluminum. Magnets act on the outside of the fore compartment.

An isometric view of the rear compartment is shown in Figure 30. The same manufacturing technique was used to fabricate the rear compartment as the leading edge section. The port and starboard bends were done with a bending press. Tape was used to connect the bents edge to the sides of the external bay. This prevented the air 


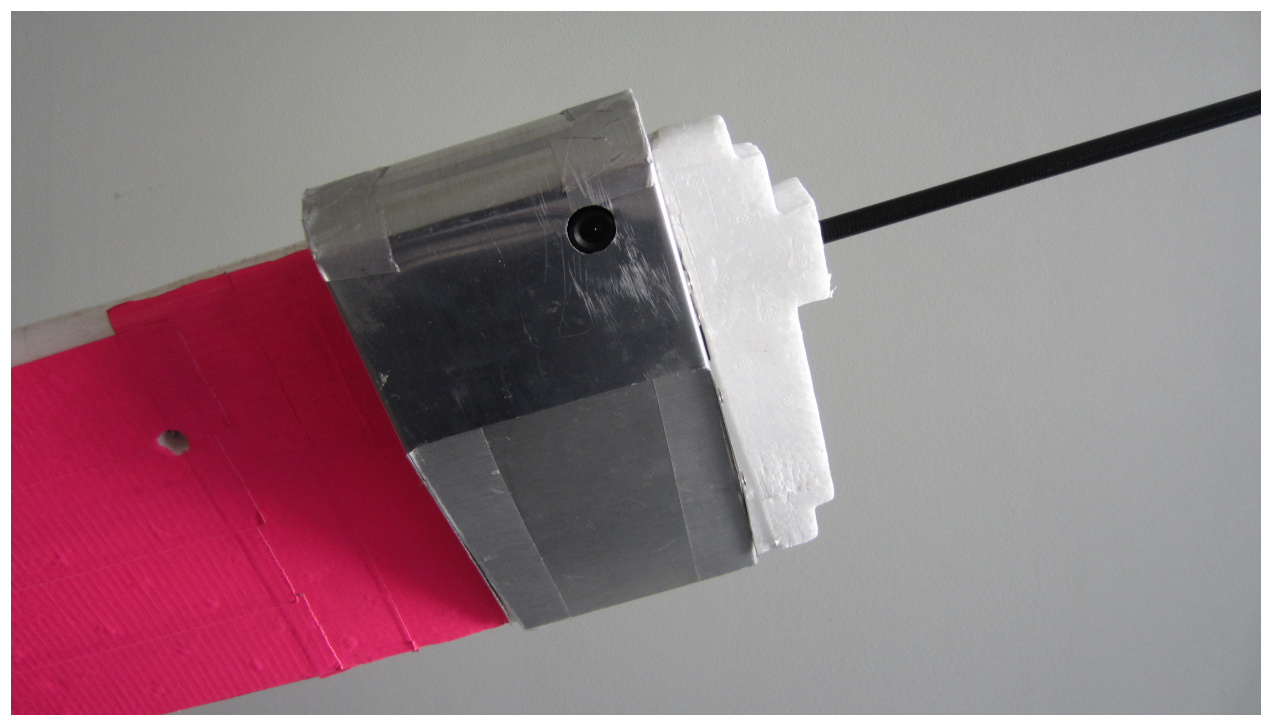

Figure 28: Bottom View of Payload Bay with Wing and Spar

flow from entering the bay through the leading edge and connected the trailing edge to the port and starboard walls. The magnets on the inside of the rear compartment align with the magnets on the outside of the front section to hold the trailing edge in place during flight. 


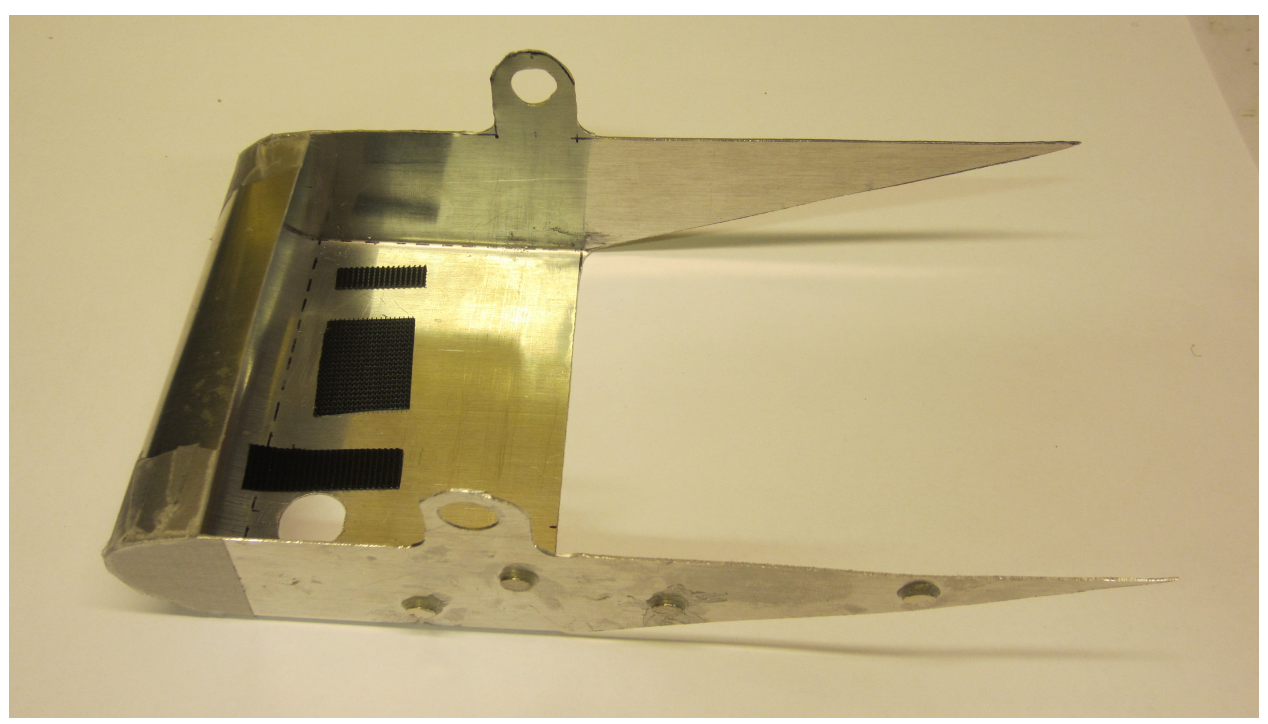

Figure 29: External Payload Bay Front Compartment Isometric

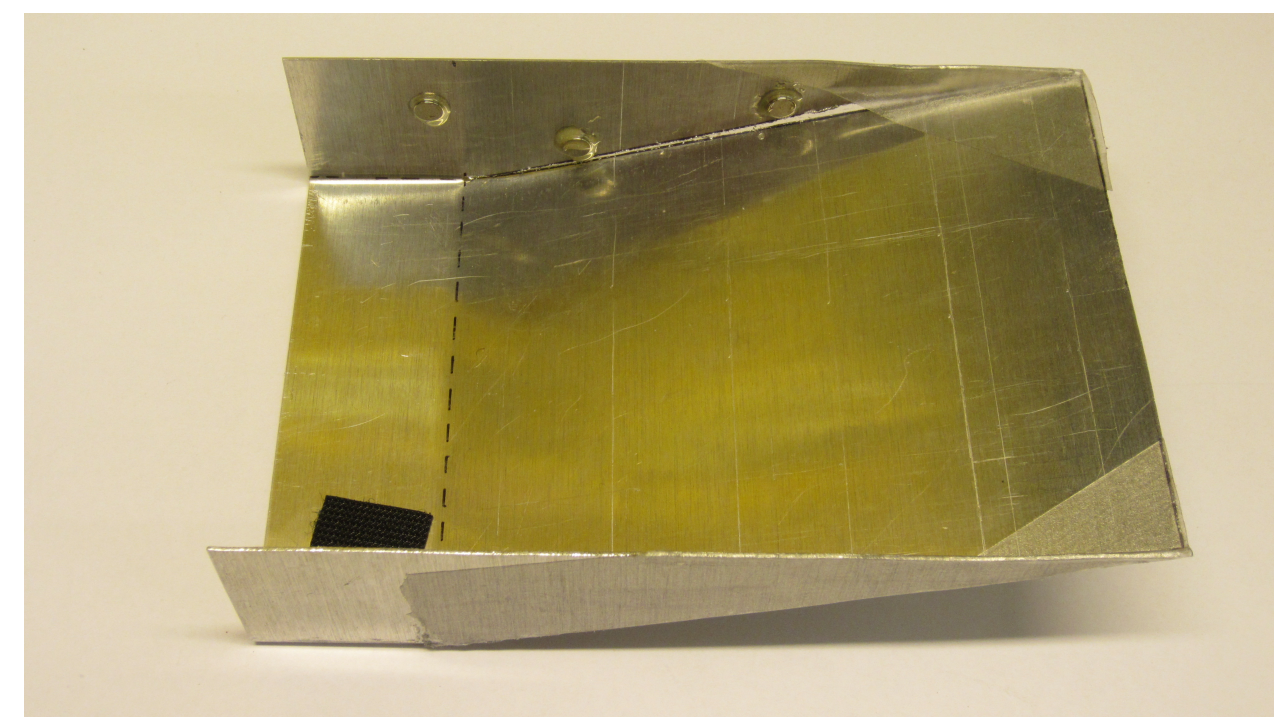

Figure 30: External Payload Bay Rear Compartment Isometric 


\section{Flight Hardware}

\subsection{Airframe}

The ORA airframe is composed of the ParkZone Radian, a remote controlled (RC) sailplane shown in Figure 31. Utilizing the COTS airframe provided more than enough lift to carry the imaging paylaod while also saving much time in the areas of design and fabrication. The 480 -size, $960 \mathrm{kV}$ brushless motor is powerful enough to enable handheld launch for take off. When the motor is not active, the propellors fold back against the fuselage to decrease parasite drag. The Radian is comprised of lightweight Z-Foam offering a balance of weight and durability, it also makes repairs relatively simple.

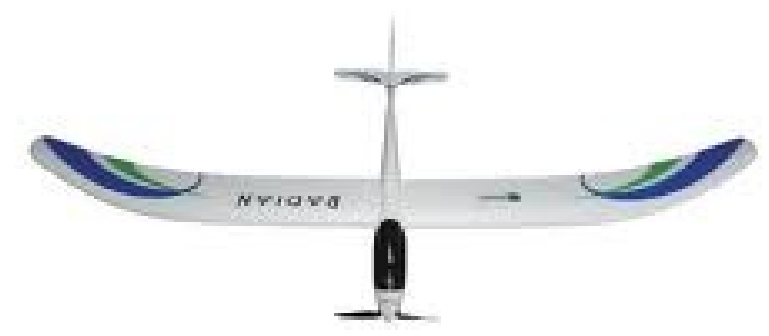

Figure 31: COTS ParkZone Radian Sailplane ${ }^{32}$

The aircraft has a 2 meter wingspan with an elliptical dihedral, which greatly increases stability and visibility. The wings are readily removable creating an entire airframe that is easily transportable. The only control surfaces on this plane are the elevator and rudder. The dihedral wingtips correct any roll moment seen by the aircraft. Pink tape was added to the underside of the wings in order to increase 
visibility. The quoted flight time of from the manufacturer is 30 minutes, however after attaching two external payload bays, the flight time decreased. A Spektrum receiver and 11.1V 1300mAh Li-Po battery with limiter came along with the airframe for the price of $\$ 250.00$.

\subsection{Controller and Receiver}

This project utilizes a Spektrum DX7s 2.4 GHz Spread Spectrum Radio system, which includes the DX7s controller and the AR9300 9-channel receiver. The DSM2 second-generation Digital Spektrum Modulation hops between frequencies to provide about a 10 mile range as long as line of sight (LOS) is clear. It is also virtually immune to all internal and external radio interference. The AR9300 combines an internal and external receiver, offering superior path diversity. The system simultanoeously transmits on two frequencies, creating dual RF paths. The system controls the rudder, elevator, and throttle. The Radian airframe does not incorporate ailerons.

\subsection{Altimeter}

\subsubsection{Spektrum Telemetry Module}

The Spektrum TM1000 DSM telemetry module was installed in order to provide the pilot with information relating to altitude and battery life. The module, shown in Figure 32, connects to the receiver in order to transmit the altitude and battery life back to the controller in real time. In order to measure battery life, this module was placed in series with the battery. For an altitude reading, an altimeter, Figure 33, needed to be connected to the telemetry module. It uses air pressure to determine the 
altitude, accurate within $3 \mathrm{ft}$, and also compensates for temperature variations. This system can also provide RF link performance, air-speed, temperature and propellor rpm. Utilizing this module provided a simple way to ensure an approximate $400 \mathrm{ft}$ altitude while safely maximizing flight time with respect to battery voltage. This path was choosen for altitude identification instead of a GPS based system because it was much easier to impliment when considering both time and money.

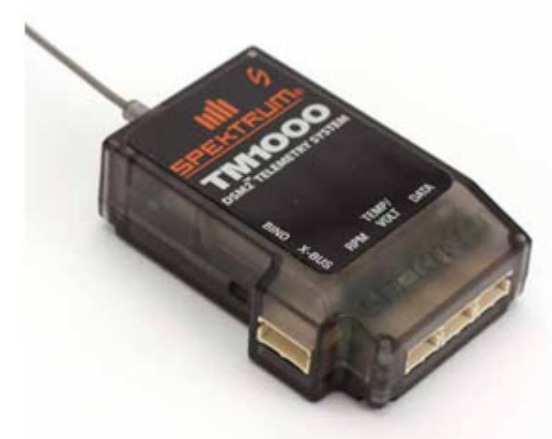

Figure 32: Spektrum Telemetry Module ${ }^{33}$

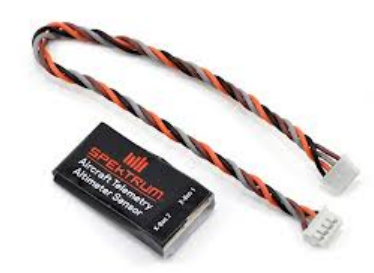

Figure 33: Spektrum Altitmeter Module ${ }^{33}$

\subsubsection{ZLog 6}

ZLog is a compact, lightweight device for measuring and recording altitude over time, shown in Figure 34. It records altitude data which can be accessed through a 
USB interface. The ZLog module uses a high-resolution barometric pressure sensor to detect changes in air pressure that occur due to variations in altitude. It is sensitive enough to detect changes on the order of one foot. It is however influenced by weather and local pressure variations. ${ }^{34}$ The ZLog is kept within the starboard external payload bay in order to shield it from the freestream flow and sun light.

When an image is taken, it is timestamped by the arduino. The amount of time (in seconds) that the processor has been operating prior to taking the picture is written to the image title. The altitude data provided by the ZLog along with the timestamp can be used in combination to confirm the aircraft is at the desired 400 ft when analyzing certain images. The ZLog and starboard Arduino receive power from the same 9 volt battery therefore ensuring they begin counting at the same time. The port imager is powered 2 seconds after the starboard imager. In order for them to be on the same time scale, a two second offest was added to the second imager's timestamp. An example of the flight altitude data stored by the ZLog6 is shown in Figure 35.

In order to validate the ZLog6 data, the Spektrum altitude ouput on the controller was recorded with video. The Spektrum data matched up extremely well with the ZLog6 altitude. They were within at least $3 \mathrm{ft}$ the entire flight. 


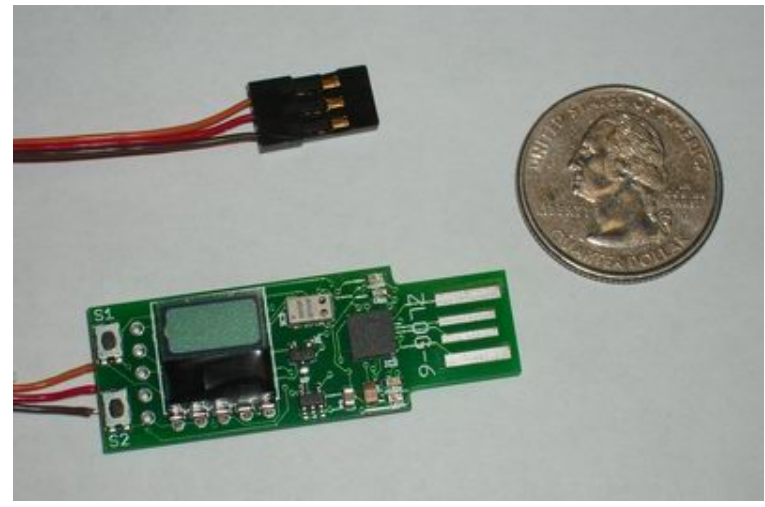

Figure 34: ZLog Version Z6R Records and Stores Altitude ${ }^{34}$

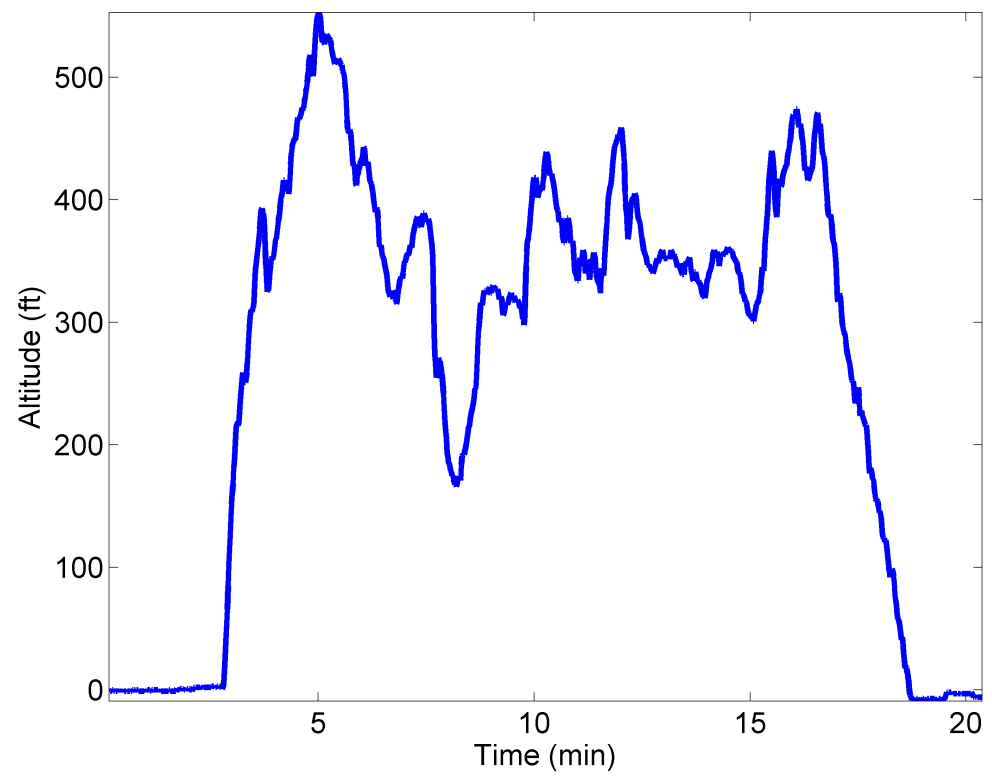

Figure 35: ZLog Flight Altitude Data Example 


\section{Software}

\subsection{Microsoft Research Image Composite Editor}

Microsoft Research Image Composite Editor (MRICE) is an advanced panoramic image stitcher. It utilizes overlapping details of photographs to create a panorama that combines the original images. The stitched panorama can be saved in a wide variety of image formats. MRICE is free to the public and easy to use.

When ORA lands, the SD card(s) may be removed from the SD shield and inserted into any computer with the composite image editor program. From there the images may be dragged from the SD card(s) to the program and a composite map can be produced within minutes. This program enables the use of virtually any computer or laptop for the GCS. MRICE has the ability to combine, as well as scale, specific images at differing resolutions. The ability to scale images is key to the ORA due to the human operator, which makes it difficult to maintain a $400 \mathrm{ft}$ constant altitude.

\subsection{Arduino Code}

When the arduino gets powered, a loop inititates which does not end until power is disconnected from the arduino. Each time through this loop, a new file is created, "IMGXXXX_Y.jpeg" with the respective timestamp in seconds replacing "XXXX" and milliseconds replacing "_Y." The SD card will take pictures for 9999 seconds (about 2.75 hours) before it starts to write over previously taken images. 
The data-logging SD sheild used in the imaging payload contains a watch battery that can be referenced for a more exact time stamp. However, the real-time-clock (RTC) arduino library, which references the watch battery, interfered with the SD shield library. From my understanding, both of the libraries conflicted by defining common variables. The issue was never located or resolved. This SD shield was purchased because the clock function on the Arduino is consistently slow. However, with the error being consistent, applying a constant correction coefficient converted the Arduino time stamp into the proper real world time. This provided the ability to reference altitude data provided by the ZLog6, described in Section 4.3.2, in order to determine the altitude for each image.

The correction coefficient was determined by powering the payload in a testbed setting. The imager was given 9 volts while being connected to the computer providing the ability to view the serial monitor. A stopwatch was started at the same time the arduino was initialized providing a reference for each time stamped image. Figure 36 shows the arduino time plotted against the stopwatch time with a best-fit line. The regression curve fit the data extremely well, as shown by the $R^{2}$ value of 1 . The arduino time was input into the best-fit equation in order to produce the actual time for each image.

There is an option to alter the resolution of the imager within this code. The possible options are 640x480, 320x240, and 160x120 pixels per image. Table 12 shows the amount of time it takes to save each image to the SD card. 


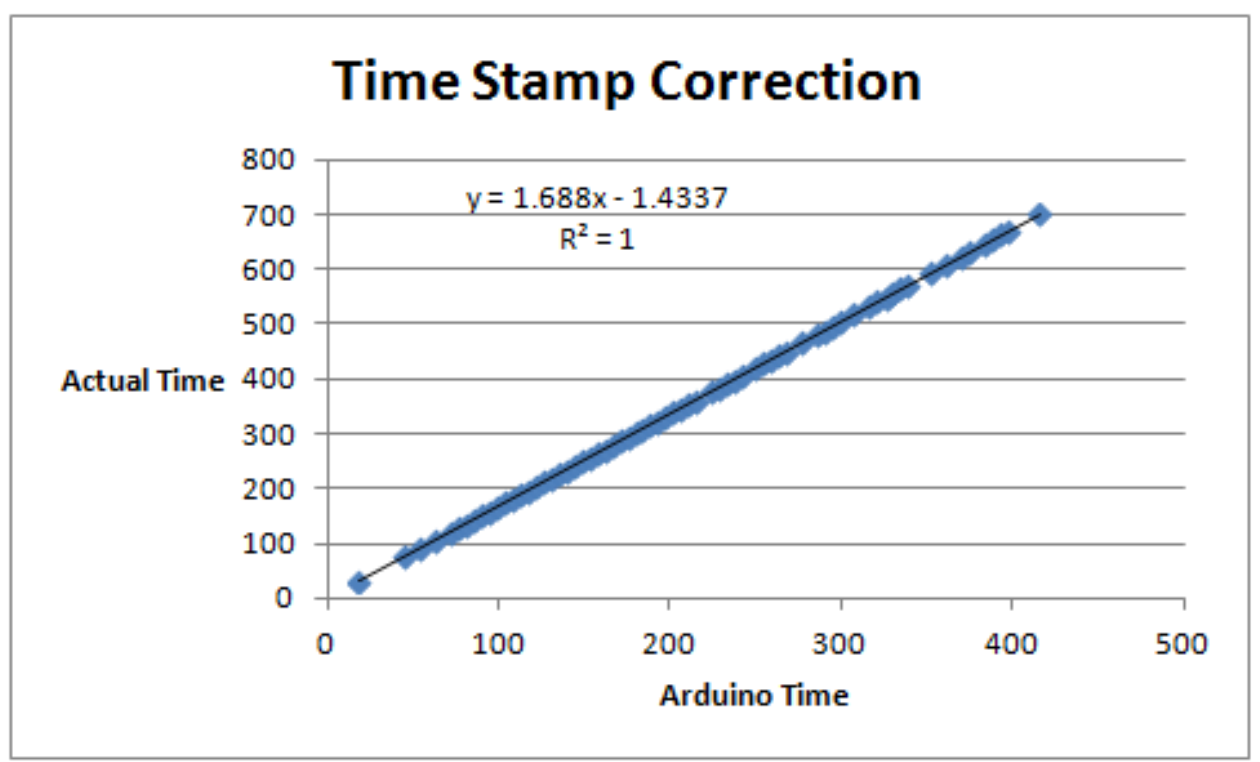

Figure 36: Correction Factor for Arduino Time Stamp

Table 12: Image Processing Time For Various Pixel Sizes

\begin{tabular}{cc}
\hline \hline Pixels per Image & Processing Time \\
\hline $640 \times 480$ & 15 seconds \\
$360 \times 240$ & 6 seconds \\
$160 \times 120$ & 2 seconds \\
\hline
\end{tabular}




\section{Imaging Performance Specifications}

\subsection{NIIRS General Image Quality Equation}

The National Imagery Interpretability Rating Scale (NIIRS) is a quantitative taskbased scale for image quality used for military, civilian, and agricultural applications. The scale ranges from 0 , representing the poorest quality, to 9 , representing the highest quality, where each unit on the NIIRS scale is worth a factor of two in resolution. A change of 0.1 is barely noticeable by a human observer, while a change of 0.2 is easily perceived. The general image quality equation (GIQE) is an empirical formula for calculating the image quality that can be expected from a given optical system. The GIQE is useful to optical engineers for designing new systems to meet specified NIIRS performance requirements, performing system trade studies and efficiently tasking existing optical systems to achieve desired levels of image quality. ${ }^{28}$ There are a few different versions of the GIQE. Version 4.0 is applied when imagery is filtered at or above the Nyquist rate (i.e. twice the highest signal frequency). Version 3.0 will be used for this project because there is no filtering utilized when capturing images. The GIQE has the following form

$$
\mathrm{NIIRS}=c_{o}+c_{1} \log _{10}(\mathrm{GSD})+c_{2} \log _{10}(\mathrm{RER})+c_{3} \frac{G}{\mathrm{SNR}}+c_{4} H
$$

where $c_{0}, c_{1}, c_{2}, c_{3}, c_{4}$ are coefficients relating to version 3.0 with values listed in Table 
13. GSD is the system ground sample distance. RER is the system post-processing relative edge response. $\mathrm{G}$ is the system post-processing noise gain. SNR is the signalto-noise ratio of the unprocessed imagery. $\mathrm{H}$ is the system post-processing edge overshoot factor. The GIQE accounts for three factors that affect the image utility: spatial resolution (GSD and RER), noise (G/SNR), and artifacts (H). Artifacts occur when the captured image illustrates a feature which is not present in the area surveyed. GSD and RER are the most dominant terms. As you can see from Equation 6.1, there are logarithmic operators acting on both GSD and RER. ${ }^{28}$

Table 13: GIQE Version 3.0 Constants

\begin{tabular}{ccccc}
\hline \hline$c_{0}$ & $c_{1}$ & $c_{2}$ & $c_{3}$ & $c_{4}$ \\
\hline 11.81 & -3.32 & 3.32 & -1 & -1.48 \\
\hline
\end{tabular}

In the follow subsections, each term will be elaborated upon. The process of obtaining values for each imaging characteristic will also be shown. Thurman and Fienup compare results from the GIQE, versions 3.0 and 4.0, in "Analysis of the general image quality equation." In that paper they provide a range of values for the five imaging attributes in Equation 6.1, shown in Table $14 .^{28}$ This will used to compare the ORA imaging characteristics in order to provide a sanity check. Even though this project uses an aircraft platform and Table 14 correlates to the optical performance of satellite systems, the comparison will show whether or not the derived values are in the correct ball-park. 
Table 14: Statistics of GIQE Terms for Imagery Used to Develop GIQE 4.0

\begin{tabular}{cccc}
\hline \hline Term & Minimum & Mean & Maximum \\
\hline GSD & $3 "$ & $20 "$ & $80 "$ \\
RER & 0.2 & 0.92 & 1.3 \\
G & 1 & 10.66 & 19 \\
SNR & 2 & 52.3 & 130 \\
G/SNR & 0.01 & - & 1.8 \\
H & 0.9 & 1.31 & 1.9 \\
\hline
\end{tabular}

\subsubsection{Ground Sample Distance (GSD)}

GSD is a measure of the spatial resolution, utilizing units of length. It is essentially the amount of space on the ground shown per pixel. The less space contained per pixel, or lower GSD, correlates to better image quality, or a higher resolution. The inverse relationship between resolution and length per pixel is taken into account within the GIQE by a negative coefficient relating to GSD, see $c_{1}$ in Table 13 . When the length per pixel decreases, the NIIRS value increases, and vise versa.

The GSD is calculated with

$$
\mathrm{GSD}=p R / f
$$

where $p$ is the imager pixel pitch (length of pixels within the camera), $R$ is the distance from the target and $f$ is the system focal length. The specifications for the CMOS imager, shown in Section 6.4, state a pixel size of $5.6 \mu \mathrm{m} \times 5.6 \mu \mathrm{m} .{ }^{27}$ The length of the pixel $(5.6 \mu \mathrm{m})$, an altitude of $400 \mathrm{ft}(122 \mathrm{~m})$ were the respective values for $p$ and $R$. However, the focal length was not provided by the camera specifications nor the 
Adafruit company when contacted. A beam of light travelling parallel and passing through a converging lens will meet at a spot behind the lens. The distance behind the lens where the light converges on the principle axis is the focal length, as seen in Figure 37 .

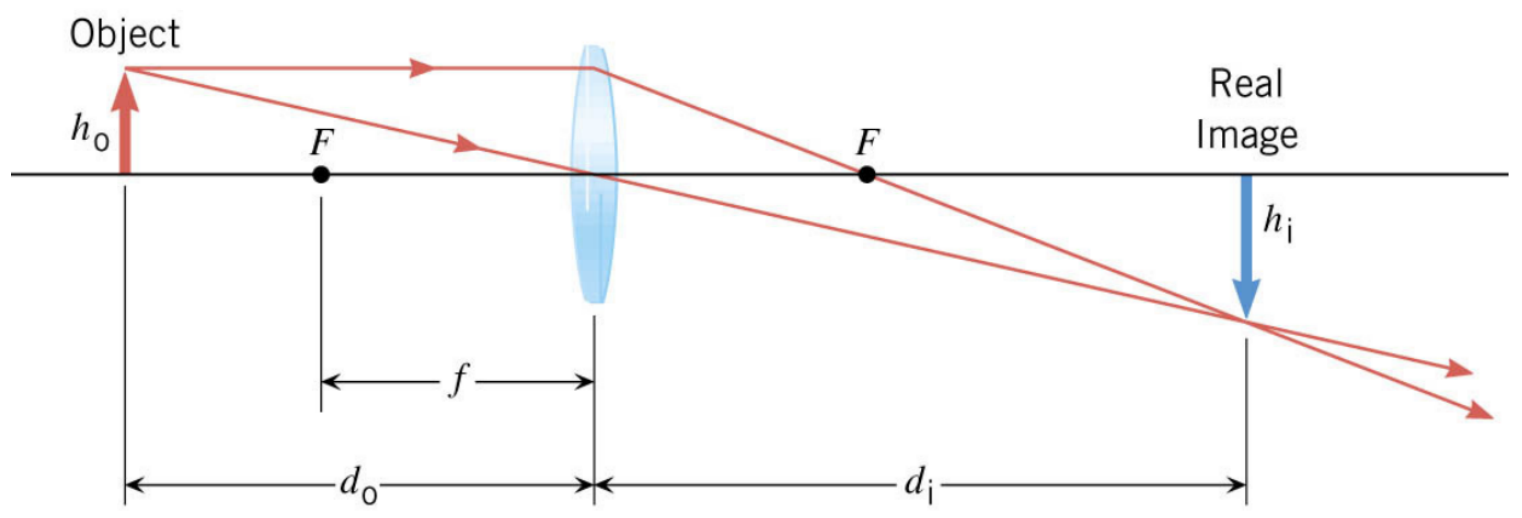

Figure 37: Focal Length of Convex Lens Relating to the Distance and Size of the Object and Image ${ }^{35}$

In order to derive an approximate focal length of the system the following equation was used

$$
\frac{1}{f}=\frac{1}{d_{o}}+\frac{1}{d_{i}}
$$

where the distance of the object and image from the lens are $d_{0}$ and $d_{i}$ respectively and $f$ is the focal length. The distance of the object can be approximated with the altitude of the aircraft when an image is taken. However, the distance of the image cannot be physically measured. In order to provide a value for the image's distance, the magnification equation was utilized as follows, 


$$
M=\frac{h_{i}}{h_{o}}=-\frac{d_{o}}{d_{i}},
$$

where $M$ is the magnification, $h_{i}$ and $h_{o}$ are the image and object height, and $d_{i}$ and $d_{o}$ are the image and object distance respectively. For the medium resolution setting (480x240), there are 400 pixels diagonally from corner to corner of the image. Multiplying the pixel length of $5.6 \mu \mathrm{m}$ by 400 pixels, the height of the image, $h_{i}$, came out to be $0.0073 \mathrm{ft}$. Measuring the distance from corner to corner of a particular image, via Google Earth, produces the height of the object, $h_{o}$.

An ORA image of the Cal Poly Baseball Field was overlayed onto Google Earth, shown by Figure 38. The ORA imagery fits fairly well but does not line-up perfectly with Google Earth. The baseball diamond matches very well while there is some relief displacement causing misalignment among the bleachers and buildings around the field. When this picture was taken, the aircraft was at $409 \mathrm{ft}$ as identified by the ZLog6. It is not precisely at $400 \mathrm{ft}$ but is close enough to the target altitude for an accurate result. Using the Ruler tool, the distance from corner to corner of the image, or $h_{o}$, was determined to be $521 \mathrm{ft}$. With these values the magnification, $M$, turned out to be $-1.4 \times 10^{-5}$. A negative value less than 1 makes sense because a convex lens of this size inverts the image while making it smaller. Using these values in Equation 6.4, as well as the $d_{o}$ of $409 \mathrm{ft}$, the distance of the image, $d_{i}$ came out to be $0.0058 \mathrm{ft}$. Because the length of the object is much larger than the length of the image, $d_{o}$ can be approximated as $\infty$. Due to the fact that $\frac{1}{\infty}$ can be set to $0, f$ is equivilent to $d_{i}$ 
or $0.0058 \mathrm{ft}$ in this case.

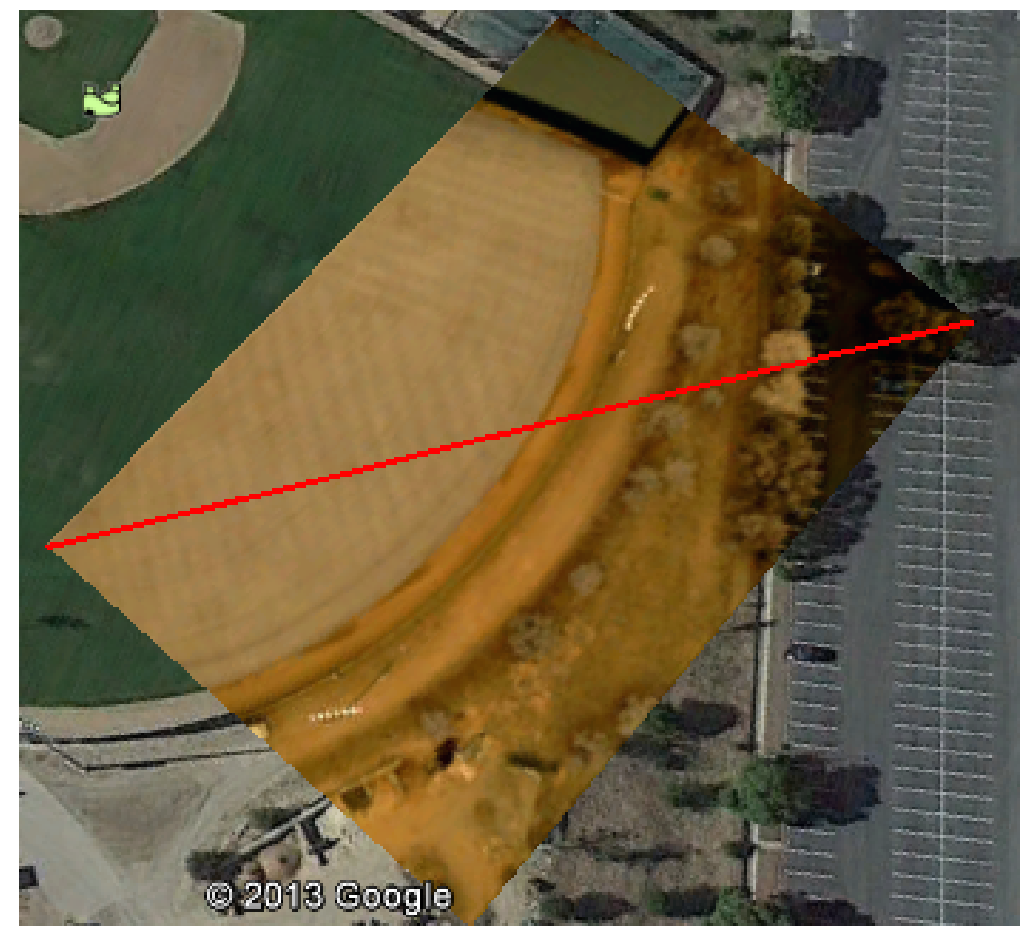

Figure 38: Google Earth Overlayed with ORA Imagery

With a pixel pitch of $5.6 \mu \mathrm{m}$, a $409 \mathrm{ft}$ distance and a focal length of $0.0058 \mathrm{ft}$ the GSD comes to be 15.6" per pixel as illustrated by Equation 6.2. By no means is this value perfect. There are many sources of uncertanty as explained in Section 7.2. For that reason, this process was completed 5 times to produce a nominal GSD of $15+/$ 1", which is just under the average in Table 14 in Section 6.1.

The GSD for the high and low resolution settings were determined to be 7.5 and 30 by using the same process for the medium resolution setting. Table 15 compares the GSD that was assumed, when choosing the camera, against the values derived from operating the system. The derived values were a little better than the ones assumed. 
This relationship was expected to be opposite, or the actual performance of the imager was expected to be less robust than the assumed values, due to variations in distance from the target. The camera specifications proposed a $60^{\circ}$ viewing angle. By the GSDs calculated, the observed viewing angle is closer to $53^{\circ}$.

Table 15: GSD Assumed and Derived

\begin{tabular}{cccc}
\hline \hline Resolution & Pixels & Assumed Value & Derived Value \\
\hline High & $640 \times 480$ & 8.5 & 7.5 \\
Med & $320 \times 240$ & 17 & 15 \\
Low & $160 \times 120$ & 34 & 30 \\
\hline
\end{tabular}

At an altitude of $409 \mathrm{ft}$, a GSD of 15" with medium resolution correlates to a $1.8 \mathrm{~mm}$ focal length. This focal length is consistent with imagers of similar size and performance. The second generation iPad has a focal length of $2 \mathrm{~mm} \cdot{ }^{36}$ The CMOS imager in the ORA payload has a 1/4" sensor. A similar digital compact 1/3" sensor at $409 \mathrm{ft}$ has a focal length of $3.6 \mathrm{~mm} .{ }^{37}$ The $1.8 \mathrm{~mm}$ focal length estimate seems like it is in the correct ballpark.

\subsubsection{Relative Edge Response (RER)}

RER is the geometric mean of normalized edge response differences measured in the horizontal and vertical directions. In laymen's terms, RER measures how well an imager captures the transition from a light color to a dark color, or vise versa. Because there is a finite number of pixels in every camera, the sensor cannot capture the imagery containing edges perfectly. Figure 39 is a good illustration of this phenomenon. As you can see, the transition between dark and light intensities 
is not ideal. It takes a few pixels to get from the dark part of the image (200 DN) to the light part of the image $(1000 \mathrm{DN}) .{ }^{38}$

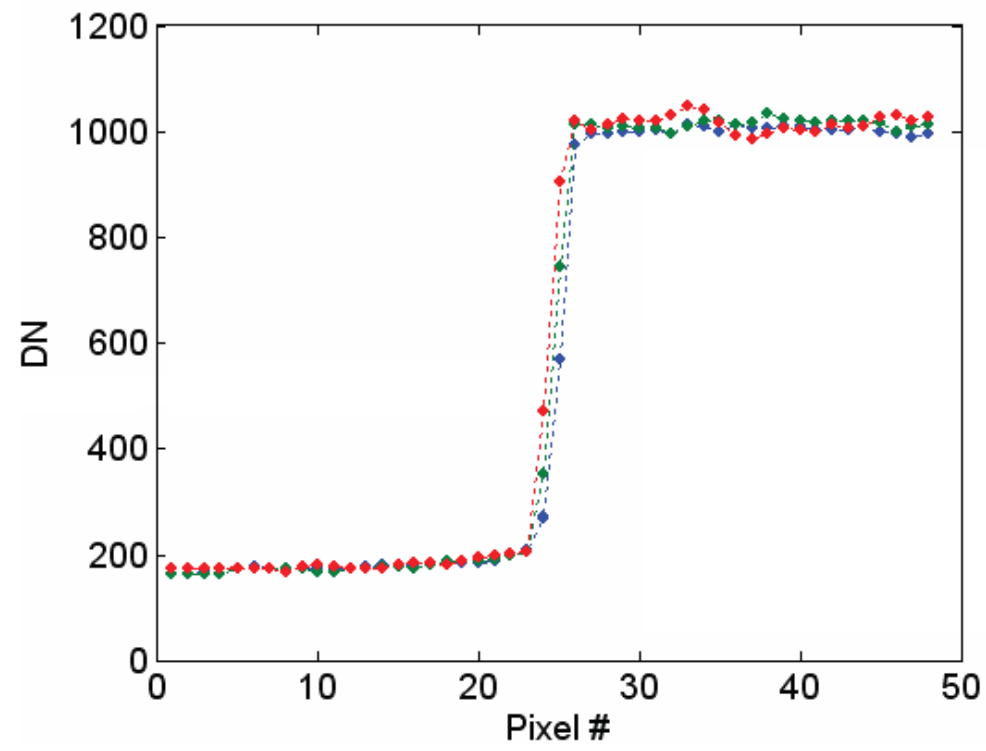

Figure 39: Relative Edge Response Between Bright and Dark Targets ${ }^{38}$

The RER is calculated with

$$
\mathrm{RER}=\sqrt{\left[E R_{X}(0.5)-E R_{X}(-0.5)\right] *\left[E R_{Y}(0.5)-E R_{Y}(-0.5)\right]}
$$

where $E R$ is the normalized edge response corresponding to the location of the Distance/GSD. Figure 40 is a good example of what such values look like. The red dashed line is the actual edge being surveyed. The -0.5 and 0.5 Distance/GSD corresponds to half a pixel away from the actual edge. GSD is equivilent to distance per 
pixel. Therefore in Distance/GSD, the distances cancel out and only pixels remain in the numerator.

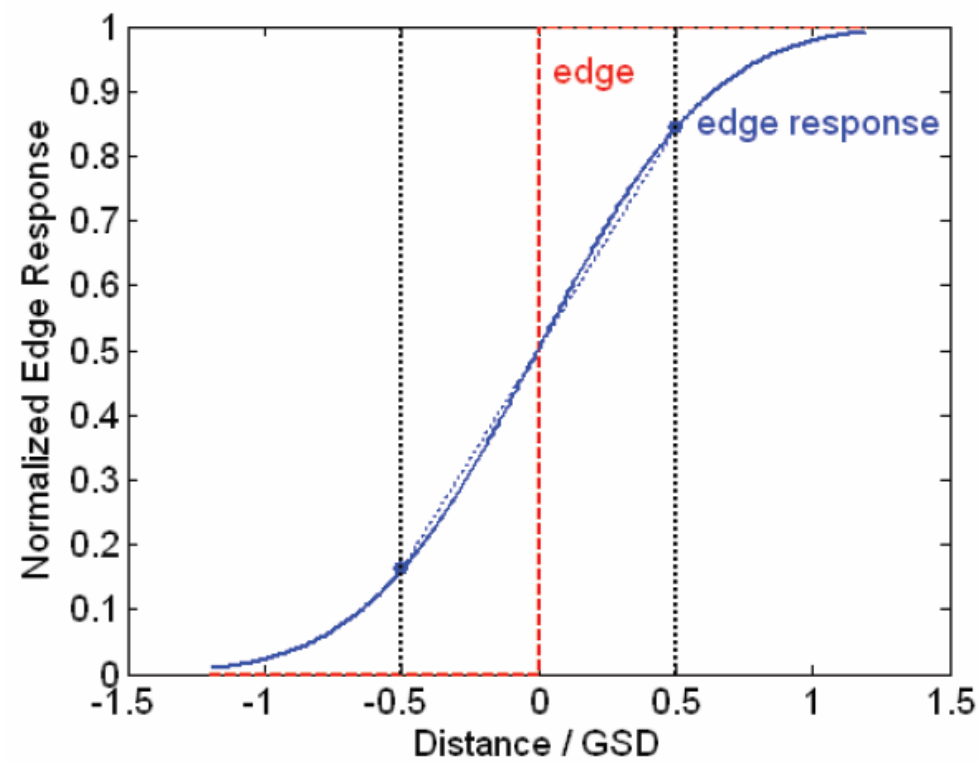

Figure 40: Normalized Relative Edge Response ${ }^{39}$

A higher RER value corresponds to a higher resolution. The max RER occurs when the edge response is contained within one full pixel, or from -0.5 to 0.5 Distance/GSD. Equation 6.5 is esseentially an averaged slope. In Figure 40, the distance in the y-axis, edge response, is being divided by 1 because it spans one pixel. This slope is calculated twice for the vertical and horizontal directions of the image, then averaged by the square root of the products. A more robust imager would have a steeper line when recognizing an edge. A higher slope is associated with less pixels capturing the edge response. A slope of zero would be the absolute worst value illustrating that the imager is not picking up the edge at all. ${ }^{38}$

RER is estimated while the imager is in operation using edge targets and the tilted 
edge technique. The edges are in a tilted orientation in order to prevent the pixels from lining up perfectly in either the vertical or horizontal direction. When NASA characterized the QuickBird satellite using the Stennis Space Center test range, they painted edges onto concrete surfaces, shown in Figure $41 .^{38}$
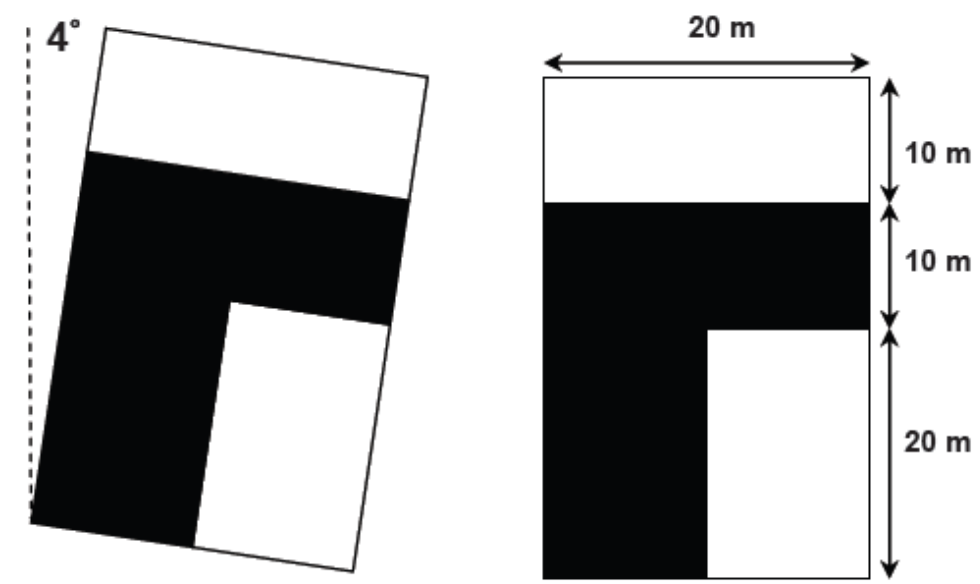

Figure 41: Tilted Edges at Stennis Space Center Test Range ${ }^{38}$

When testing the imaging payload of ORA, natural images captured by the system were used to determine the RER values instead of an apparatus similar to Figure 41. This is a common process. It is utilized in the report "Image-Based Estimation and Validation of NIIRS For High-Resolution Satellite Images." 39

The image shown in Figure 42 has a distinct edge, located by the red dot, that can be used to estimate the RER. The mean image intensity was determined by separating and averaging the red, green and blue wavelengths for each pixel. A single row of pixels was isolated and analyzed in order to determine the horizontal edge response. The brightness from left to right of the row containing the red dot is shown 
in Figure 43. This edge is a good point for analysis due to the full colors before and after the edge. The red to black surfaces demonstate relatively constant brightness values compared to other sections of the image.

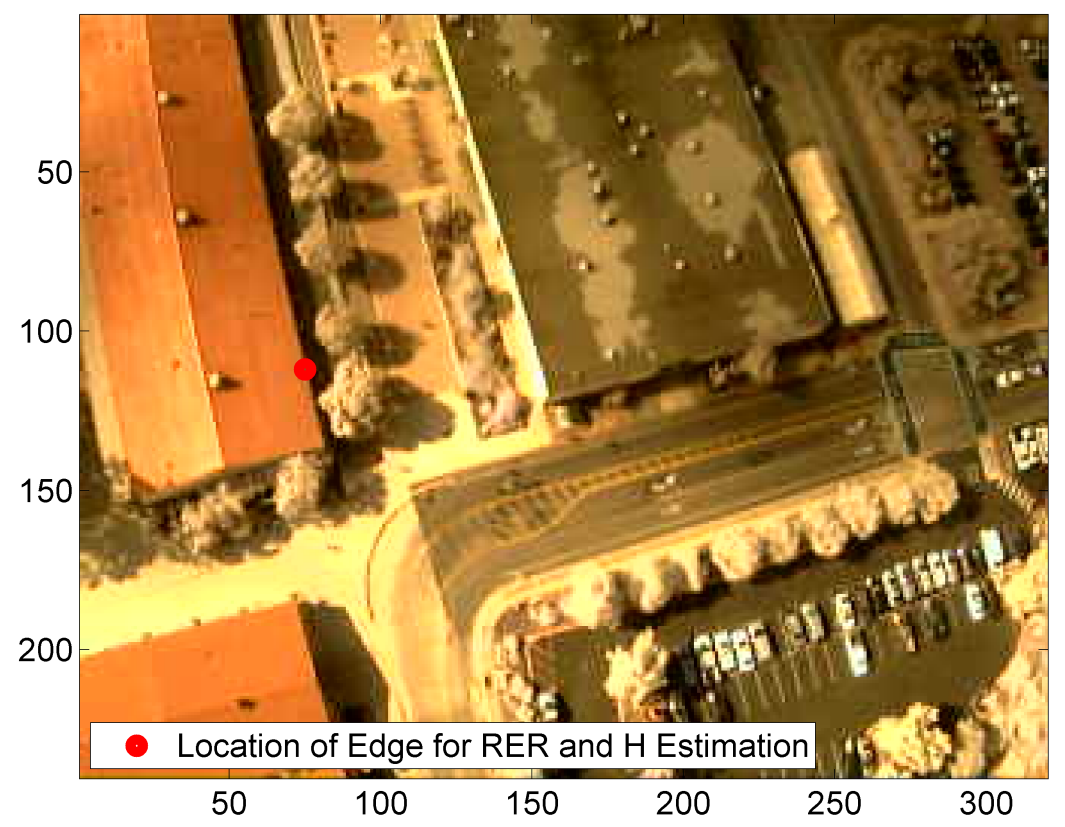

Figure 42: Image Analyzed For RER and H Evaluation

Figure 44 contains the same data as Figure 43 but is zoomed in upon the edge location. The brightness was normalized on the y-axis. The pixel number was turned into Distance/GSD and localized around the edge on the x-axis. The normalized brightness at -0.5 and 0.5 Distance/GSD is half of the numerics needed to determine the RER in Equation 6.5. This process was completed at the same location, while looking at the column of pixels for the vertical edge response. The vertical and horizontal normalized edge response values of 0.42 and 0.09 were averaged in Equation 


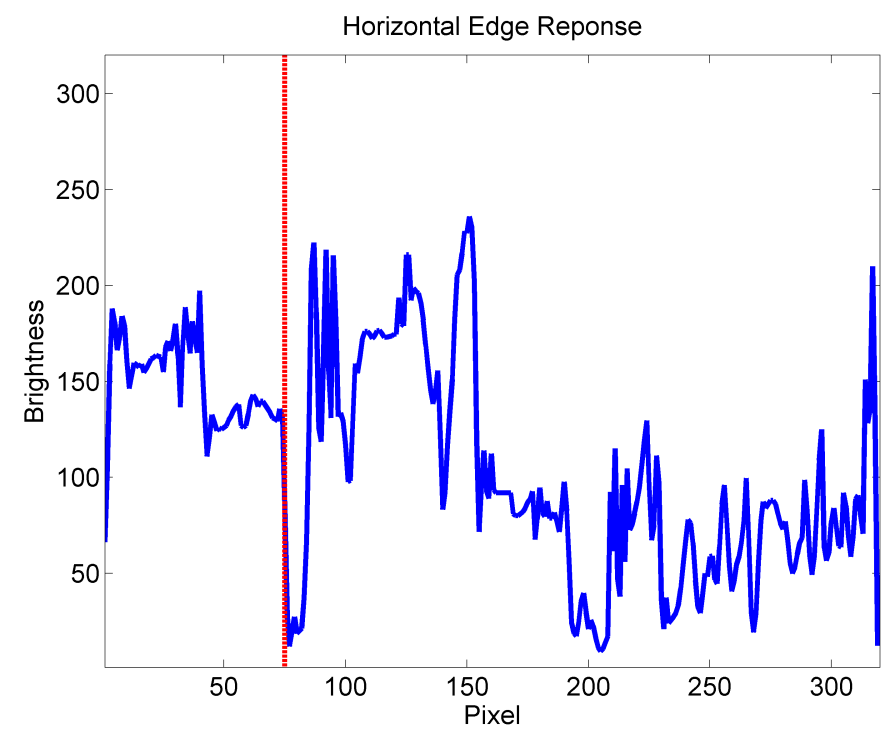

Figure 43: Image Brightness for the Row of Pixels Containing Edge

6.5 to produce a RER value of 0.194 . The discrepency between the horizontal and vertical differences is due to the orientation of the edge. Because it was more vertically orientated, it took more pixels to identify the edge while looking through a column of pixels than compared to row. This is why the tilted edge technique is used and the edge response in each direction is averaged. If the edge was closer to a $45^{\circ}$ angle, the vertical and horizontal responses would be closer togther.

This process was repeated five times with different images at an altitude as close as possible to $400 \mathrm{ft}$. The nominal RER value came out to be $0.19+/-0.02$. This estimation is just under the minimum value on Table 14 in Section 6.1. Table 16 shows there is a big discrepancy between the derived value of 0.19 and the assumed value of 0.92 , when estimating the NIIRS prior to purchasing the camera. RER is the main reason the camera needed to operate with medium resolution in order to meet 


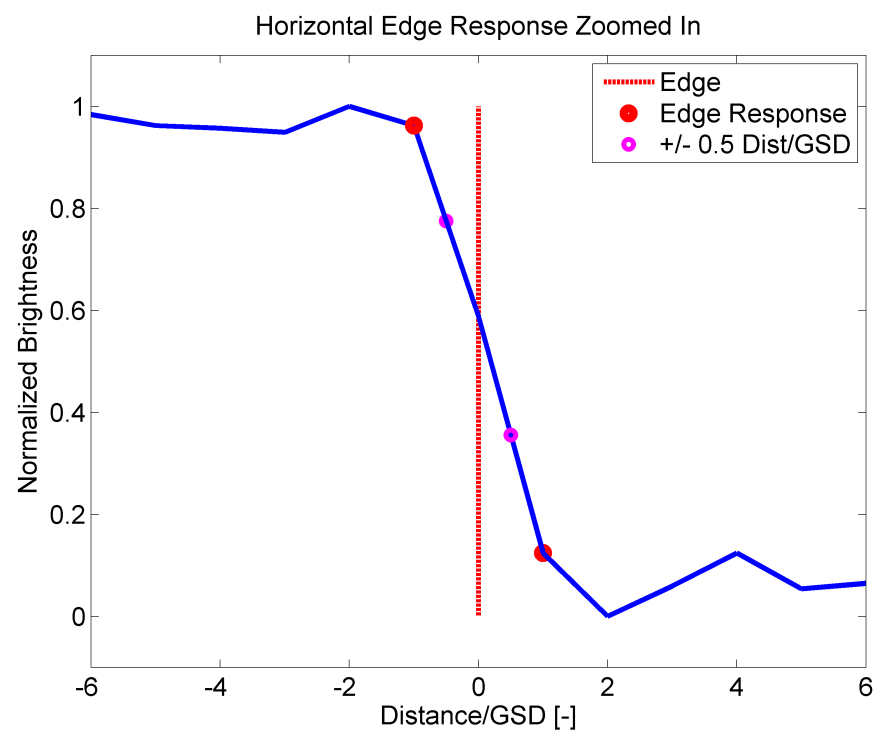

Figure 44: Normalized Image Brightness for the Row of Pixels Containing Edge

the NIIRS level 4 requirement. The discrepancy in RER is most likely due to the performance of the imager. The optical quality of a $\$ 40$ camera is no match for an imager within a satellite. The average value of 0.92 was assumed because the UAV camera is much closer than the satellite. However, the distance from the object was not as advantageous as anticipated.

Table 16: RER Assumed and Derived

\begin{tabular}{cc}
\hline \hline Assumed Value & Derived Value \\
\hline 0.92 & 0.19 \\
\hline
\end{tabular}

\subsubsection{Edge Overshoot Factor $(\mathrm{H})$}

The overshoot term accounts for the impact of noise and edge-overshoot artifacts on the human visual system. The $\mathrm{H}$ term acts as a post-processing penalty when the image has been corrected too much. The coefficient, $c_{3}$, is negative and takes away 
from the fidelity of the image quality. Therefore an imager with a lower $\mathrm{H}$ value is considered a higher performing system. The overshoot is determined with the edge response much like $\mathrm{RER}$. $\mathrm{H}$ is calculated by

$$
\mathrm{H}=\left\{\begin{array}{l}
\operatorname{ER}(1.25 p), \text { if there is an undershoot } \\
\max [E R(x)] \text { on interval } \mathrm{x} \in[1 p, 3 p], \text { if there is an overshoot }
\end{array}\right.
$$

where $E R$ is the edge response of the system and $p$ is the number of pixels from the center. Figure 45 is the horizontal edge response relating to Figure 42 and shows no evidence of an overshoot of the edge. An overshoot was not expected with this system because no post-processing was completed.

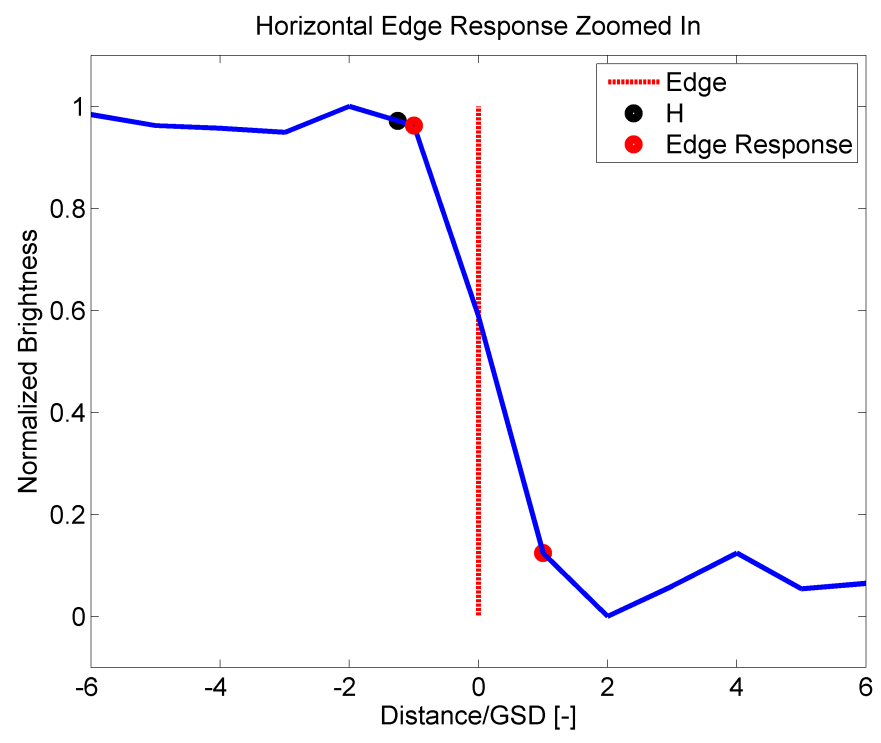

Figure 45: Edge Response Overshoot for Column of Pixels Containing Edge

In the case of an overshoot, the $\mathrm{H}$ value is characterized by the max edge response of the system on the interval from one pixel to three pixels as shown by Equation 6.6. 
An overshoot is the worst possible case contributing a larger $\mathrm{H}$ value when compared to the undershooting case. When evaluating the edge artifact, the edge needs to go from dark to light. That is the reason why the overshoot is determined by going from right to left in Figure 45. Because the imager did not have an overshoot when evaluating the row of pixels, a horizontal $\mathrm{H}$ value of 0.97 was determined at $1.25 p$. By averaging the horizontal and vertical overshoot artifacts, the overall $\mathrm{H}$ value of 0.86 was determined for the image in Figure 42.

This process was completed on five separate images. Averaging each overshoot factor provided an $\mathrm{H}$ of $0.76+/-0.09$. This is a bit below the minimum value of 0.9 in Table 14 in Section 6.1. Table 17 compares the overshoot derived value against the assumed value, when estimating the NIIRS. The system performs no post-processing on the images and therefore performed much better with respect to the overshoot artifact.

Table 17: H Assumed and Derived

\begin{tabular}{cc}
\hline \hline Assumed Value & Derived Value \\
\hline 1.31 & 0.76 \\
\hline
\end{tabular}

\subsubsection{Signal-to-Noise Ratio (SNR)}

The signal-to-noise ratio is a measure that compares the level of a desired signal to the level of background noise. Industry standards measure SNR in decibels (dB) of power. Decibels is a logarithmic scale where $0 \mathrm{~dB}$ describes a 1:1 ratio between signal and noise. The definition of imagery signal to noise ratio is defined as the average 
signal value over the standard deviation of the signal. As provrided by the Adafruit specifications, the imager has a SNR of $45 \mathrm{~dB} .^{27}$

\subsubsection{Noise Gain (G)}

Gain refers to the magnitude of the amplification a given system produces. Usually gain can be adjusted through software to meet the needs of a given application. For example, the gain can be increased when the application is photon starved and a high sensitivity mode is required. This would be the case when imaging at night with an EO camera. Alternatively, the gain can be reduced when a high SNR mode is required. ${ }^{40}$

The gain within the CMOS imager in this project is automatically adjusted depending on the amount of light surveyed. The gain does not affect the GIQE as much as variables such as GSD and RER. The specifications in Section 6.4 illustrate a max analog gain of $16 \mathrm{~dB}$, which was utilized for the GIQE calculation. With a $\mathrm{G}$ of 16 and a SNR of 45 , the G/SNR term turns out to be close to 0.36 .

\subsection{NIIRS Evaluation and Error}

The requirement for a NIIRS level 4 imager was met by operating with a medium resolution setting. Equation 6.1 in Section 6.1 was utilized as well as the values derived or provided for this system, shown in Table 18. SNR and G did not have any uncertanties associated with it due to the fact that they were provided by the camera specifications. 
Table 18: GIQE Values For ORA Imager with Medium Resolution

\begin{tabular}{ccccccc}
\hline \hline Criteria & GSD & RER & SNR & G & H & NIIRS \\
\hline Value & $15 "$ & 0.19 & 45 & 16 & 0.76 & 4.0 \\
Uncertanty & $1 "$ & 0.02 & NA & NA & 0.09 & 0.4 \\
\hline
\end{tabular}

\subsubsection{Error Propogation}

The standard deviation values associated with GSD, RER and H, shown in Table 18, were determined through the following formula,

$$
\sigma=\sqrt{\frac{1}{n-1} \sum_{i=1}^{n}\left(x_{i}-\bar{x}\right)^{2}}
$$

where $\sigma$ is the standard deviation, $n$ is the number of measurements and $x$ is the mesurement value. In order to find the uncertanties, GSD, RER and $\mathrm{H}$ were determined and input into Equation 6.7 for all five images. Each image is shown in Section B of the Appendix.

The absolute uncertainty of the NIIRS was determinded as follows,

$$
\sigma_{N I I R S}=\sigma_{G S D}+\sigma_{R E R}+\sigma_{H}
$$

where $\sigma$ is the absolute uncertainty pertaining to each variable. There are no uncertanties of SNR and G taken into account because they were provided by the camera specifications. The errors associated with each variable are not indpendent. For example, if the aircraft was pitched up the distance from the target would increase and have negative effects on GSD, RER and H. Due to the coupled nature of the vari- 
ables, Equation 6.8 was used and not the square root of the sum of the squares. The GIQE, Equation 6.1, takes into acount GSD and RER with a logarithmic operator. Therefore, the absolute error of GSD and RER is a function of the relative error as follows,

$$
\begin{array}{r}
f=a \log A \\
\sigma_{f} \approx a \frac{\sigma_{A}}{A \ln 10} .
\end{array}
$$

The values and uncertanties of GSD, RER and H, shown in Table 18, along with Equation 6.8 create a NIIRS value of 4.0 with a 0.4 uncertainty.

\subsubsection{NIIRS Validation Test Plan}

The Civil NIIRS Criteria states that with a certain rating level, the imaging system should have the the ability to identify specific objects. ${ }^{41}$ Each level satisfies their respective objectives.

\section{Rating Level 3}

- Detect large area (i.e., larger than 160 acres) contour plowing.

- Detect individual houses in residential neighborhoods.

- Detect trains or strings of standard rolling stock on railroad tracks (not individual cars).

- Identify inland waterways navigable by barges.

- Distinguish between natural forest stands and orchards. 
Rating Level 4

- Identify farm buildings such as barns, silos, or residences.

- Count unoccupied railroad tracks along right-of-way or in a railroad yard.

- Detect a basketball court, tennis court, volleyball court in urban areas.

- Identify individual tracks, rail pairs, control towers, switching points in rail yards.

- Detect jeep trails through grassland

\section{Rating Level 5}

- Identify Christmas tree plantations.

- Identify individual rail cars by type (e.g., gondola, flat, box) and locomotives by type (e.g., steam, diesel).

- Detect open bay doors of vehicle storage buildings.

- Identify tents (larger than two person) at established recreational camping areas.

- Distinguish between stands of coniferous and deciduous trees during leaf-off condition.

- Detect large animals (e.g., elephants, rhinoceros, giraffes) in grasslands.

\section{Rating Level 6}

- Detect narcotics intercropping based on texture.

- Distinguish between row (e.g., corn, soybean) crops and small grain (e.g., wheat, oats) crops.

- Identify automobiles as sedans or station wagons.

- Identify individual telephone/electric poles in residential neighborhoods.

- Detect foot trails through barren areas. 


\section{Rating Level 7}

- Identify individual mature cotton plants in a known cotton field.

- Identify individual railroad ties.

- Detect individual steps on a stairway.

- Detect stumps and rocks in forest clearings and meadows.

The Operationally Responsive Aircraft with dual imaging payloads will be flown at $400 \mathrm{ft}$ while capturing photos of the specified objects, in order to prove the imaging system has at least a level 4 rating while taking medium resolution images. There is a local basketball court that can be easily surveyed. Even though it does not reside in an urban area, the court is a great test case. The closest building to the test space is the Cal Poly Hangar. It will replace farm buildings for the level 4 calibration.

Objects from the 3 and 7 levels will also be surveyed in order to determine if the derived rating is too conservative or agressive. The level 3 rating is difficult to illustrate with the given parameters and the local test flight area. A few baseball fileds will be surveyed as a replacement for a large area contour plowing. There is an orchard close to the flight area but no natural forest stands. In order to prove a level 5 rating, a two person tent will be set up in the field. Even though it is not at a recreational camping area, a tent is an accessible test object. For the level 6 rating, automobiles will be attempted to be identified as sedans or station wagons. At level 7, imaging systems can identify the indiviual railroad ties, which are the rectangular supports underneath the rails of railraod tracks, as well as individual 
steps on a stairway. The ties and steps are perfect tests due to their close proximity to the test flight area.

\subsection{Resolution vs Coverage Area}

A key element to remote sensing is choosing the correct vehicle and flight operations to satisfy various sensor requirements. The GSD and size of the field of view are directly related to the distance from the target. In our case, the altitude of the aircraft determines the pixel density and coverage area. If an operator is more worried about sensor performance than obtaining written permission from the FAA, the altitude may be chosen to provide sufficient image resolution or coverage.

Coverage area and resolution are inversely proportionate by nature. At high altitudes, the coverage area is large but the resolution is bad. While lower to the ground, the coverage area is small and the resolution better. The highest quality image is at the lowest altitude while the best coverage area is at the highest altitude. Figure 46 and 47 show the GSD and coverage area, respectively, with typical altitudes ranging from $100 \mathrm{ft}$ to $1,000 \mathrm{ft}$. The higher resolution setting lowers the ground sampling distance because, by definition, it uses more pixels per area surveyed.

\subsection{CMOS Camera and Board Specifications}

The CMOS camera utilizes an electronic rolling shutter. This is where each frame is recorded by scanning the field of view horizontally. By moving the scanner, the image sensor can continue collecting photons while the data from the scanner is being 


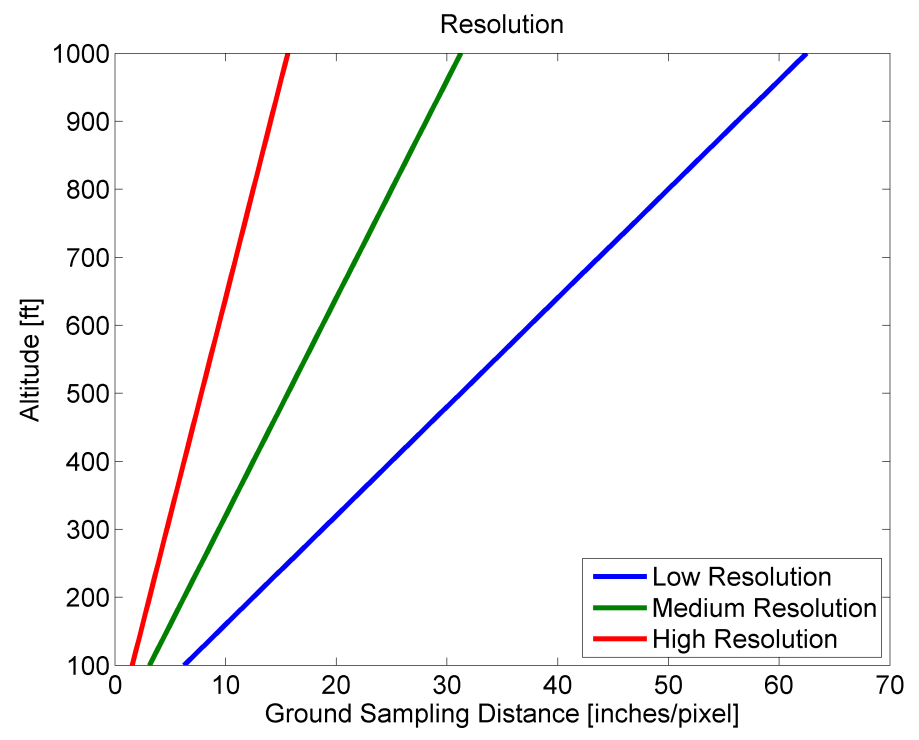

Figure 46: Pixel Density Per Image within Common Flight Altitudes

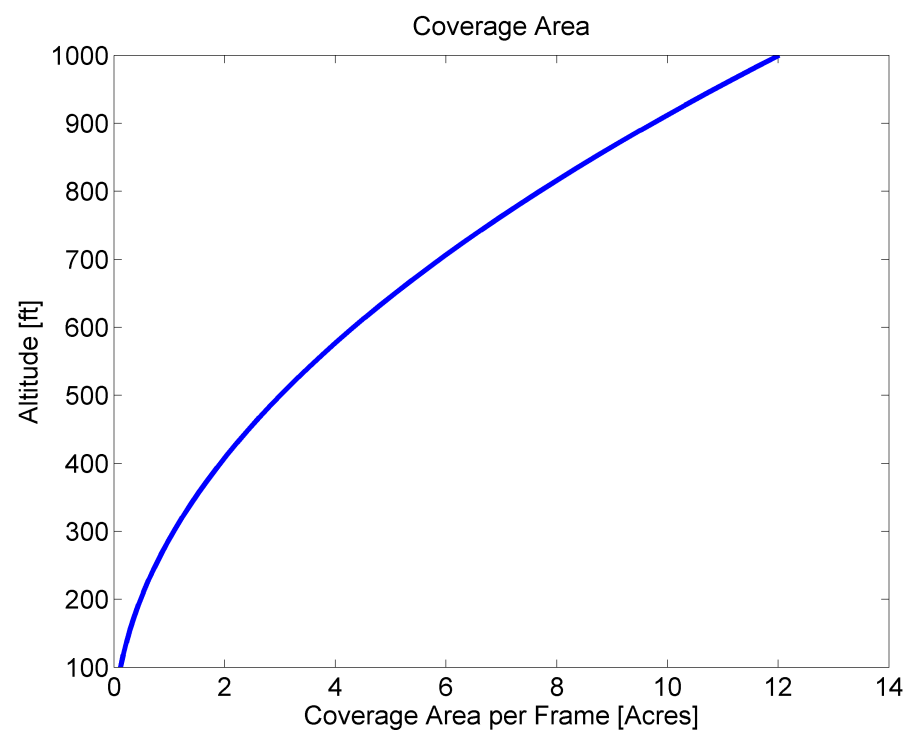

Figure 47: Coverage Area Per Image Depending on Altitude

processed.

Vibrations, high frequency movements, as well as light adversely affect rolling shutters because the field of view is constantly changing. The rolling shutter scans 
sections of the image at different times so each line of photons do not match up directly when its target is moving. Jitter, skew, smear, and partial exposure are all caused by this phenomenon.

These pitfalls, which occur much more frequently in everyday camera use compared to remote sensing applications, have not affected the ORA results. The fact that the payload is currently limited to still images taken at high altitudes has diminished any negative results. Vibrations leading to jitter have not caused any issues either. Smear has been virtually nonexistent due to the fact that every target has been stationary. Here is a list of specifications from the TTL Serial JPEG Camera. ${ }^{27}$

- Module size: $32 \mathrm{~mm}$ x $32 \mathrm{~mm}$

- Image Sensor: CMOS 1/4inch

- CMOS pixels: 30M

- Pixel size: $5.6 \mu \mathrm{m} * 5.6 \mu \mathrm{m}$

- Output format: Standard JPEG/M-JPEG

- White balance: Automatic

- Exposure: Automatic

- Gain: Automatic

- Shutter: Electronic rolling shutter

- SNR: 45DB

- Dynamic range: 60DB

- Max analog gain: 16DB

- Frame speed: $640 * 48030 \mathrm{fps}$

- Scan mode: Progressive scan 
- Viewing angle: $60^{\circ}$

- Monitoring distance: 10m, maximum 15m (adjustable)

- Image size: VGA (640*480), QVGA (320*240), QQVGA (160*120)

- Baud rate: Default 38400, Maximum 115200

- Current draw: $75 \mathrm{~mA}$

- Operating voltage: $\mathrm{DC}+5 \mathrm{~V}$

- Communication: 3.3V TTL (Three wire TX, RX, GND) 


\section{Test Results}

\subsection{NIIRS Validation}

ORA was tested with dual imaging payloads capturing medium resolution pictures (320x240 pixels) flying as close as possible to $400 \mathrm{ft}$. In order to quantify the Level 4 NIIRS value, the following objects were targeted:

- Orchard - Level 3

- Basketball Court - Level 4

- Two-Person Tent - Level 5

- Individual Car Identification - Level 6

- Railroad Ties - Level 7

Multiple targets ranging different levels were incorporated in the case that the estimated NIIRS value was too aggressive or conservative compared to the actual image performance. Level 3 and 4 were validated as the orchard and basketball courts were easily identifyable as expected, shown in Figures 48 and 49 respectively.

It was more difficult to identify a two-person tent, which is circled in red in Figure 50. If the tent was not set-up personally, it could not have been correctly identified. For that reason, the Level 5 NIIRS value could not be validated, even though it was tested at an altitude of $432 \mathrm{ft}$. This was expected due to the NIIRS value of $4.0+/-$ 0.4. Even though the tent was not distinguishable, an observer could tell something 


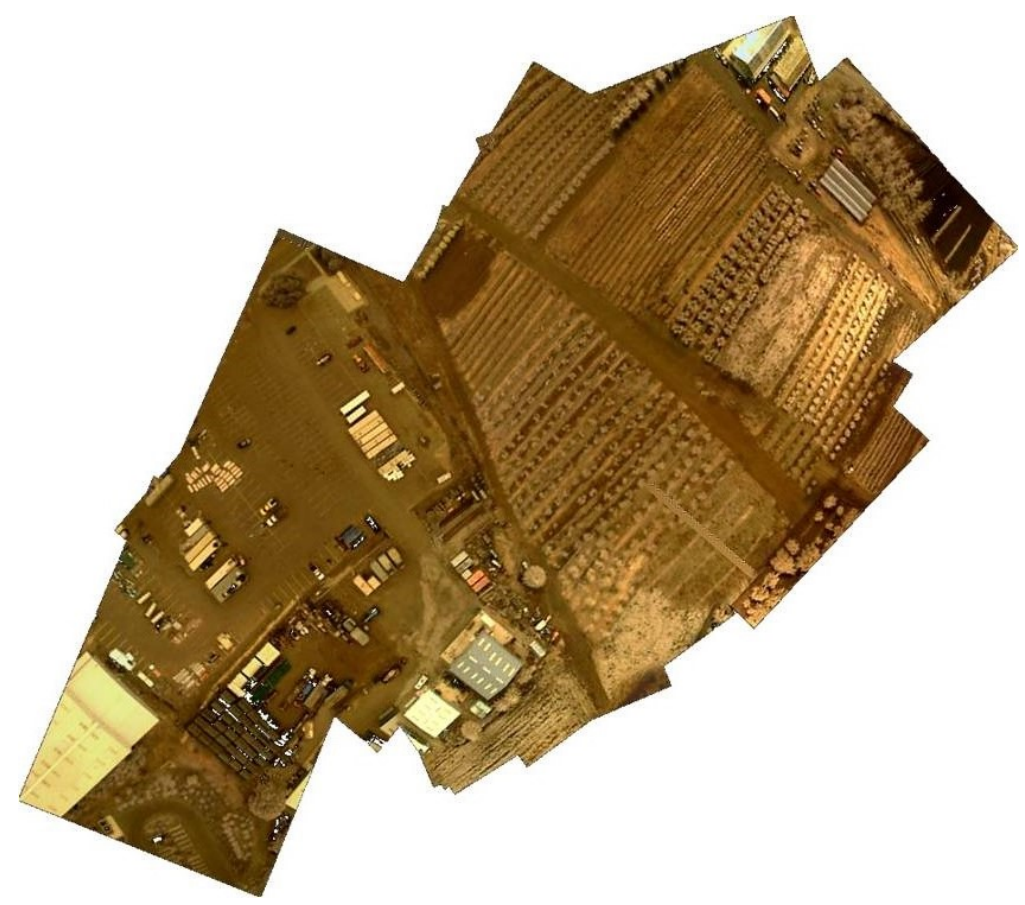

Figure 48: Orchard Level 3 Validation at $413 \mathrm{ft}$

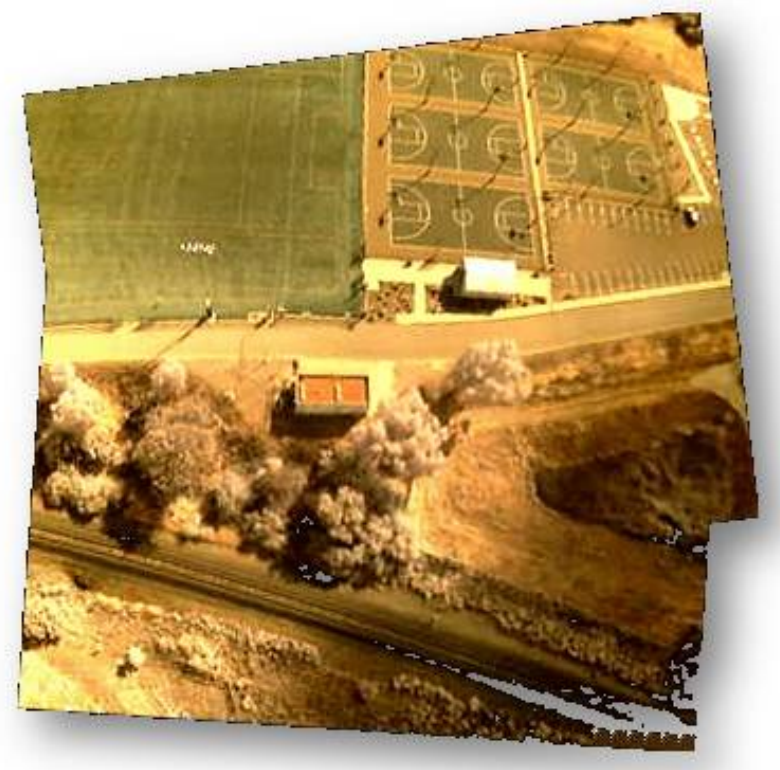

Figure 49: Basketball Court Level 4 Validation at $416 \mathrm{ft}$ 


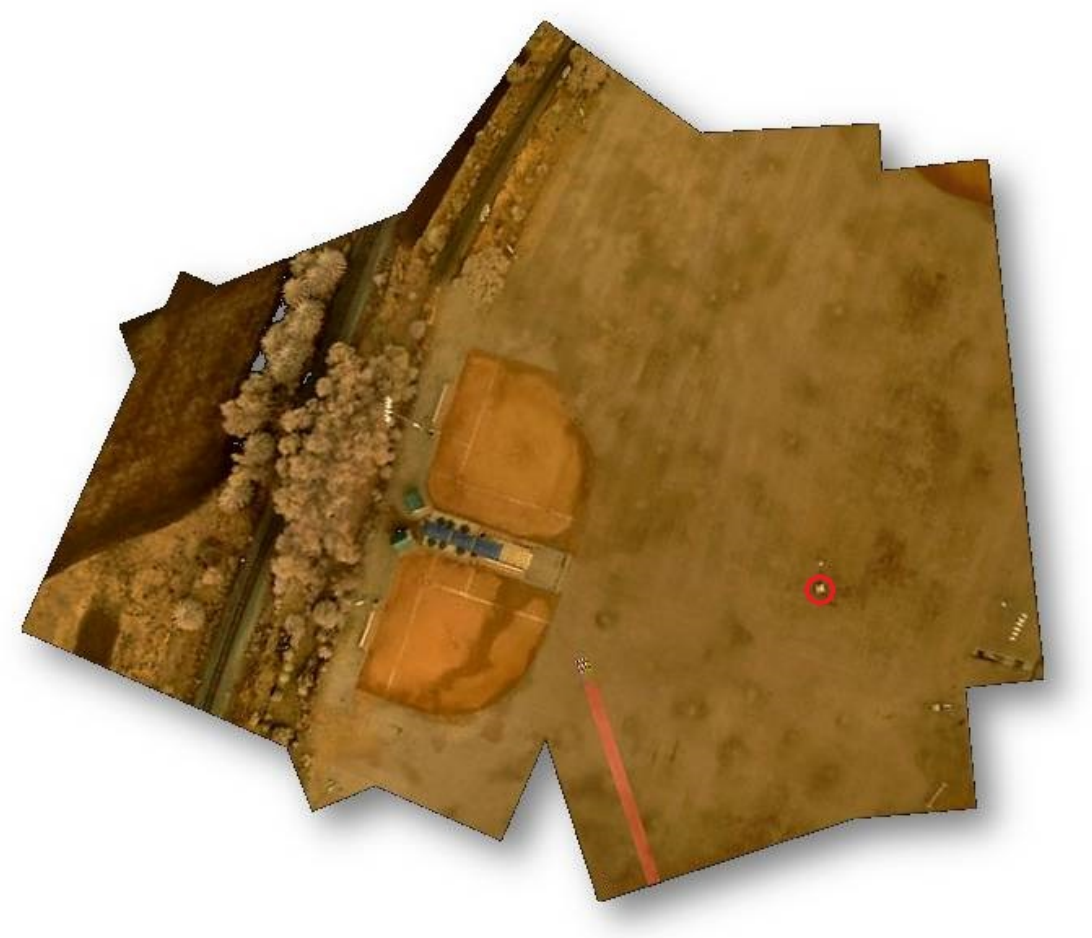

Figure 50: Tent Level 5 Validation at $432 \mathrm{ft}$

was there. This, along with the higher altitude, supports the claim that the NIIRS value may be on the upper end of the 0.4 uncertainty.

In Figure 48, it is difficult to distinguish the type of individual cars in the parking lot, disproving a Level 6 evaluation. Railroad ties were no where close to being properly identified illustrating the NIIRS value is far away from a Level 7 as expected.

\subsection{Composite Map}

There were difficulties when trying to compile a composite map. Figure 51 is an attempt at creating a composite map by overlaying images onto Google Earth. The Microsoft Research Composite Image Editor (MRICE) was successful in combining 
localized images, as seen in Figures 48, 49 and 50, but could not create an all encompassing map. By trying to survey the orchards, basketball court and parking lot, ORA did not capture enough images of the land inbetween the points of interest to successfully combine them. A smaller coverage area is needed to produce an all encompassing map.

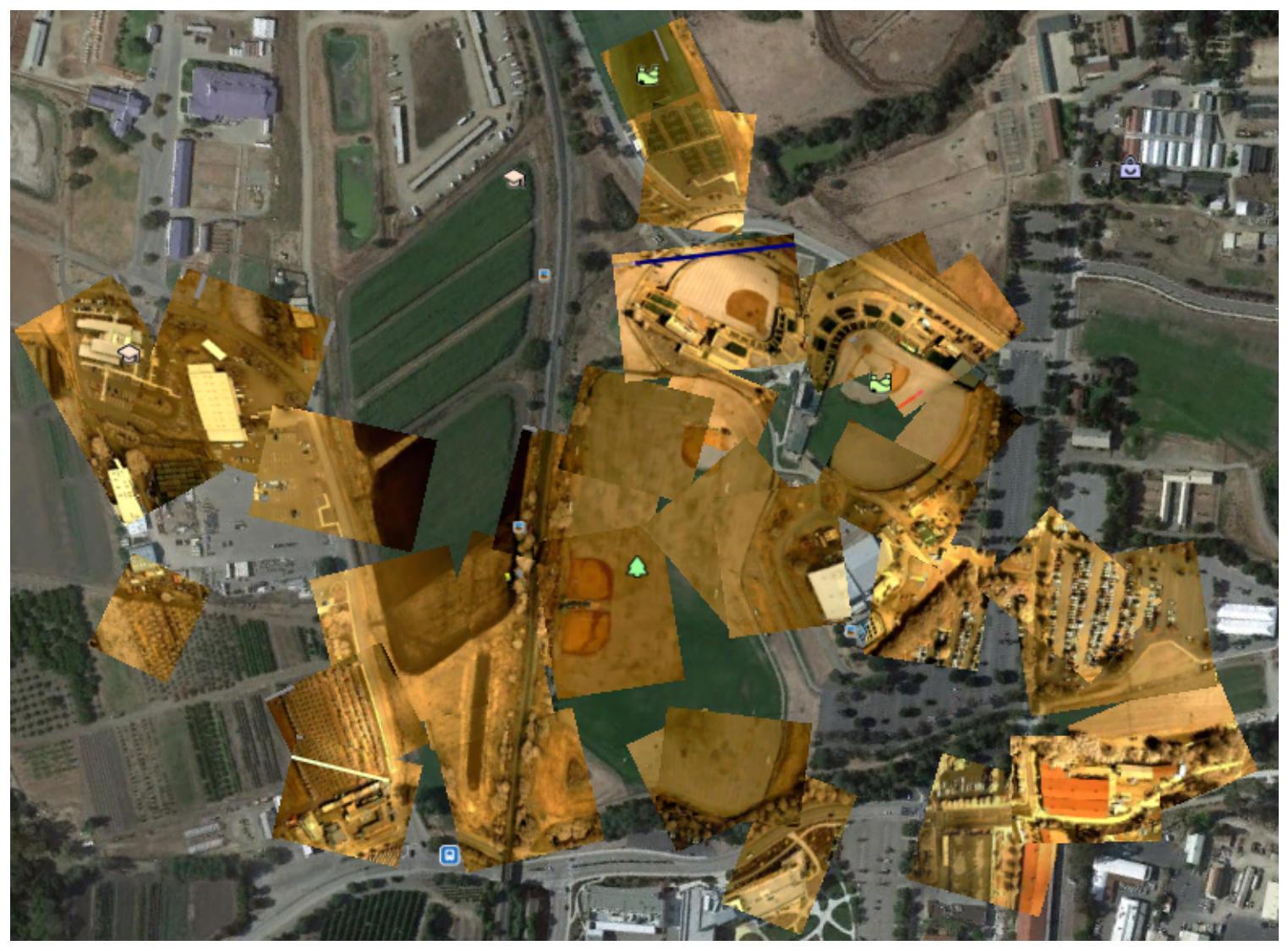

Figure 51: ORA Images Overlayed onto Google Earth

Another source of error contributing to the MRICE failure was having a human operator. In order to get images that have matching details, the aircraft needs to stay straight and level. It was extremely difficult to keep ORA straight and level at 
a $400 \mathrm{ft}$ altitude. In Figure 51, notice the tilted orientation of the top most baseball field with the purple line of distortion. If images are captured of the same plot of land at different attitudes, MRICE is not able to combine them. An autopilot would be a great addition for this aircraft in order to keep it straight, level and at a $400 \mathrm{ft}$ altitude. Figure 52 shows the altitude of the test flight and the difficulty of staying level at $400 \mathrm{ft}$.

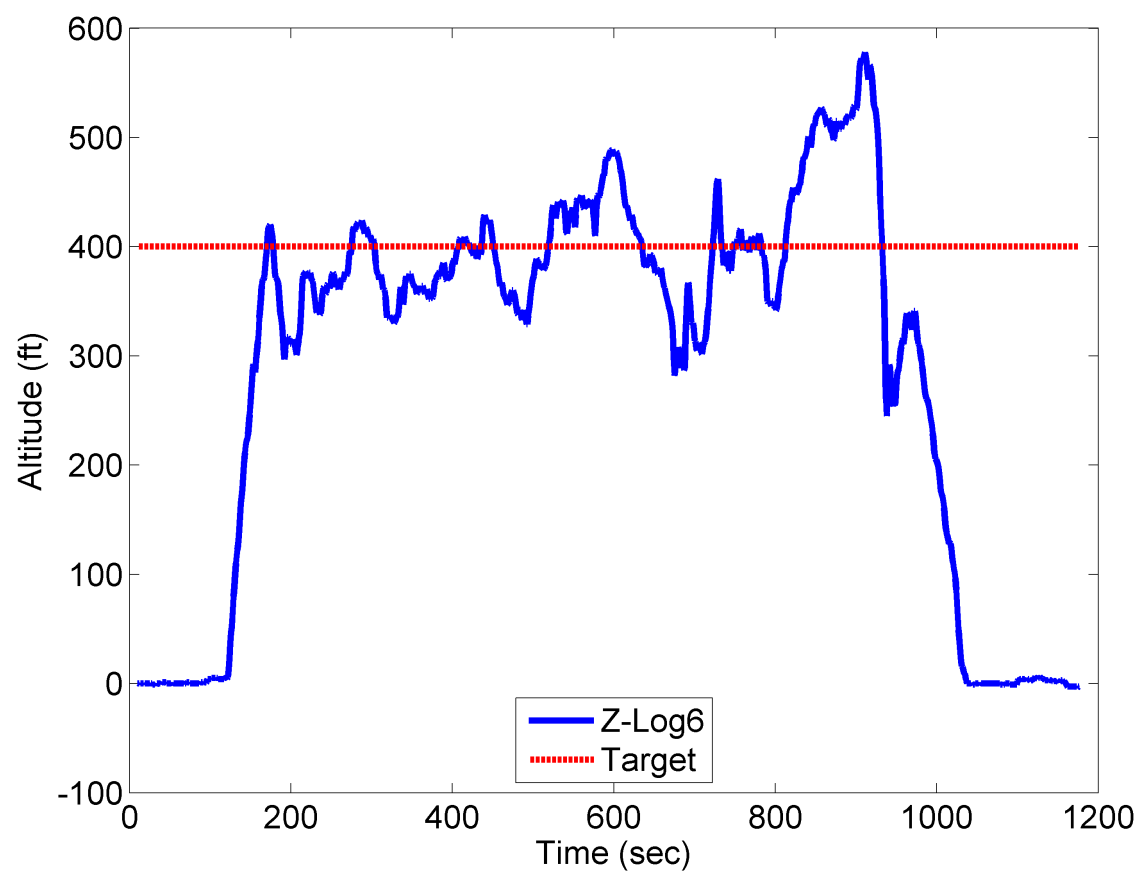

Figure 52: Test Flight Altitude

Relief distplacement is a characteristic of aerial images. Objects farther away from the nadir, or directly below the imager, lean away from the center of the image. This phenomenon can be seen at the corners of each image. Therefore when there is a small amount of detail overlap at the edges of pictures, MRICE cannot combine 
them because the same details have differing characteristics. Relief displacement contributed to the fact that MRICE needed much more than the edges of images to overlap in order to create a full composite map.

\subsection{Crash}

When conducting the second test flight with the imagers set on the low resolution setting, ORA crash landed into the Cal Poly library. Imaging the Cal Poly campus was not intended. While traveling from the orchards to the parking lot, the aircraft stopped receiving signals from the controller. It seemed like the receiver died. After conducting more research, the library may not have been such a coincidence after all. The Spektrum receiver runs on a $2.4 \mathrm{GHz}$ frequency signal. Almost everything wireless, from cell phones to routers to blue tooth devices, operate on the $2.4 \mathrm{GHz}$ band. The receiver is supposed to hop frequencies in the case that the $2.4 \mathrm{GHz}$ signal is crowded. However, it is possible that the receiver got bombarded with $2.4 \mathrm{GHz}$ noise and ignored the controllers signal. To show exactly how abruptly the aircraft went down, Figure 53 shows the altitude of the crash landing test flight.

One positive aspect of the crash landing was validating the protection requirement set on the external payload bay. After a nose dive that brutally harmed the airframe, the imaging hardware is still operational. However the damage was so severe that ORA will not have the ability to fly again. Figures 54 and 55 show the extent of the damge to the airframe and payload bay respectively. 


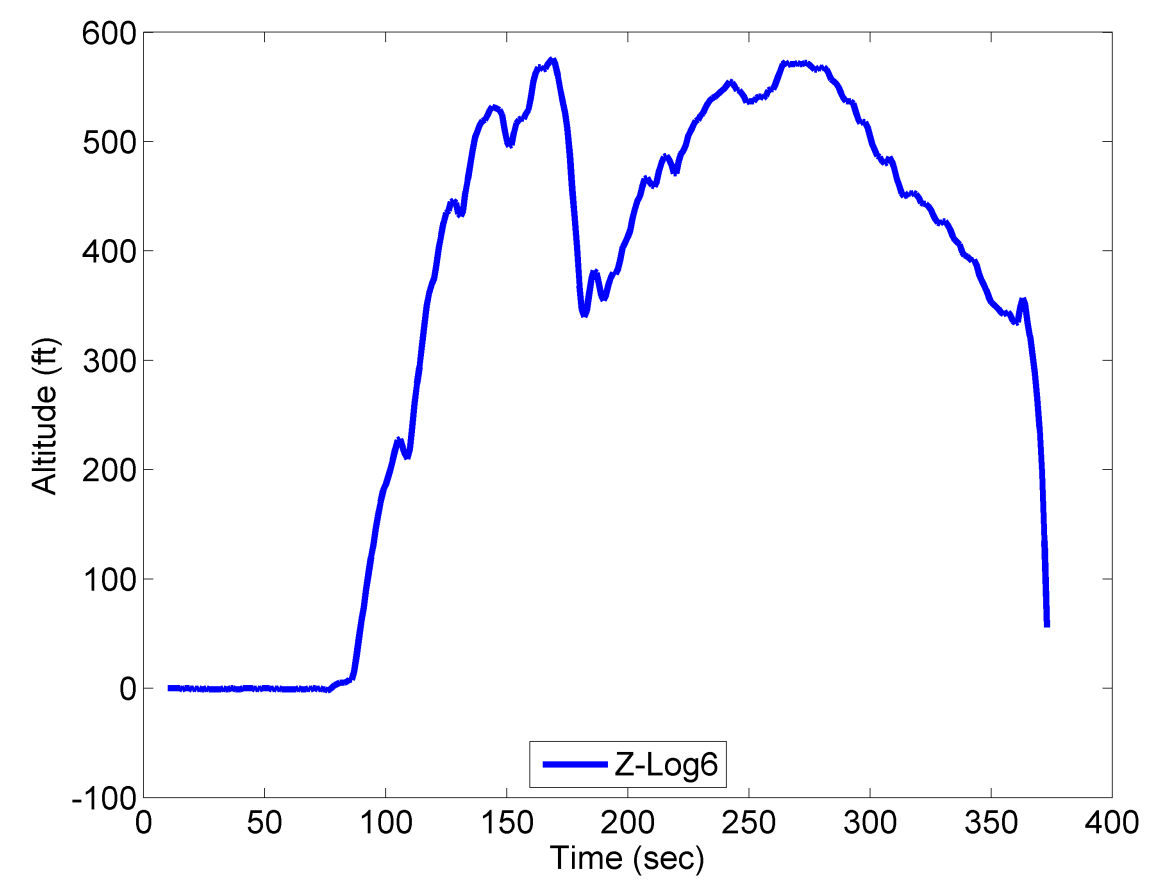

Figure 53: Crash Landing Flight Altitude

\subsection{Requirement Validation}

Requirements were placed on the aircraft and control system in order to maximize ease of operation while providing adequate performance. These requirements produced an aircraft that has the ability to be launched by an individual operator. The aircraft can be hand launched while operating the controller. In order for a single-handed launch to be possible, a requirement of 10 lbs was set on the system. ORA, with dual external payload bays containing imagers, weighs $2.5 \mathrm{lbs}$. Therefore the $10 \mathrm{lb}$ requirement was met with margin. Table 19 illustrates a weight breakdown for the airborne system. RC equipment includes the equipment needed for flight which encompases the receiver, altimeters, battery, servos, etc. 


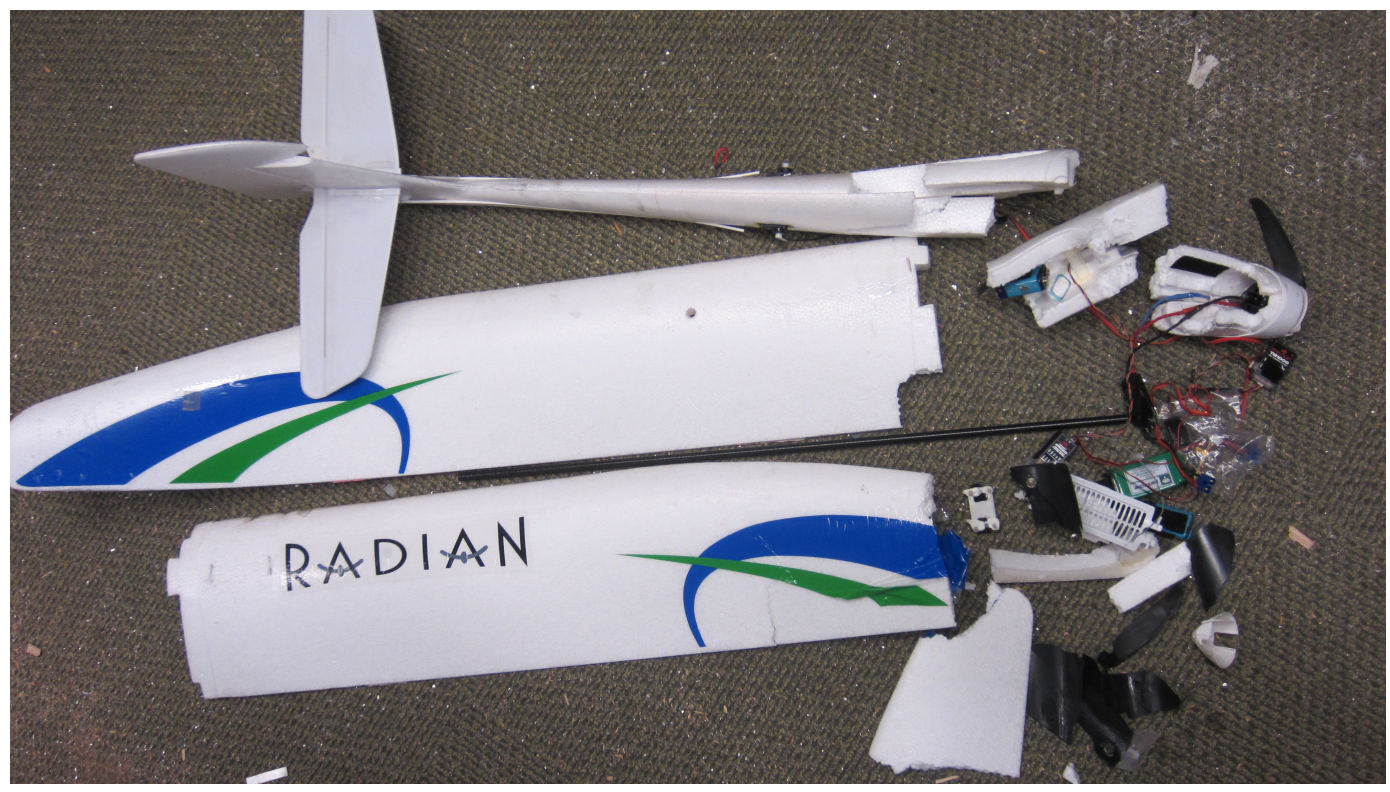

Figure 54: ORA Post Crash Landing

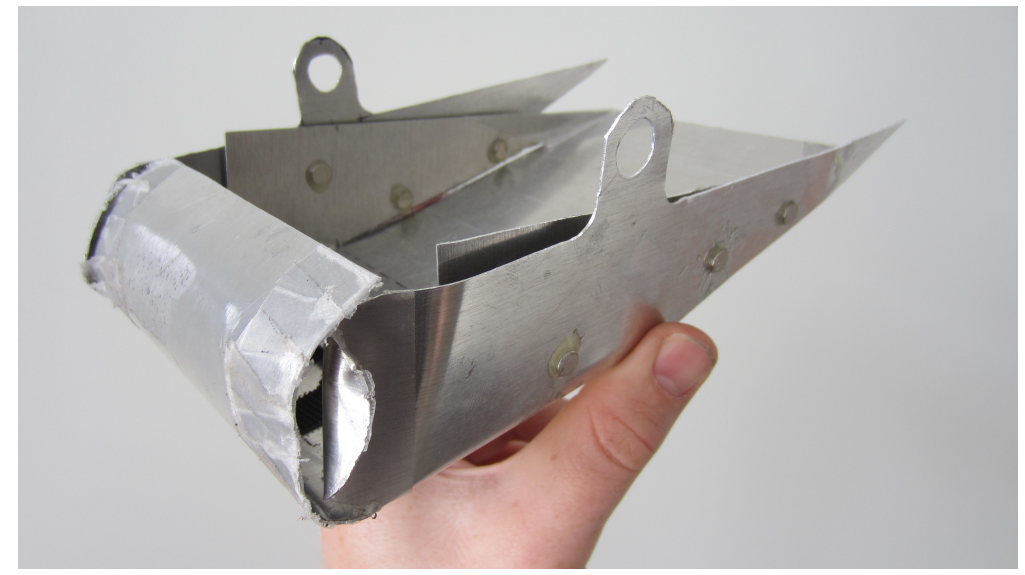

Figure 55: External Payload Bay Post Crash Landing

The GCS consists of a laptop and controller, for stiching the images together and piloting the aircraft respectively. Weights of various laptops will differ, but the one used for the test flight weighs $5.6 \mathrm{lbs}$. With the controller weighing $1.9 \mathrm{lbs}$, the total GCS weighs $7.5 \mathrm{lbs}$, much lower than the $25 \mathrm{lb}$ limit. ORA loaded with dual imaging payloads flying at $400 \mathrm{ft}$ had a wost case endurance of 15 minutes. The 
Table 19: ORA Weight Breakdown

\begin{tabular}{ccc}
\hline \hline Component & Weight (lb) & Quantity \\
\hline External Bay & 0.23 & 2 \\
Camera & 0.03 & 2 \\
Case & 0.03 & 2 \\
Arduino Uno & 0.05 & 2 \\
SD Shield & 0.06 & 2 \\
Airframe & 0.98 & 1 \\
RC Equipment & 0.69 & 1 \\
\hline Total & 2.46 & \\
\hline
\end{tabular}

ParkZone Radian specifications state a 30 minute endurance. Howver, the endurace will always be a function of the wind speed and how aggressively the aircraft is flown. Adding almost a pound to the plane decreased the endurance more than originally anticipated. The amount of energy expelled keeping the aircraft at $400 \mathrm{ft}$ was also under estimated. Purchasing a larger battery would be an easy solution to this problem, assuming the extra battery weight does not affect the system too adversely. Endurance may increase with an autopilot onbaord as well, again with the assumption that the extra weight is not too cumbersome. Making small corrections to stay at the desired altitude is more ideal for the battery compared to large manuevers by a human operator.

The requirement of costing less than $\$ 1,000$ is to ensure that the system is not too expensive for the individual consumer. The $\$ 1,000$ milestone was barely met. Table 20 is a cost breakdown of the system components. A 3-channel receiver, a battery and servos come with the Radian airframe. The controller used in this project is a high end model. Another less robust controller would work with the system, driving 
down the cost. The altimeters, which were vital to this project for verifying imaging accuracy, may not be needed as well depending on the application. The total cost of $\$ 921$ does not include tax or shipping.

Table 20: ORA Cost Breakdown

\begin{tabular}{ccc}
\hline \hline Component & Cost $(\$)$ & Quantity \\
\hline External Bay & 14 & 2 \\
Camera & 40 & 2 \\
Arduino Uno & 22 & 2 \\
SD Shield & 20 & 2 \\
Airframe & 250 & 1 \\
Controller & 300 & 1 \\
ZLog6 & 80 & 1 \\
Spektrum Altimeter & 99 & 1 \\
\hline Total & 921 & \\
\hline
\end{tabular}

Versatility is the basis behind the external payload bay requirements. With a volume of $500 \mathrm{~cm}^{3}$, the bay has the ability to accomodate other sensor packages as well as future upgrades. The imaging package, composed of an Arduino UNO, SD shield, and camera, can be removed and replaced with any self-contained sensor package, as long as they are within the limiting height and width of $4.1 \mathrm{~cm}$ and $11.0 \mathrm{~cm}$ respectively. See Chapter 3 for more details on the external payload bay dimensions. Determined through flight testing, the maximum takeoff gross weight of the Radian airframe is 5.3 lbs. The weight of ORA with empty external payload bays is $2.1 \mathrm{lbs}$. Therefore the airframe can accomodate a payload weight of $3.2 \mathrm{lbs}$. Keep in mind that a heavier payload leads to a shorter endurance. Also the CG location is a function of the payload weight. The weight needs to be evenly distributed port to 
starboard as well as fore to aft. The airframe has the ability to hold two rechargeable 9 volt batteries, one for each payload bay, in the cock pit. The batteries were placed as far forward as possible to mitigate the CG from being located behind the quarter cord of the wing. These 9 volts can be replaced with any battery that fits within the aircraft in order to power custom sensors.

The external payload bays can be changed out easily. The wing needs to be removed from the fuselage as well as the spar from the wing before the external bay can be pulled out. Detaching one payload bay and attaching the another can be completed in 2 minutes and 13 seconds, almost half of the required time. The aft compartment of the external bay has the ability to be removed allowing access to the SD card. In order to produce a composite map of all the images taken, the SD card needs to be removed and inserted into a laptop with Microsoft Research Composite Image Editor. As Section 7.2 illustrates, the production of the composite map could not be completed with the images captured in the test flight. Therefore both the requirements of producing one composite map and making it accessible within 10 minutes were not met.

The imager met the NIIRS level 4 requirement. This was set in place to ensure a herd of cattle can be identified. One future upgrade that would benefit the imaging system is the incorporation of an autopilot with GPS. The arduino and camera are connected in a way where the serial ports are free for future integration of a GPS module for stamping altitude and attitude on each image. This would enable scaling 
of images and relief displacement correction.

The camera is recessed within the external payload bay and adequately protected. There are no protruding elements of the imaging system that can be damaged when landing. After ORA's crash landing, each imager was still fully operational. The requirement of adaquate protection for the hardware was proven first hand. Table 21 shows all the requirements and their status.

Table 21: Requirement Validation

\begin{tabular}{ccc}
\hline \hline Criteria & Requirement & Status \\
\hline \hline System & Produce One Composite Image & Failed \\
& Ability to Accomodate Various Sensors & Accomplished \\
\hline ORA & Operatable by 1 person & Accomplished \\
& Weigh Less than 10 lbs & Met with Margin \\
& Endurance of 20 Minutes & Failed \\
& Max Altitude of at Least 400 ft & Accomplished \\
& Cost Less than $\$ 1,000$ & Met with Margin \\
\hline GCS & Weigh Less than 25 lbs & Met with Margin \\
\hline Payload Bay & Ability to Accomodate Various Sensor Layouts & Accomplished \\
& Changed Out within 5 Minutes & Met with Margin \\
& Adequate Hardware Protection During Landing & Accomplished \\
\hline Imaging System & NIIRS Level 4 & Accomplished \\
& Map Accessible within 10 Minutes of Landing & Failed \\
& Allow For Future Upgrades & Accomplished \\
\hline \hline
\end{tabular}




\section{Final Remarks}

\subsection{Conclusions}

ORA, the ISR UAV developed in this project, utilizes dual aluminum external payload bays attached to a ParkZone Radian aircraft. The bays were designed to hold an imaging payload which produces a composite map of the land surveyed. The imaging system incorporates an Arduino Uno, SD Shield, as well as a CMOS camera and board. The Arduino processor saves individual images to an SD card. Once the aircraft has landed, the operator combines the images with the Microsoft Research Image Composite Editor to create an individual composite map. This imaging payload has a NIIRS value of $4.0+/-0.4$, which is equivalent to identifying a basketball court within a residential environment.

Each external payload bay can contain approximately $500 \mathrm{~cm}^{3}$, with a height and width limit of $4.1 \mathrm{~cm}$ and $11.0 \mathrm{~cm}$ respectively. ORA with dual payload bays can accomodate any payload that fits within the bay and weighs less than a combined 3.2 lbs. ORA was designed for use by academic institutions, individual consumers, future customers new to the UAS industry, as well as anybody trying to get airtime for custom sensors. Possible payloads that can be accomodated by ORA include but are not limited to a Geiger counter, atmospheric sensors and communication relay devices. 
ORA accompanied with the EO imaging payload can be utilized in many applications. A cattle farmer would be able to have their land surveyed in order to produce a map illustrating the location of their grazing cows. ORA has the ability to assist in diagnosing power-outage problems by flying over power lines and locating issues. It can identify injured individuals on biking or hiking trails. ORA can also survey a recently extinguished forest fire and highlight locations emmiting smoke, signifying possible areas where the fire will be reignited. Any mission needing visual ISR over a larger area is ideal for the fixed wing ORA.

If individuals want to develope their own sensors for air operations, ORA is versatile enough to accomodate certain sized sensor packages. Academia instructing on remote sensing can utilize this system as an inexpensive learning tool for students. Individuals needing an eye in the sky do not need to resort to expensive drones developed for the military. A researcher investigating the interaction between a fresh water river feeding into the ocean can use ORA to provide visualizations of the mixing water and, with an IR camera upgrade, maybe even water temperature. For people that are new to the aerospace industry, ORA may be a powerful learning tool. After flying this aircraft, one will quickly determine the flight and optical performance necessary for their mission. 


\subsection{Future Work}

\subsubsection{Autopilot}

Incorporating an autopilot to replace the pilot in the loop would be a great advancement for this system. Two shortcomings of this project, the diminished endurance and the failure to produce a composite map, would be aided by including an autopilot. With a human in the loop, it was extremely difficult to keep the aircraft straight and level at $400 \mathrm{ft}$. Large manuevers were executed everytime the plane strayed away from the target altitude. If an autopilot was in the loop, smaller more consistent aircraft manuevers would be executed which may save battery life. The consistency of the autopilot may also help the composite map production by providing a straight and level imaging platform at a consistent altitude.

In order to get ORA to a point where it is able to be operated by consumers without prior avation knowledge, an autopilot is needed. The ArduPilot is an Arduino compatible UAV controller with an ATMega328. It requires a GPS module and infrared $\mathrm{X}, \mathrm{Y}$ and $\mathrm{Z}$ rangefinders to create a functioning UAV. It handles both stabilization as well as navigation and supports a "fly-by-wire" mode that can stabilize the aircraft when flying manually under RC control. Also multiple 3D waypoints can be input by the user. ${ }^{42}$ ArduPilot would be a great, easy, open-source solution for an autopilot. 


\subsubsection{GPS Image Tagging}

The GPS module that would accompany an autopilot would give opportunities for a more robust version of the software. The serial ports on the Arduino Uno are unoccupied for this exact purpose. With a GPS module on-board, the location and orientation may be written to each image through the serial ports. Data like altitude and orientation would be extremely useful for scaling and correcting distorted images respectfully. With a GPS coordinate pinned to every picture, a more accurate composite map may be produced. Each image would be placed in its specified location eliminating the need for Microsoft Research Composite Image Editor and overlapping details to manufacture a composite map.

\subsubsection{Imaging Upgrades}

Zoomed Imager

The dual imaging payloads are ideal for separate cameras operating with different levels of zoom. Under one wing, a system can capture wide-angle context images. Under the other wing, a separate imaging payload with a narrow-angle field of view can operate producing more detailed images. This would be extremely useful if there were certain locations that were of high interest. With a GPS module writing location to each picture, these high-detailed points of interests can be placed either directly on the map or off to the side with a label and arrow illustrating its location on the map. 


\section{Infrared Imager}

Another imaging upgrade that would benefit the system is the incorporation of an IR camera. This would allow night operation (with a FAA permit). Also an IR imager would be great for the mission of identifying hot spots within extinguished forest fires. Currently the forset service marches through recently extuinguished areas with handheld IR sensors looking for fires nestled from sight. Embers within a hollow tree trunk is a good example. ORA, fitted with an IR imager under one wing and a context imager under the other, would have the ability to overlay heat values from the IR camera on top of a composite map of the forest fire. This would allow the forest service to manage their time and man power more efficiently.

The swap out of a visible to IR imager is relatively straight forward. However, the most intimidating aspect of IR imagers is the price tag. A similar, less robust, result can be reached through software and image processing. The EO camera in ORA's imaging payload captures a wide spectrum of wavelengths. The wavelengths can be isolated allowing the measurement of intensities. Laying a contour of the IR wavelengths' intensities over a composite map would accomplish the same goal, with less fidelity, as a high performance IR imager. 
Bibliography

[1] Arjomandi, D. M., "Classification of Unmanned Aerial Vehicles," http://personal.mecheng.adelaide.edu.au/maziar.arjomandi/Aeronautical2006.

[2] "UAV Platform Categories," http://uavbusinessreview.com/platform-categories, Nov 2011.

[3] AeroVironment, "Family of Small UAS," http://www.avinc.com/uas/small_uas/, 2012.

[4] Army-Technology, "Shadow RQ-7 Tactical Unmanned Aircraft System, United States of America," http://www.armytechnology.com/projects/shadow200uav/, 2012.

[5] Wheeler, W., "Global Hawk: Thar She Blows," http://www.armytechnology.com/projects/shadow200uav/, Mar 2012.

[6] DefenseTech, "ItsyBitsy Drone," http://defensetech.org/2005/04/05/itsy-bitsydrone/, April 2005.

[7] UTC, "Puma AE: An All Environment Mini-UAV," http://defensetech.org/2005/04/05/itsy-bitsy-drone/, July 2013. 
[8] Turkish Central News String, "Aerial Vehicle Tactical Control System," http://turkishcentralnews.com/2013/05/05/surveillance-and-reconnaissance2013.

[9] Wikipedia, "Northrop Grumman RQ-4 Global Hawk," http://en.wikipedia.org/wiki/Northrop_Grumman_RQ-4_Global_Hawk, July 2013.

[10] Defense Industry Daily, s., "From Dolphins to Destroyers: The ScanEagle UAV," http://www.defenseindustrydaily.com/from-dolphins-to-destroyersthe-scaneagle-uav-04933/, Nov 2012.

[11] Insitu, "ScanEagle System," http://www.insitu.com/systems/scaneagle, 2012.

[12] Wired, "Boeing's Best-Selling Aircraft Fits on Your Shoulder," http://www.wired.com/autopia/2009/08/boeing-uav/, Aug 2009.

[13] USAF, "SCAN EAGLE," http://www.af.mil/information/factsheets/factsheet.asp?id=10468, Sept 2011.

[14] Air Force, U. S., "Bat Unmanned Aerial Vehicle, United States of America," http://www.airforce-technology.com/projects/northropgrummanbat/, 2012.

[15] Northrop-Grumman, "Bat UAS," July.

[16] UAS-Technologies, "Silent Falcon," http://www.silentfalconuas.com/Silent_Falcon_spec_sheet.1 2012. 
[17] UAS-Technologies, "Falcon Vision," http://www.silentfalconuas.com/falconvision_spec_sheet.p 2012.

[18] MLB-Company, "V-Bat UAV," http://spyplanes.com/wpcontent/uploads/2012/08/V-Bat-Brochure_2012.pdf, 2012.

[19] Army-Technology, "RW-11 Raven Unmanned Aerial Vehical, United States of America," http://www.army-technology.com/projects/rq11-raven/, Jan 2012.

[20] Time, "RW-11 Raven Drone," http://www.time.com/time/specials/packages/article/0,28804,2 June 2011.

[21] "Falcon-UAS," http://www.falcon-uav.com/, 2012.

[22] "Current Falcon UAS Price List," http://www.falcon-uav.com/pricing/, 2012.

[23] Platoni, K., "That's Professor Global Hawk," Air 83 Space Magazine, May 2011, http://www.airspacemag.com/flight-today/Thats-Professor-Global-Hawk.html.

[24] Honeywell, "Honeywell T-Hawk Unmanned Aerial Vehicle Reaches 10,000th Flight Milestone," http://www.honeywellnow.com/2010/06/18/honeywell-thawk-unmanned-aerial-vehicle-reaches-10000-flight-milestone/, June 2008.

[25] Unmanned, "MD4-1000 Unmanned Aerial Vehicle (UAV) Specifications and Data Sheet," http://www.unmanned.co.uk/autonomous-unmannedvehicles/uav-data-specifications-fact-sheets/md4-1000-unmanned-aerial-vehicleuav-specifications-and-data-sheet/, 2011. 
[26] Chiles, J. R., "Drones for Hire," Air 83 Space Magazine, Jan

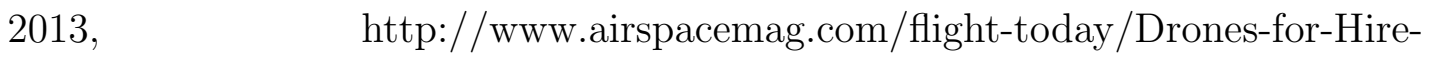
179517781.html?c=y\&story=fullstory.

[27] "TTL Serial Camera Technical Details," http://www.adafruit.com/products/397.

[28] Thurman, S. T. and Fienup, J. R., "Analysis of the general image quality equation," Proceedings of the 2008 SPIE Workshop, The Institute of Optics, University of Rochester, Rochester, NY 14627, May 2008.

[29] "Tutorials Products Camera," http://www.ladyada.net/wiki/tutorials/products/camera/index Mar 2012.

[30] Arduino, "Arduino Uno R3," http://arduino.cc/en/Main/arduinoBoardUno, 2013.

[31] Adafruit, "Adafruit Data Logging Shield for Arduino," http://www.adafruit.com/products/243.

[32] Parkzone, "Parkzone Radian EP Glider," http://www.perthrc.com.au/parkzoneradian-ep-glider-rtf.html.

[33] Spektrum, "TM1000 DSMX Full-Range Telemetry Module," http://www.spektrumrc.com/Products/Default.aspx?ProdID=SPM9548, 2012. 
[34] HexpertSystems, "ZLog 6ZR Manual," http://www.hexpertsystems.com/zlog/install/Z6RManual.pdf, 2011.

[35] Cosmos, "Real Image," http://astronomy.swin.edu.au/cosmos/R/real+image.

[36] Shimpi, A. L. and Gowri, V., "iPad Mini Review," http://www.anandtech.com/show/6429/ipad-mini-review/9, Nov 2012.

[37] Cambridge, "Understanding Camera Lenses," http://www.cambridgeincolour.com/tutorials/camera-lenses.htm.

[38] Blonski, S., Ross, K., Pagnutti, M., and Stanely, T., "Spatial Resolution Characterization for Aerial Digital Imagery," Tech. rep., NASA, Stennis Space Center, 2006 Civil Commercial Imagery Evaluation Workshop, Laurel, MD.

[39] Kim Taejung, Kim Hyunsuk, K. H., "Image-Based Estimation and Validation of NIIRS For High-Resolution Satellite Images," Tech. rep., Inha University, Republic of Korea and Korea Aerospace Research Institute.

[40] Photometrics, "High Performance EMCCD \& CCD Cameras for Life Sciences: Gain," http://www.photometrics.com/resources/learningzone/gain.php, 2013.

[41] "Imagery Resolution Assessments and Reporting Standards Committee: Civil NIIRS Reference Guide," http://www.fas.org/irp/imint/niirs, Mar 1996.

[42] Sparkfun, "ArduPilot," https://www.sparkfun.com/products/8785, 2013. 


\section{A MATLAB and Arduino Code}

Available upon request. E-mail crburt@calpoly.edu. 
B Images for NIIRS Evaluation

Table 22: Image 1 NIIRS Data

\begin{tabular}{cc}
\hline \hline Criteria & Value \\
\hline Altitude & $409 \mathrm{ft}$ \\
GSD & $15.6 "$ \\
RER & 0.191 \\
H & 0.822 \\
\hline
\end{tabular}

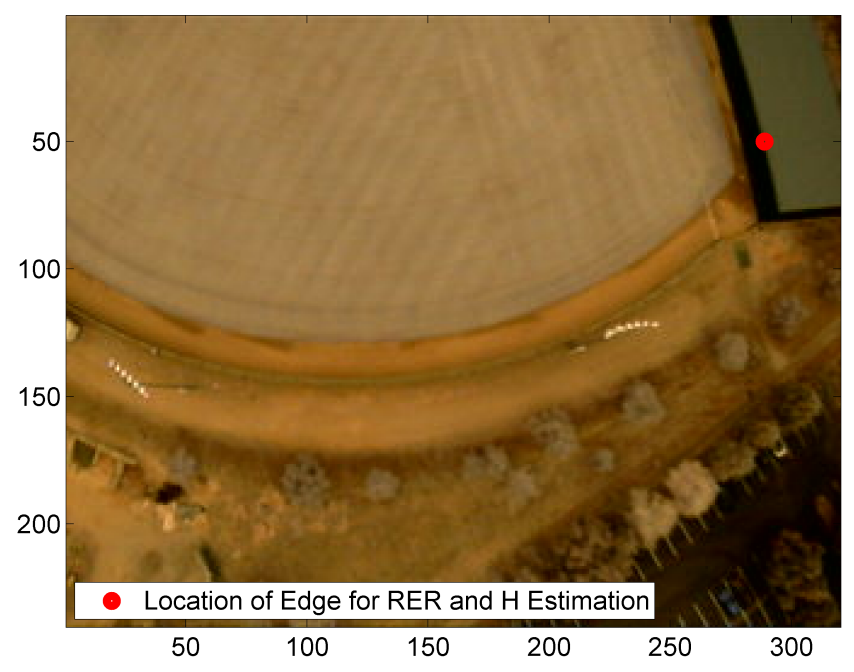

Figure 56: Image 1 


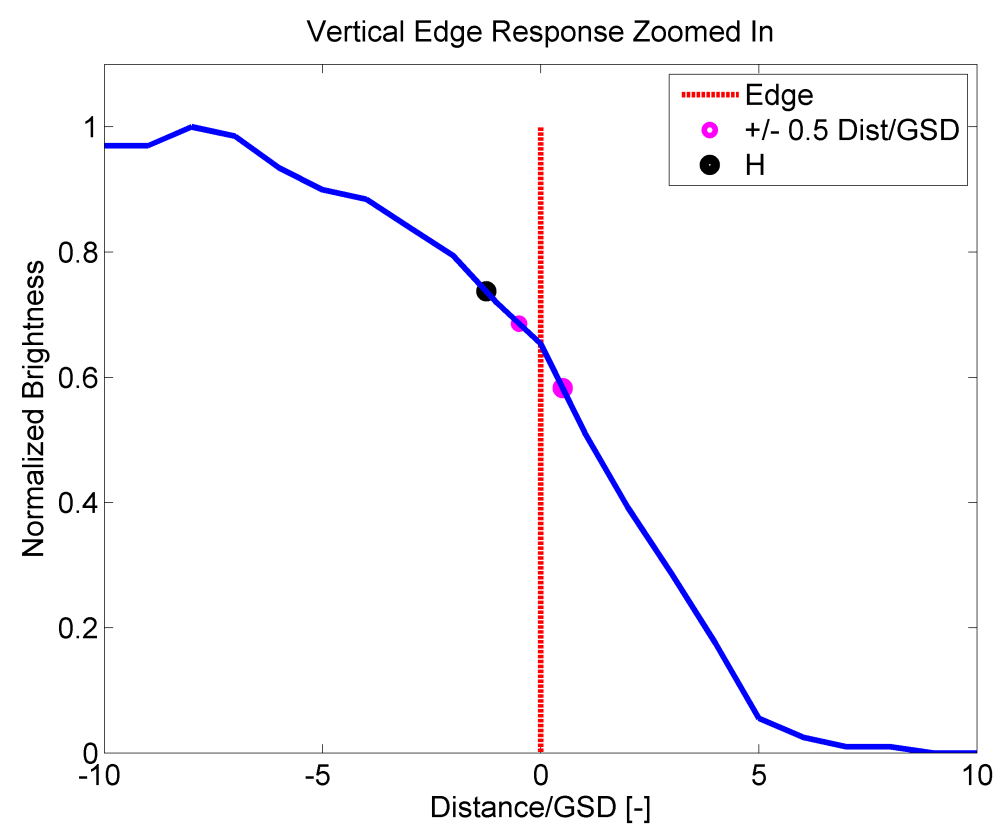

Figure 57: Vertical Edge Response for Image 1

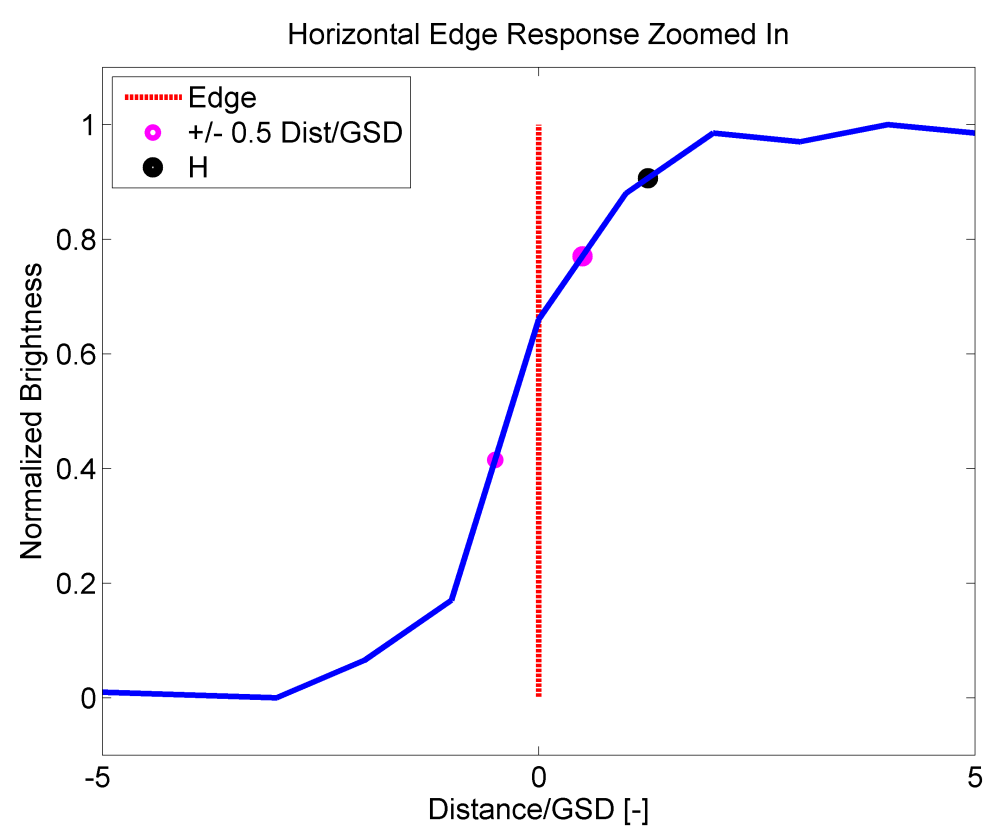

Figure 58: Horizontal Edge Response for Image 1 
Table 23: Image 2 NIIRS Data

\begin{tabular}{cc}
\hline \hline Criteria & Value \\
\hline Altitude & $392 \mathrm{ft}$ \\
GSD & $15.9 "$ \\
RER & 0.194 \\
H & 0.864 \\
\hline
\end{tabular}

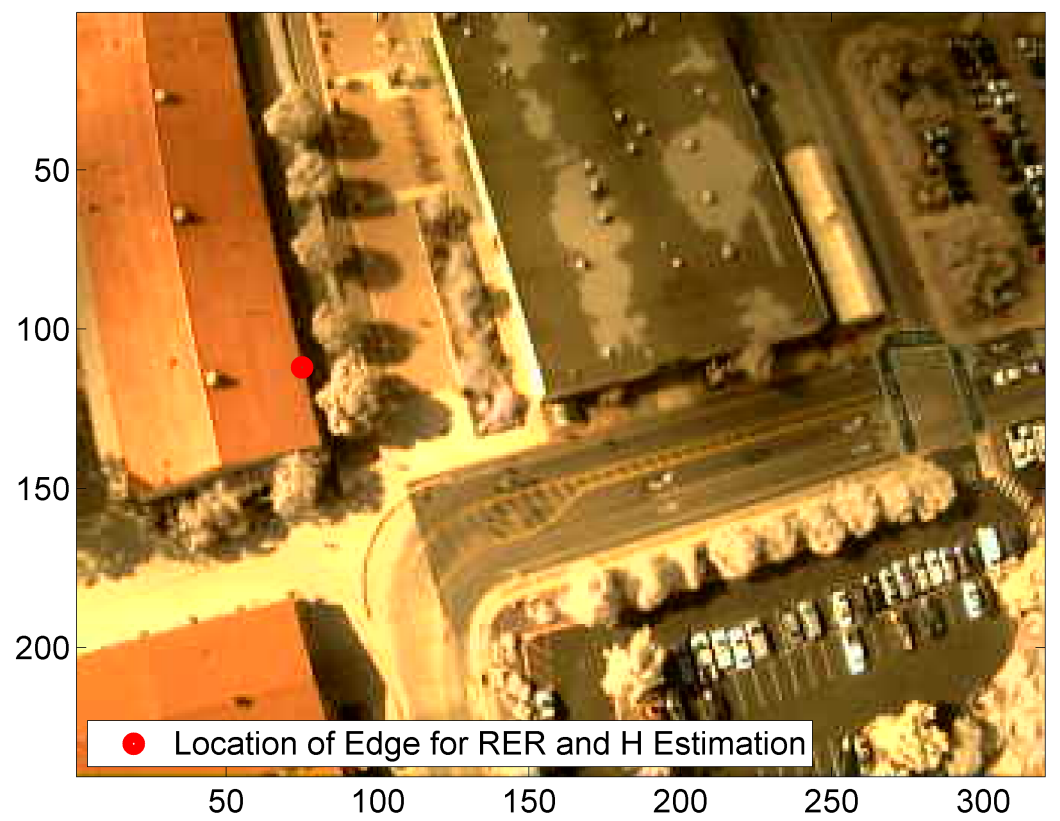

Figure 59: Image 2 


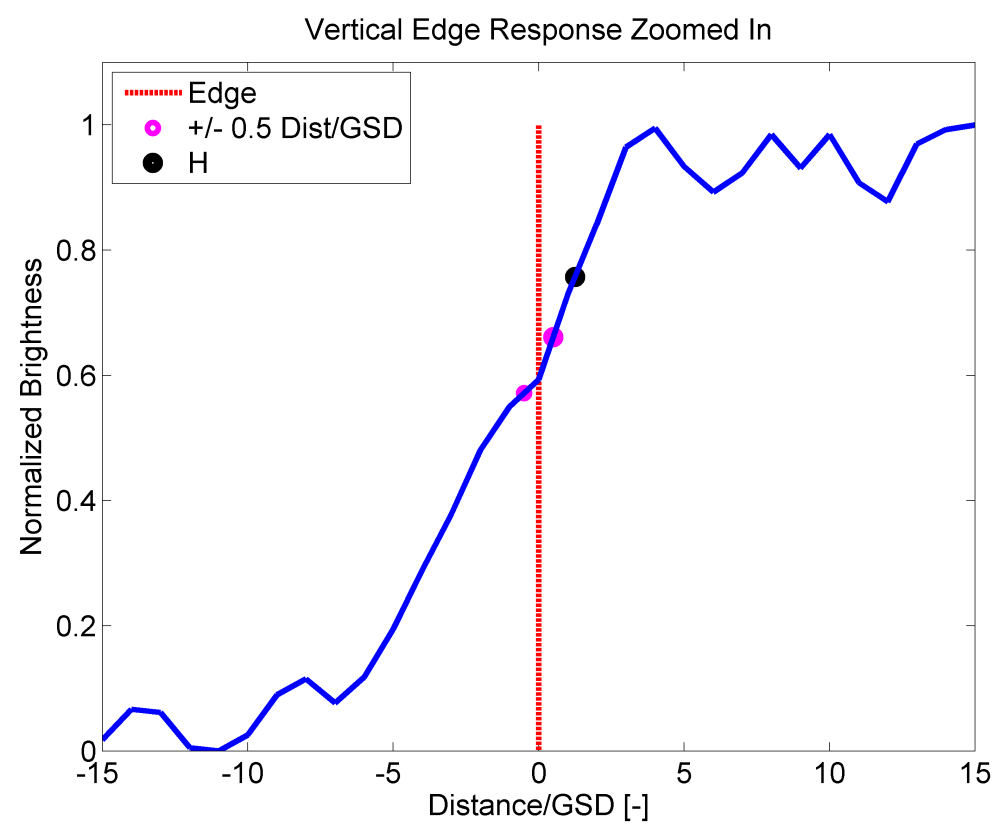

Figure 60: Vertical Edge Response for Image 2

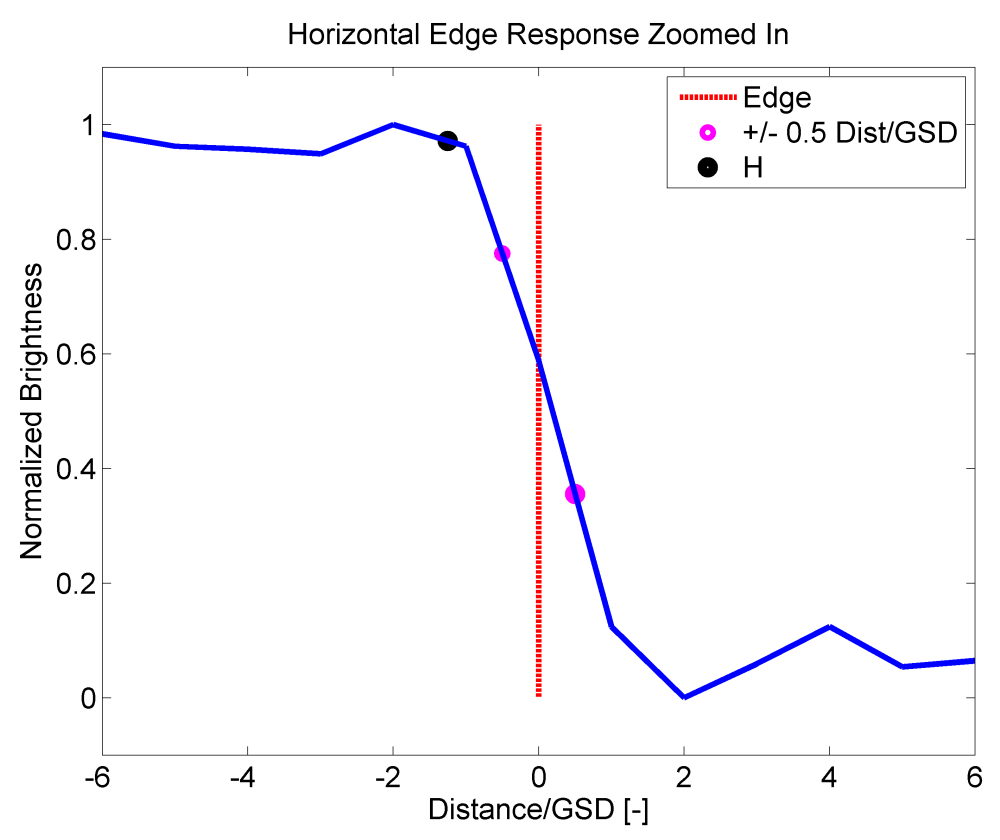

Figure 61: Horizontal Edge Response for Image 2 
Table 24: Image 3 NIIRS Data

\begin{tabular}{cc}
\hline \hline Criteria & Value \\
\hline Altitude & $408 \mathrm{ft}$ \\
GSD & $14.6 "$ \\
RER & 0.160 \\
H & 0.651 \\
\hline
\end{tabular}

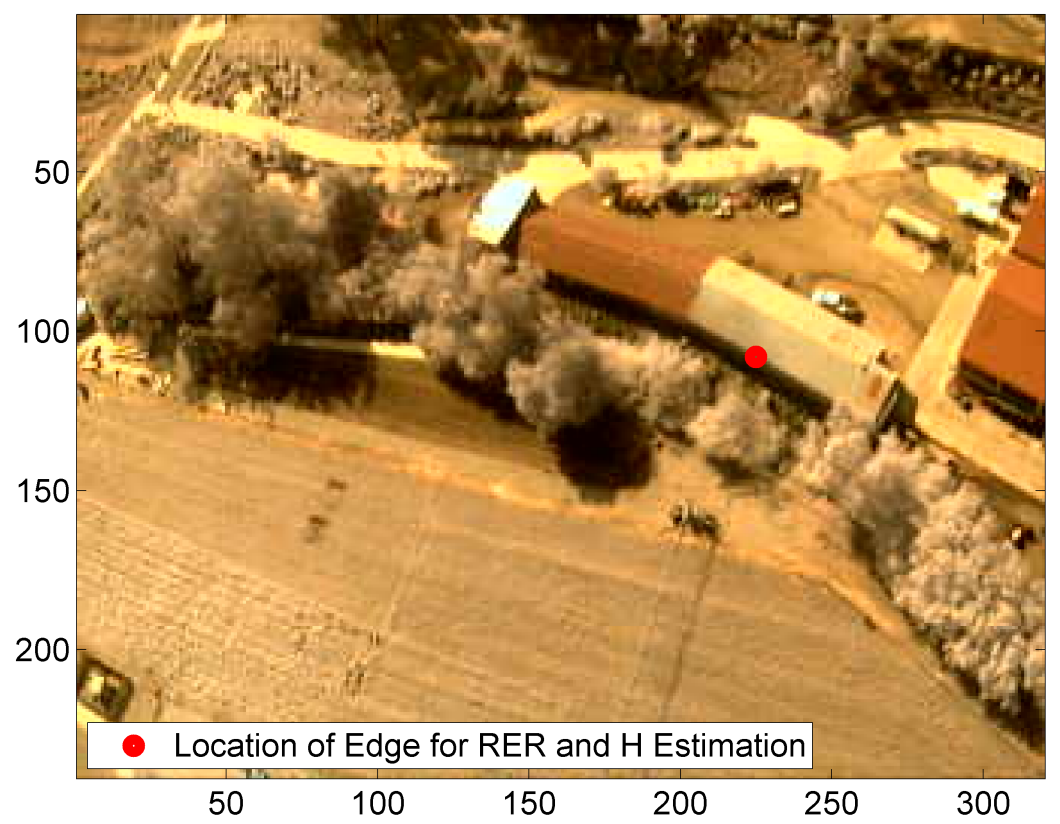

Figure 62: Image 3 


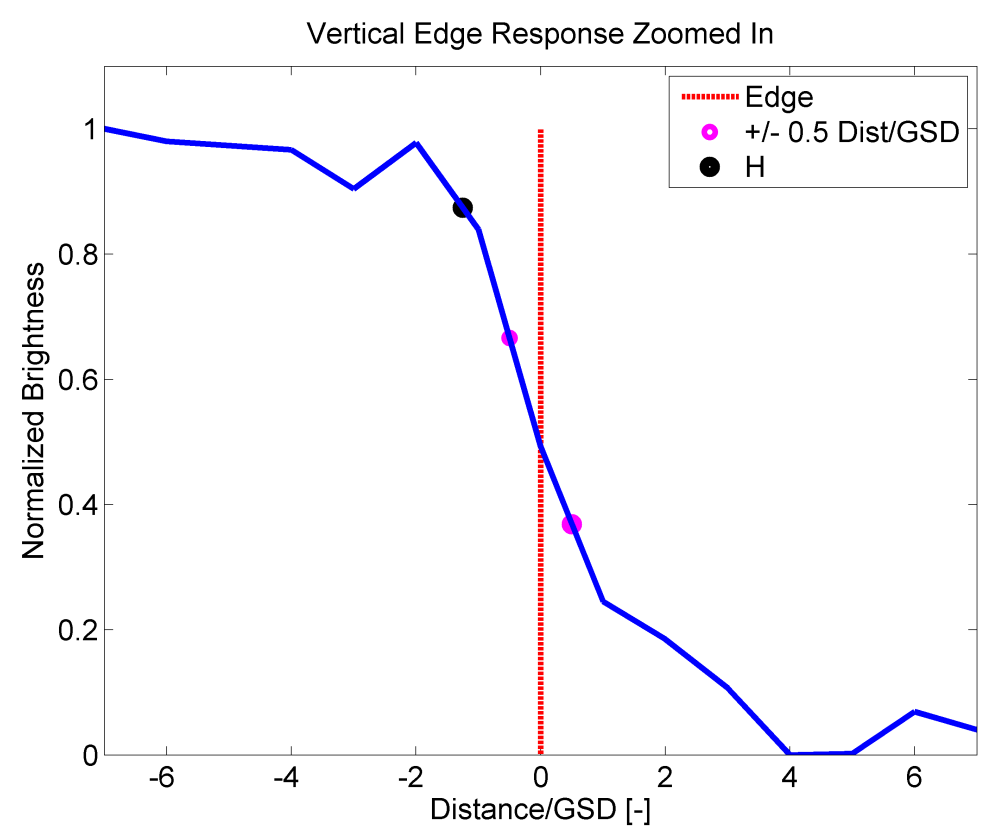

Figure 63: Vertical Edge Response for Image 3

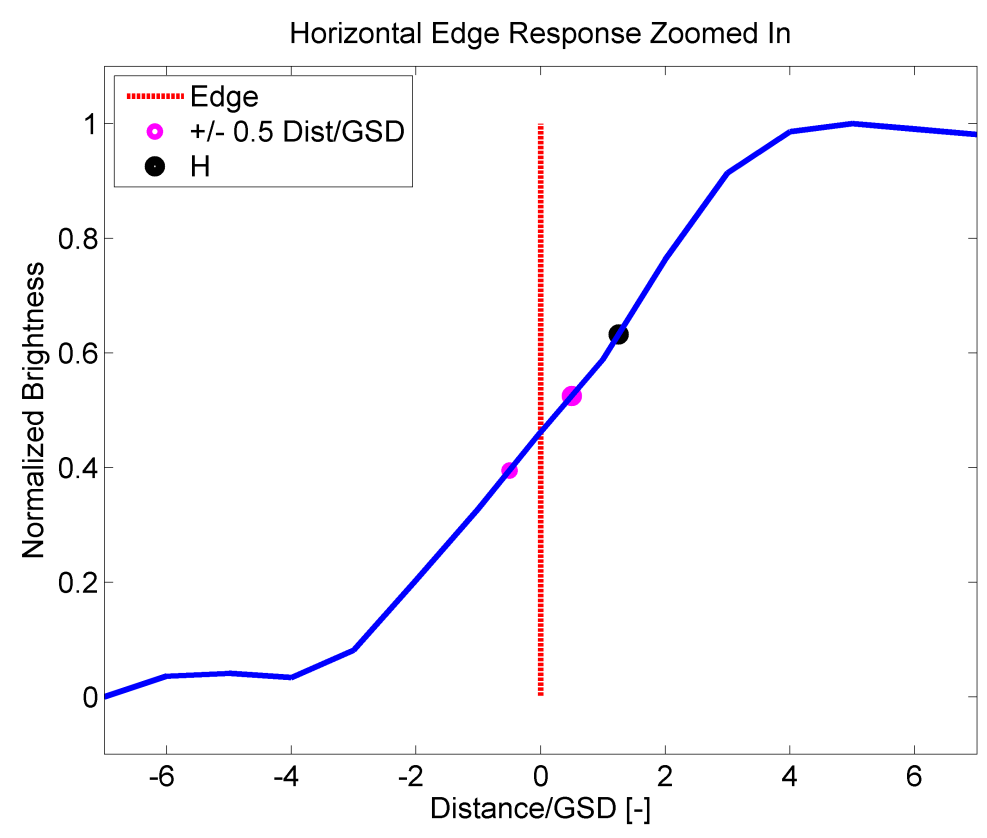

Figure 64: Horizontal Edge Response for Image 3 
Table 25: Image 4 NIIRS Data

\begin{tabular}{cc}
\hline \hline Criteria & Value \\
\hline Altitude & $409 \mathrm{ft}$ \\
GSD & $16.0 "$ \\
RER & 0.193 \\
H & 0.766 \\
\hline
\end{tabular}

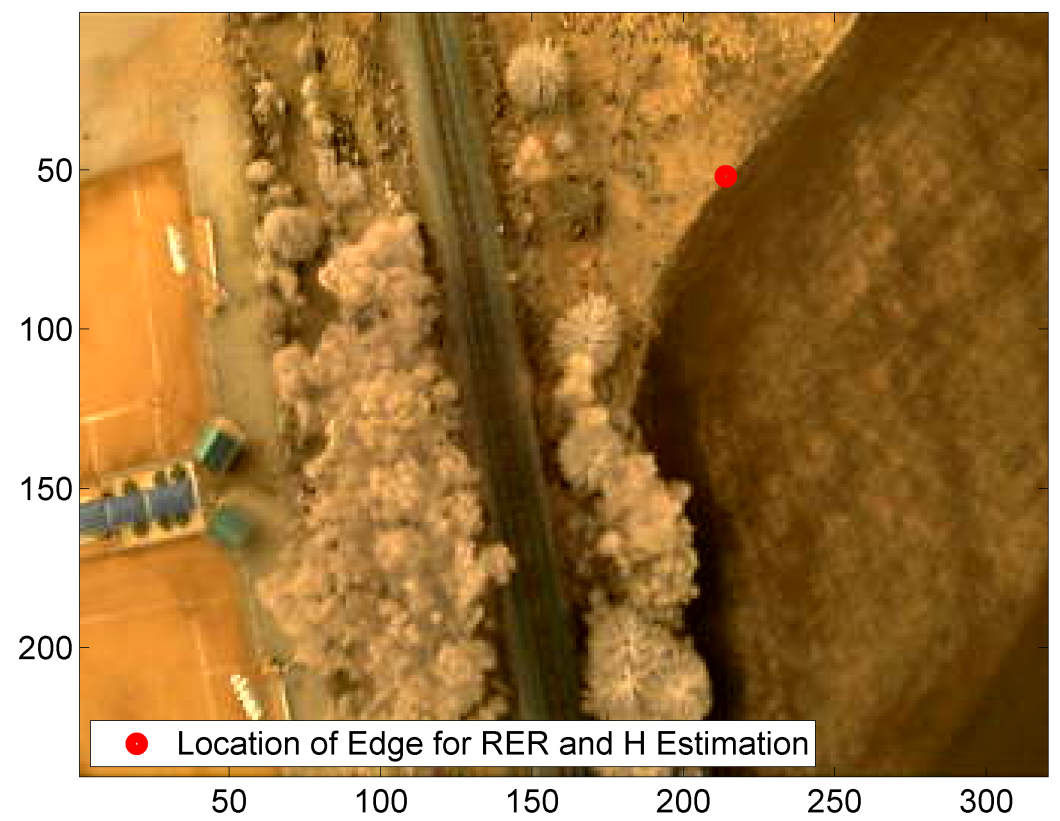

Figure 65: Image 4 


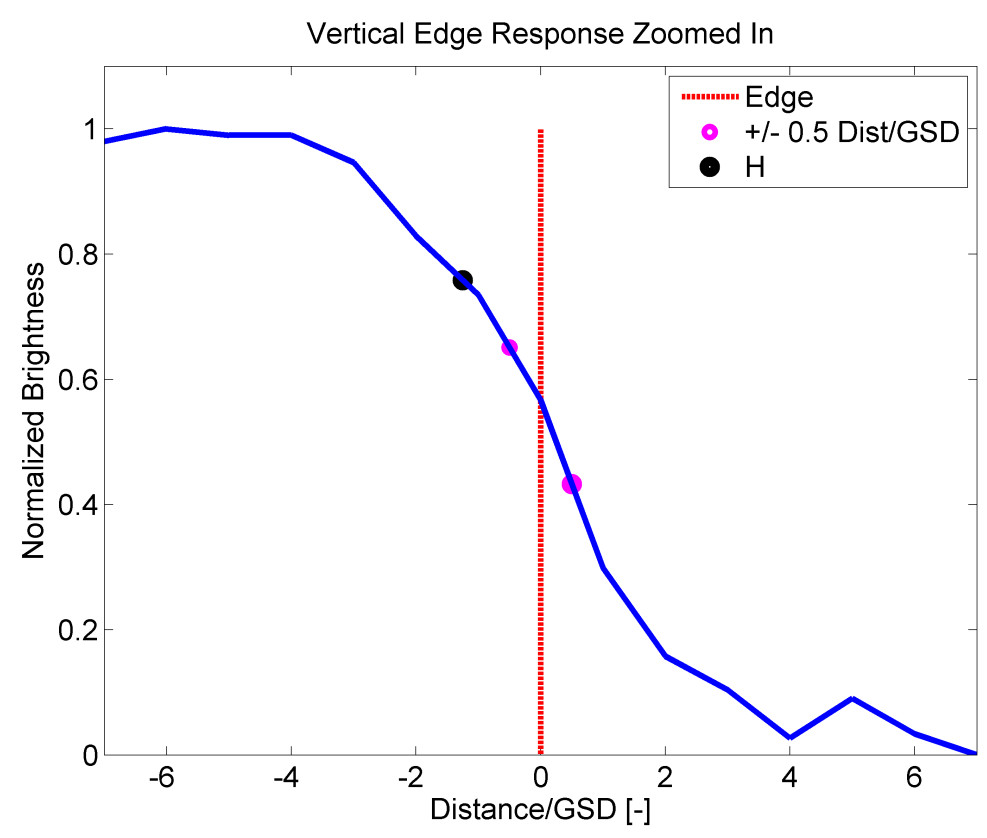

Figure 66: Vertical Edge Response for Image 4

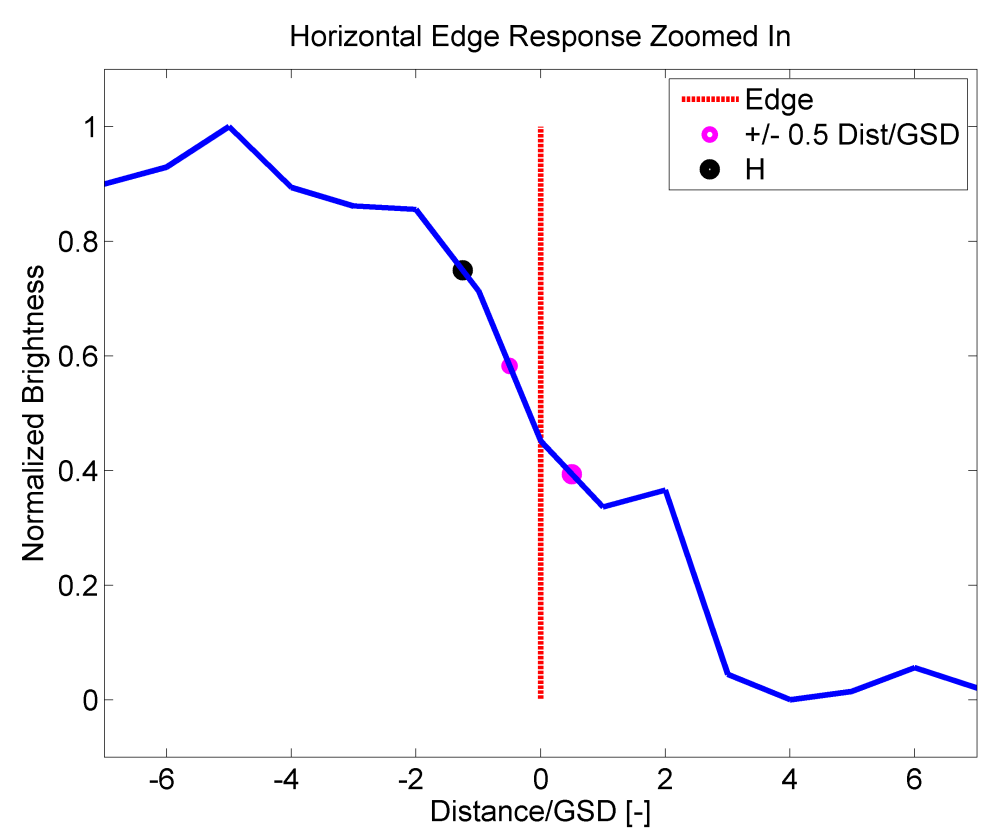

Figure 67: Horizontal Edge Response for Image 4 
Table 26: Image 5 NIIRS Data

\begin{tabular}{cl}
\hline \hline Criteria & Value \\
\hline Altitude & $409 \mathrm{ft}$ \\
GSD & $16.0 "$ \\
RER & 0.193 \\
H & 0.766 \\
\hline
\end{tabular}

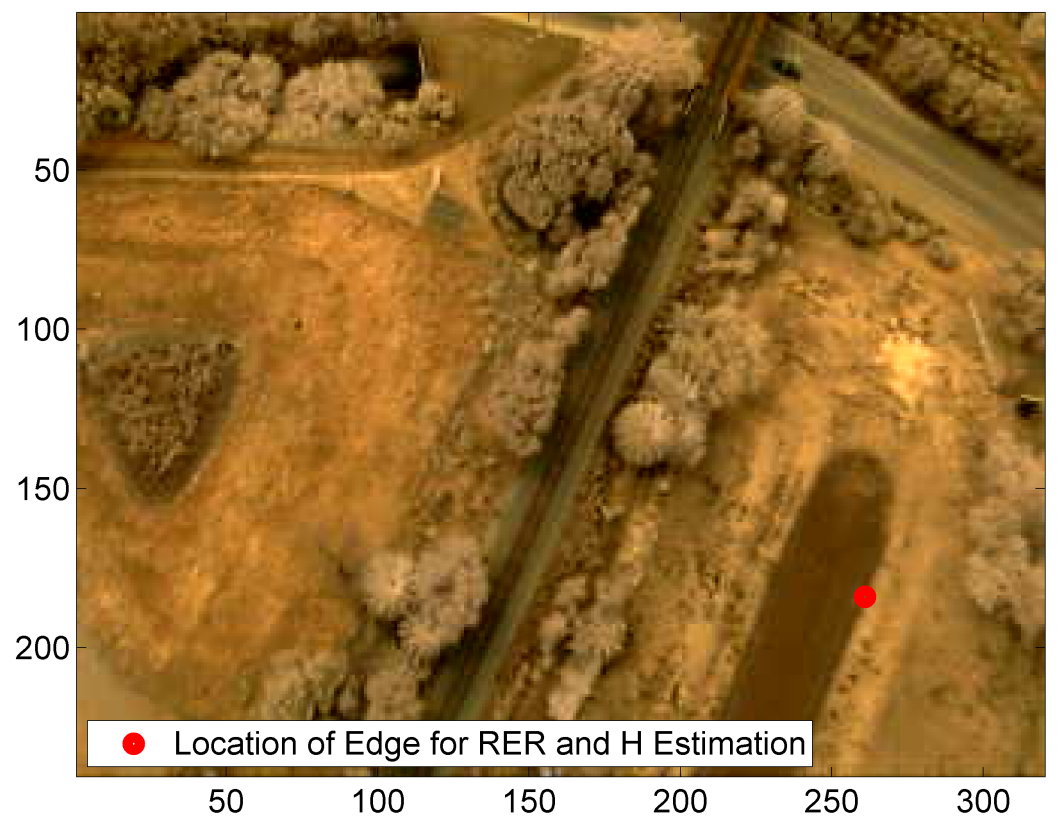

Figure 68: Image 5 


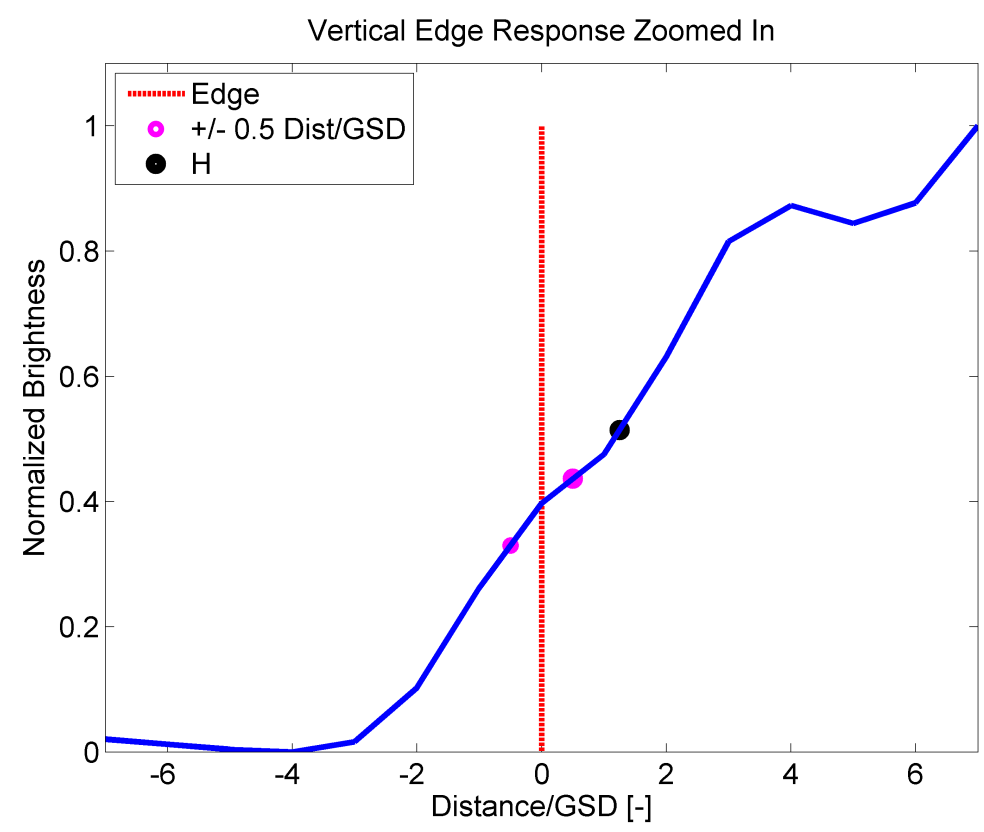

Figure 69: Vertical Edge Response for Image 5

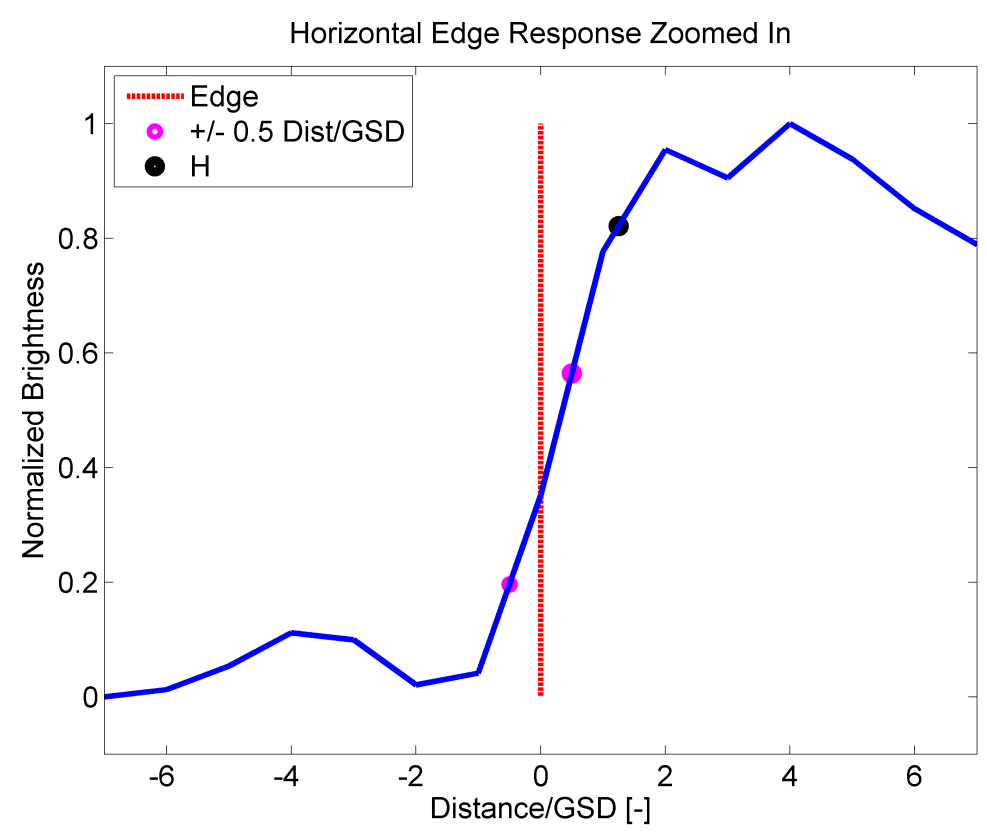

Figure 70: Horizontal Edge Response for Image 5 